\title{
VEGETATION AND REPRODUCTION WITH SPECIAL REFERENCE TO THE TOMATO
}

\author{
A DISSERTATION \\ SUBMITTED TO THE FACULTY \\ OF THE OGDEN GRADUATE SCHOOL OF SCIENCE \\ IN CANDIDACY FOR THE DEGREE OF \\ DOCTOR OF PHILOSOPHY
}

DEPARTMENT OF BOTANY

BY

EZRA JACOB KRAUS AND HENRY REIST KRAYBILL

Private Edition, Distributed By

THE UNIVERSITY OF CHICAGO LIBRARIES

CHICAGO, ILLINOIS

Reprinted from

Station Bulletin i49, Oregon Agricultural College

January I9I8 



\title{
Tbe University of Cbicago
}

\section{VEGETATION AND REPRODUCTION WITH SPECIAL REFERENCE TO THE TOMATO}

\author{
A DISSERTATION \\ SUBMITTED TO THE FACULTY \\ OF THE OGDEN GRADUATE SCHOOL OF SCIENCE \\ IN CANDIDACY FOR THE DEGREE OF \\ DOCTOR OF PHILOSOPHY \\ DEPARTMENT OF BOTANY
}

BY

EZRA JACOB KRAUS AND HENRY REIST KRAYBILL

Private Edition, Distributed By

THE UNIVERSITY OF CHICAGO LIBRARIES

CHICAGO, ILLINOIS

Reprinted from

Station Bulletin i49, Oregon Agricultural College

January $19 \mathrm{I} 8$ 


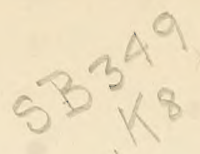

Gifit

Universit

EF 201915

$$
\because \vdots \vdots
$$




\section{Oregon Agricultural College}

\section{Experiment Station}

Vegetation and Reproduction with

Special Reference to the Tomato

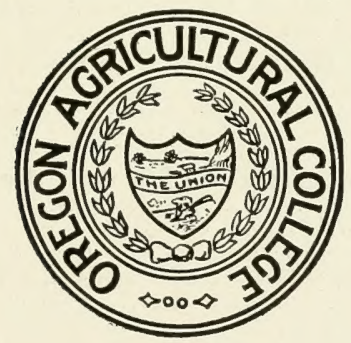

CORVALLIS, OREGON 


\section{STATION STAFF \\ Board of Regents of the Oregon Agricultural College and
Experiment Station}

Hon. J. K. Weatherford, President

Hon. N. R. Moore, Secretary

HoN. C. L. Hawley, Treasurer

HoN. JeFFERSON Myers.

HoN. JAMES Withycombe, Governor of the State.

HoN.

HoN Ben W. Olcotr, Secretary of State.

Hon. Charles E. Spence, Master of the State Grange.

Hon. Clara H. Waldo.

Hon. Walter M. Pierce.

HON. M. S. WOODCOCK.

HoN. H. VoN Der HelleN

Hon. G. M. Cornwall

\section{Administration}

Albany

Corvallis

MeCoy

Portland

Salem

Salem

Oregon City

Portland

La Grande

Corvallis

Wellen

Portland

W. J. KerR, D. Sc

A. B. Cordley, D. Sc.

E. T. REED, B. S., A. B.

May Workinger

E. L. Potter, B. S.

E. J. Fuelsted, B. S

O. M. Nelson, B. S

Department of Animal Husbandry

Chief in Animal Husbandry Assistant Professor in Animal Husbandry Assistant in Animal Husbandry

\section{Department of Bacteriology}

T. D. ВескWITH, M. S.

\section{Department of Botany and Plant Pathology}

H. P. Barss, M. S.

M. B. McKAY, M. S

W. M. ATwOOD, PH. D

W. E. LAWRENCE, B. S

C. E. Owens, M. A

H. V. TARTAR, B. S

R. H. RoBINSON, B. S.

H. G. Miller, B. S

N. E. Bullis, B. S

P. M. Brandt, A. M

V. D. Chappell, M. S

P. S. Lucas, B. S.

IERNe AHERN.

W. L. Powers, M. S..

A. L. Lovett, B. S.

*W. J. Chamberlin, B. S.

F. A. Lathrop, M. S

Leroy ChILD, B. S

G. R. Hyslop, B. S

H. A. Sснотн, M. S.

B. F. SHEeHAN, M. S.

C. I. Lewis, M. S. A.

V. R. GARDNER, M. S

E. J. Kraus, Ph. D.

A. G. Bouquet, B. S

L. F. LINGLE, A. B.

A. F. BARss, M. S.

G. G. Brown, B. S.

\section{Department of Agricultural Chemistry}

Chief in Botany and Plant Pathology Pristant in Botany and Plant Pathology Associate Professor in Botany and Plant Pathology Associate Profor in Botany and Plant Pathology Assistant Professor in Botany and Plant Pathology

President Editor

Secretary to Director

Chief in Agricultural Chemistry Research Assistant in Agricultural Chemistry Research Assistant in Agricultural Chemistry Research Assistant in Agricultural Chemistry

\section{Department of Dairy Husbandry}

Chief in Dairy Husbandry

Assistant Professor in Dairy Husbandry Assistant in Dairy Manufacturing Assistant in Dairy Production

\section{Department of Domestic Science}

Research Assistant in Domestic Science

\section{Department of Drainage and Irrigation}

Chief in Drainage and Irrigation

\section{Department of Entomology}

Chief in Entomology

Research Assistant in Entomology

Research Assistant in Entomology

Entomologist, Hood River, Acting Superintendent

Department of Farm Crops

Chief in Farm Crop Expert in Vetch Investigations Assistant Professor in Farm Crops

\section{Department of Horticulture}

Vice-Director, and Chief in Horticulture Pomologist

Professor of Horticultural Research Professor of Olericulture

Assistant Professor of Horticultural Products Research Assistant in Horticulture Research Assistant in Horticulture, Hood River

\section{Department of Poultry Husbandry}

JAMes Dryden Department of Soils and Farm Management

Chief in Soils and Farm Management Associate Professor in Soils

H. D. SCUDDER, B. S...

C. V. RuzeK, B. S.

\section{Department of Veterinary Medicine}

Chief in Veterinary Medicine

B. T. Simms, D. V. M.

RoBert Withycombe, B. S.

D. E. STEPHENS, M. S.

R. W. Allen, M. S.

F. C. Reimer, M. S

L. R. Breithaupt, B. S...

A. E. EngBretson, B. S

*On leave of absence.
Supt. Eastern Oregon Branch Experiment Station, Union Supt. Sherman County Dry-Farm Br. Exp. Station, Moro Supt. Umatilla Branch Experiment Station, Hermiston Supt. Southern Oregon Branch Exp. Station, Talent Act. Supt. John Jacob Astor Br. Exp. Station, Astoria Supt. Harney Co. Branch Experiment Station, Burns 


\section{TABLE OF CONTENTS}

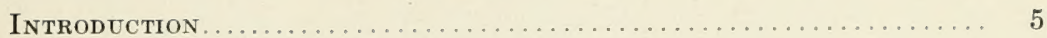

General Discussion.................................. 6

Relations to Practice................................. 13

I. Cultivation and Companion Cropping ................. 13

II. Nitrogenous Fertilizers.......................... 16

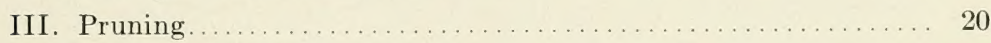

HistoRICAL . . . . . . . . . . . . . . . . . . . . . . . . . . . 33

Material and Methods................................. 36

Experimental ................................. 36

Materials.................................... 36

Chemical...................................... 38

Sampling and preservation of samples................ 38

Extraction..................................... 38

Total Nitrogen.................................. 39

Nitrate Nitrogen ............................... 39

Carbohydrates............................... 39

Free reducing substances...................... 40

Sucrose.................................. 40

Polysaccharides........................... 40

General statement.......................... 40

Moisture and Dry weight ......................... 41

Microchemical.................................. 41

Free-reducing substances........................ 41

Nitrates................................... 41

Starch....................................... 41

Anatomical Methods............................... 41

Presentation of Data ................................. 42

Chemical.................................... 42

Experiment II ........................... 42

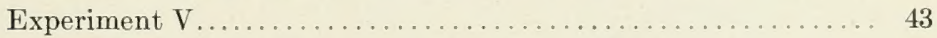

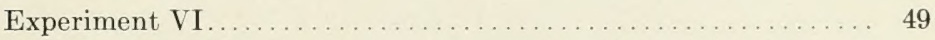

Experiment VII ............................. 51

Discussion...................................... 61

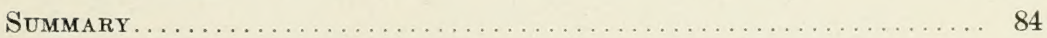

Acknowledgments . . . . . . . . . . . . . . . . . . . . . . . 87

Literature Cited ................................ 87 


\section{FOREWORD}

This bulletin is one in the series of those issued in connection with the investigations on the problem of pollination of the pomaceous fruits which have been in progress at this Station for a number of years. Most of the ideas expressed are the direct result of such studies. After having made extended morphological and histological investigations, and finding in them, as yet, little more than a confirmation of the already well-recognized microscopic situations, it appeared that physiological and bio-chemical investigations must be made to establish a true basis for determination of the factors involved, particularly so when the variable and conflicting evidence of a wide range of experiments was considered. With this general idea in mind, Mr. E. J. Kraus was granted a leave of absence in order to continue these investigations while studying in the Department of Botany at the University of Chicago. While he was there, it was possible for him to secure in this work the cooperation of Mr. H. R. Kraybill, who was at that time on leave of absence from the Department of Agricultural Chemistry of the Pennsylvania State College. This bulletin is the result of the cooperative efforts of Messrs. Kraus and Kraybill and has been submitted by them in fulfillment of the thesis requirements for the degree of Doctor of Philosophy from the University of Chicago.

Because of the nonavailability of fruit trees, it was necessary in carrying out the studies, to use some other plant. After considering a wide range of species, the tomato was finally selected, since in its general responses in vegetation and fruit setting it accords very closely to those observed in apple and pear trees; and moreover, with few exceptions, the plants are self fertile under a wide range of environmental modifications, but can be rendered barren or sterile.

\section{I. LEWIS,}

Chief, Division of Horticulture. 


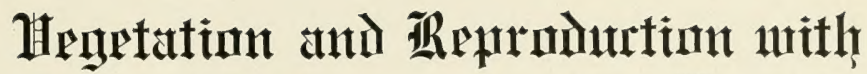

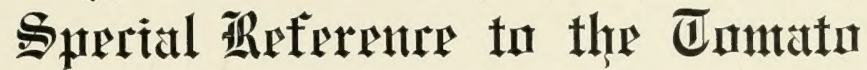

\author{
(Lycopersicum esculentum Mill.)
}

\author{
By E. J. Kraus and H. R. Kraybill
}

\section{INTRODUCTION}

The question of the differentiation of sexually reproductive parts, blooming, fruit setting, and fruit development has been a topic for investigation and speculation for many years. It has been approached in many different ways. Much has been learned; many facts remain unexplained and without correlation; not a few facts are still to be established. More recently the influences of self- and cross-pollination in various plants, particularly those of commercial importance, have been taken up for serious study. The whole subject is so vast that these studies must naturally concern themselves with special phases of the problem. It has been necessary to do much simple testing throughout a wide field and variety of plants under varying conditions. Morphological, anatomical, and histological investigations have been and still are necessary for the determination of the exact structures involved. Physiological studies must be extended and utilized in order to arrive at any final explanation of the conditions observed or the determination of their means of regulation. Not one of these types of study can be spared as a means of finally bringing the problem within the limits of practice.

More specifically the work with plants of commercial importance has dealt and must still deal with the determination of so-called affinities or compatibilities between plants in so far as fruit setting and seed development are concerned. This naturally has led to an investigation of the parts and processes concerned in fertilization, seed and fruit development, and their interrelation. While many of the results have simply furnished microscopic details of what was already well known macroscopically, yet some facts were added. There is still a wide opportunity for such work. Some insight into the mechanism and processes of abscission has been gained; much more is needed. The value of physiological studies can scarcely be over emphasized, but these of necessity must be so detailed and thorough, considering the multiplicity of factors involved, that at best individual investigations can cover only restricted fields.

Pending the more definite working out of details through any one or all of the foregoing methods, the very fertile field of established agricultural and horticultural practice is open for study. Whether such practices are good or bad from the commercial viewpoint, they furnish many suggestions that 
may be correlated and interpreted in connection with the available results of controlled investigations. The material reported and the viewpoints expressed in this paper embody some of the results of such a study undertaken in connection with the fruit-setting problem, in so far as it concerns higher plants.

Four general conditions of the relation of nitrates, carbohydrates, and moisture within the plant itself, and the responses apparently correlated therewith, will be discussed. These are:

(1) Though there be present an abundance of moisture and mineral nutrients, including nitrates, yet without an available carbohydrate supply vegetation is weakened and the plants are non-fruitful;

(2) An abundance of moisture and mineral nutrients, especially nitrates, coupled with an available carbohydrate supply, makes for increased vegetation, barrenness, and sterility;

(3) A relative decrease of nitrates in proportion to the carbohydrates makes for an accumulation of the latter; and also for fruitfulness, fertility, and lessened vegetation.

(4) A further reduction of nitrates without inhibiting a possible increase of carbohydrates, makes for a suppression both of vegetation and fruitfulness.

This analysis is not intended, in any way, to convey the idea that only these compounds-carbohydrates, nitrates, and moisture-are concerned in vegetation and fruitfulness, but that the study in hand is principally concerned with them and the response resulting from an alteration of their relative proportions within the plant. It would be extremely difficult also to draw rigid lines between any particular class and the one next to it; since they intergrade insensibly one into another and yet, generally speaking, are recognizably distinct.

\section{GENERAL DISGUSSION}

In any discussion concerning vegetation and fruit setting, it is necessary to keep clearly in mind their interrelation as plant functions. One is prone to think of them as diametrically opposite expressions, whereas in fact no sharp and clear line can be drawn between them. There is perhaps a possibility of drawing a definite line of division between the production of true gametes and vegetation, but there are plenty of cases on record, in which seeds, and particularly fruits, are regularly produced with scarcely even an approach at gamete differentiation. It is granted that fruits are intimately associated with gametic reproduction in the higher plants, but that does not in any sense remove them from the category of vegetative structures. The most that can be claimed is that they are merely specialized structures, occupying a position between truly vegetative organs and gametes, and that in discussing them they must be regarded from both points of view.

It is really necessary that this situation be brought out clearly, since in some of the work dealing with the question of fertility and sterility in plants the conclusions are based on an inspection and record of the number of fruits produced rather than the number of viable seeds or preferably seedlings. This point is discussed in greater detail later. 


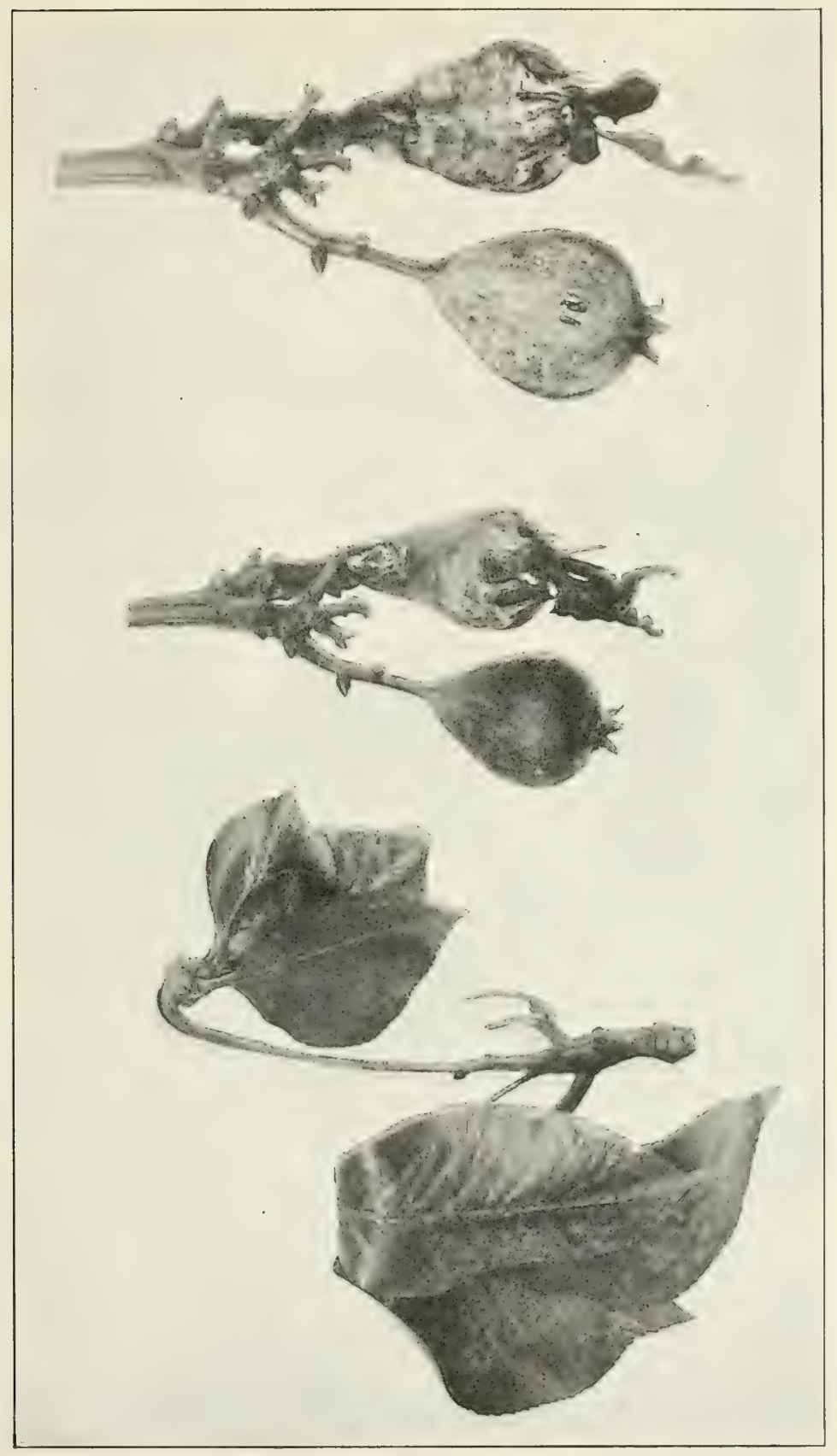

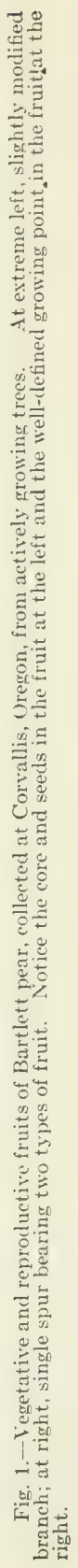


A study of the comparative morphology of fruits reveals the fact that widely different structures may enter into the conspicuous or edible portion. The parts which may be concerned are axis, bract, pedicel, torus, calyx, petal (rarely), stamen, and carpel. The mature fruit may consist of any particular one, several, or all these parts separated and distinct, or firmly united. One structure or group of structures may develop out of all proportion to others, resulting in the wonderful range of fruit types already well known. But the point is, that whatever the nature or whatever the appearance of the fruit, it is a specialized vegetative part generally concerned with the production of seed; this seed in itself actually may be an entirely sporophytic structure.

There is a wide range in the external expression of the capacity of plants to produce fruits and seeds. There are many varieties of plants, representing wide ranges of families and orders, which produce mature fruits entirely without seeds or in some cases functional ovules, while other varieties within the same genus under identical conditions fail to mature fruits unless embryocontaining seeds are present. To discuss this situation two classes are made.

I. Barren forms are those which entirely fail to produce flowers or fruitlike structures, shed such structures at an early period, or fail to develop them to maturity.

II. Fruitful forms are those which do produce and mature fruits, whether such fruits do or do not contain seeds.

There are three types of this condition. (1) The first is best designated by the term parthenocarpy, in which there is a development of the fruit wholly independent of any pollination of the stigmas or fertilization of the ovules. As a matter of fact, in many parthenocarpic forms, development within the ovules does not proceed beyond the mother-cell stage. The term refers to the development of fruit structures other than the seeds. (2) The second class comprises forms in which development of the flesh proceeds only if pollination of the stigmas has taken place. Usually also fertilization takes place, but there is an abortion of the embryos at a more or less advanced stage. In spite of the fact that seed formation is thus eliminated, fruit development continues to a normal, though frequently early, maturity. (3) The third type of development is that following normal pollination, fertilization, and seed development or that occurring in apogamous forms. The terms sterile and fertile have at times been confused with, and used in place of, barren and fruitful. In this discussion these terms will be used in the limited sense as already suggested by Kraus (28).

Sterile forms are those which produce no viable seeds, either because of failure of gametic union, abortion of the embryo, or embryos resulting from a gametic fusion. Fertile forms are those which produce viable embryos resulting from a gametic union.

The terms fertile and fertility are extraordinarily confused in the literature. On the one hand they have been used to designate a condition of fruitfulness with little or no regard for the idea of production of new individuals, while 


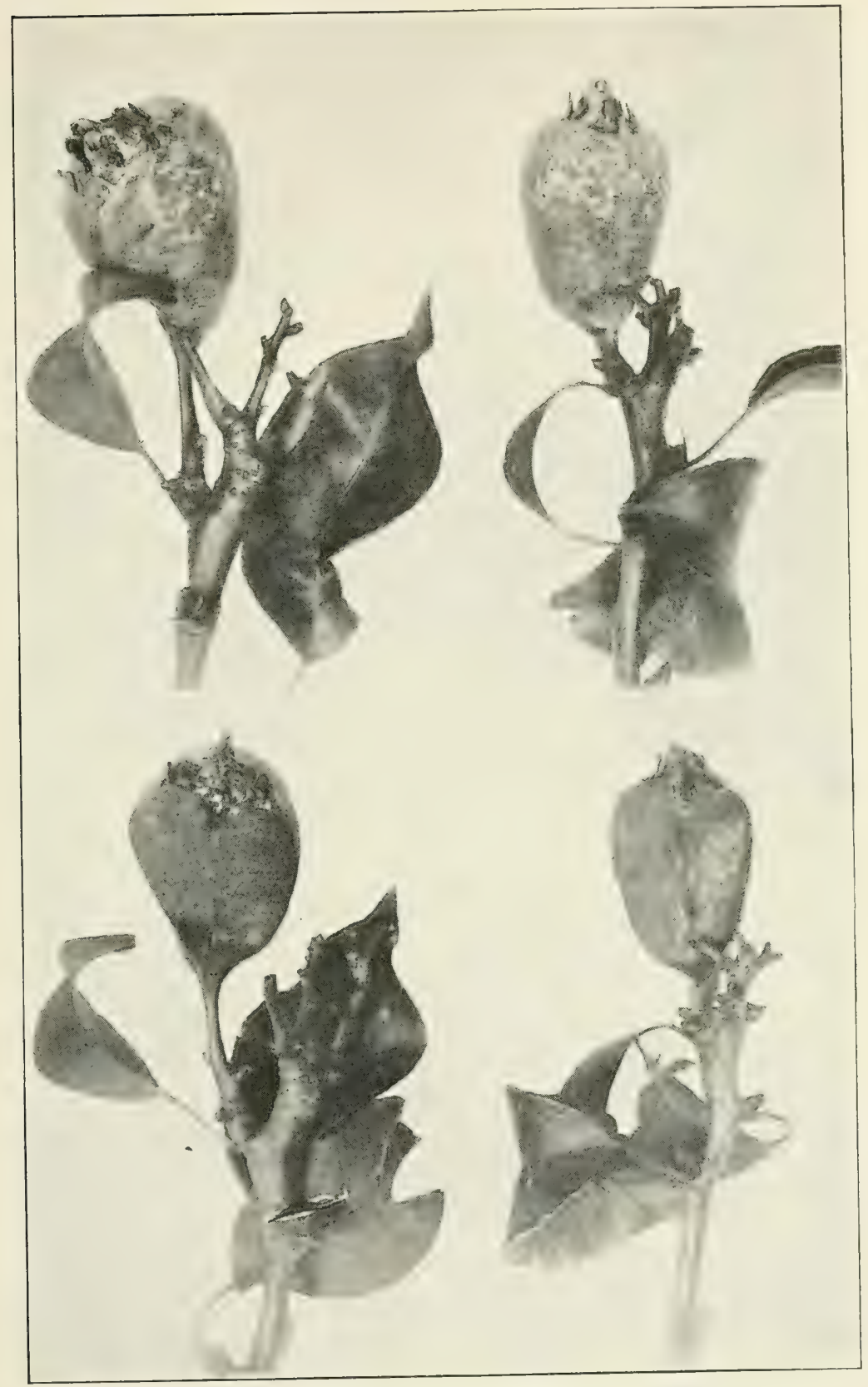

Fig. 2,-Vegetative fruits of the d'Anjou pear, collected at Corvallis, Oregon. Such fruits were of fairly common occurrence at the tips of vigorously vegetative branches in the fall of 1917 . These fruits were entirely vegetative structures with well-defined growing points; many intermediate forms were also found. 


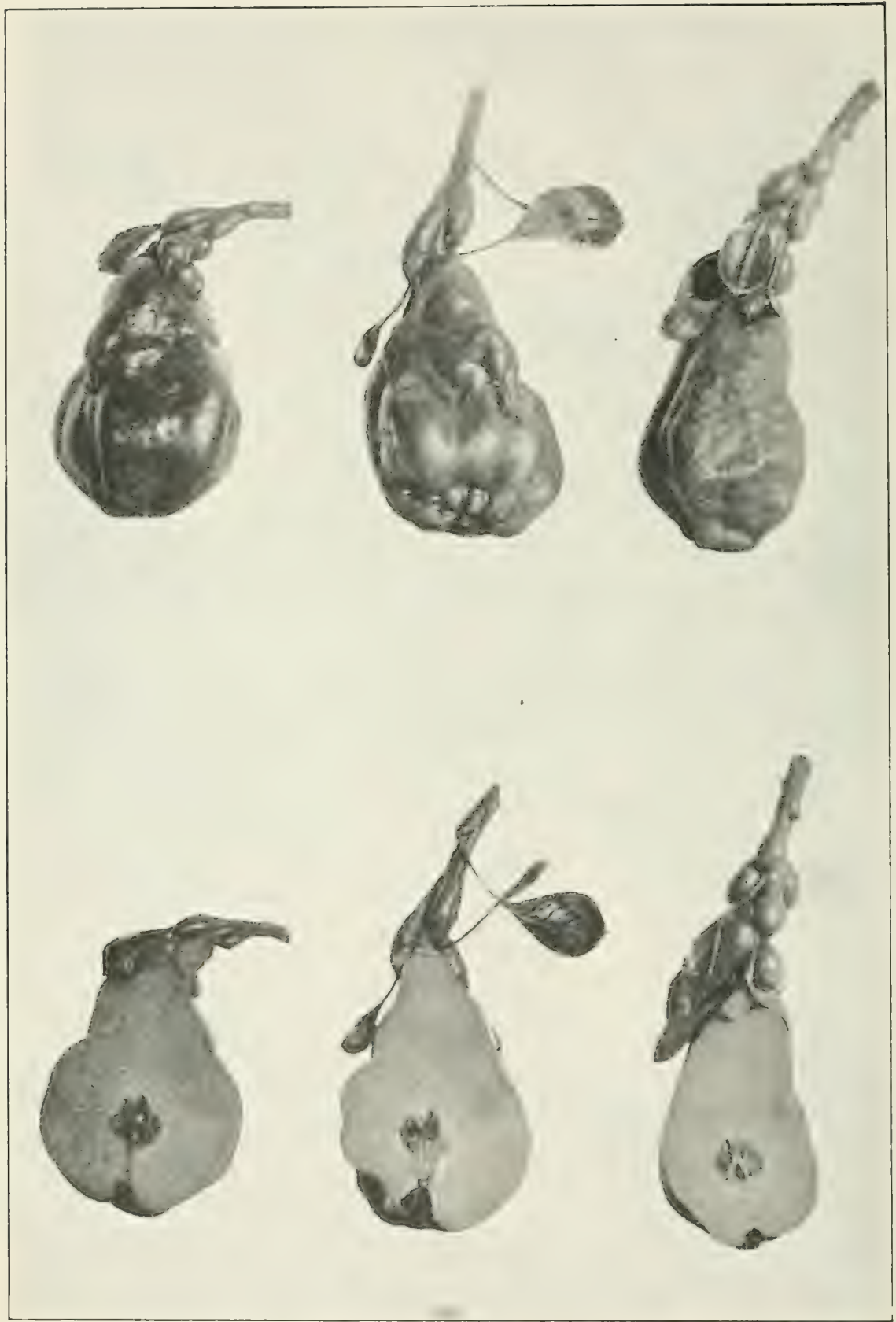

Fig. 3.-Fruits of the Bartlett pear. Though markedly deformed, they are truly reproductive in type. 
on the other hand they have served to convey the idea of great reproductive capacity frequently without regard to the manner or method of the origin of the offspring. Again, an organism has been considered fertile if it produced new individuals through seed, without reference to the exact origin of the embryos. In the present discussion, the term fertility is limited to the production of viable embryos through the union of true gametes. This limited view really excludes a number of seminally reproductive forms, in fact all cases of apogamy and vegetative apogamy and parthenogenesis, using the term parthenogensis to mean the development of an embryo from a haploid egg without fusion with a male nucleus. Whether this truly occurs in plants is still a matter for investigation, but cases of apogamy and vegetative apogamy are found with sufficient frequency to cast doubt on some records of supposed fertility and to warrant a careful investigation of this point in any form studied.

It seems better, therefore, when not using terms specifically to speak of the reproductive capacity of plants rather than their fertility. Even this terminology leaves much to be desired, though there is little to be gained from mere multiplicity of terms. There is a very closely graded series from vegetative reproductivity to true sexual (gametic) reproductivity, the only sharp line of separation being the differentiation of true gametes and fertilization. Thus plants may be multiplied by stems, leaves, or roots, not at all modified from the average structure; by these same organs distinetly modified, such as bulbs, tubers, fleshy roots and the like, or by seeds, the embryos of which have resulted from sporophytic budding or vegetative apogamy. It is worthy of note, that when stems or leaves are used as cuttings for vegetative propagation a larger percentage of them will produce roots and continue growth provided they are not too soft or succulent, but allowed to harden; the conditions for hardening are in a broad way much the same as those which make for the differentiation of fruit-producing parts. This will be considered later.

A discussion of fruit production is naturally tied up with the question of fertility and sterility. The sense in which these terms are used has been pointed out; from that viewpoint some records of fertility in plants have really been records of self-fruitfulness or at best vegetative apogamy. A recent paper by Stout (41) discusses at some length several reports and suggested explanations of fertility and sterility; it is therefore unnecessary to discuss that matter here. Stout adds many instances of self and cross-fertility, and intersterility in Cichorium intybus, a condition which Gardner (9) also found to be the case of several varieties of the sweet cherry, (Prunus avium) in Oregon. Stout states that the sterility probably is due to physiological incompatibility, but that "to what degree such incompatibilities involve pollen-tube growth, irregular fusions of gametes, or embryo abortion, has not been adequately determined." It would be particularly interesting to know the extent of embryo abortion in the forms which he studied. In the apple, sterility, unless it be otherwise in varieties not yet investigated, is due almost wholly to embryo-abortion, as previously pointed out by Kraus (28). Such degeneration also occurs in Oenothera (Davis [6]), in certain tobacco hybrids (Goodspeed [12]), 
cherry, almond, pear, plum, and tomato. It will probably be found to occur in a very wide range of species.

Now th's type of sterility is of particular significance since the degree of embryo abortion varies, to a very marked extent, with different varieties and particularly with environment, using this term in its broader sense. It is also a fact that many varieties of fruits, particularly those which are fleshy, show a marked correlation between flesh and seed development; but such a correlation varies greatly according to the variety of fruit, and even within the same variety, depending upon environment or as sometimes stated, "upon the vegetative vigor of the plant." There are plenty of instances, however, of entirely seedless fruits, which develop either parthenocarpically or as a condition of self-fruitfulness. Vegetative vigor itself is probably really nothing more nor less than a response to environment. In other words, mere vegetative extension and fruitfulness are not separate and distinct functions of the plant but each is an external expression of an internal condition. One is much too inclined to interpret plant functions as desirable or undesirable from a commercial or practical viewpoint rather than a physiological one. On the former basis it is desirable that fruit plants be producing fruit and at the same time making sufficient vegetative extension to distribute such fruit over a large producing surface or to provide area for the production of future crops, whereas from the physiological viewpoint each plant can be regarded as an expression of an adjustment to its surroundings, or in the process of adjustment, whatever its condition. Such an expression may be evident only as a rapid vegetative extension, the formation of reproductive parts, or a combination of the two in varying degrees. Now the commercial grower seeks the most profitable combination of the two. Each has come to interpret for himself what is most desirable; but few growers have any considerable knowledge of the means of regulation. It is well recognized that it is not necessarily only the greatest number of fruit buds or even of fruits that is most desirable, but also the quality, and with perennial forms, continued production.

What, then, are the factors or conditions which make for vegetative extension and those which make for fruitfulness? While it is not possible as yet to define the exact effects or functions of specific substances, still it is possible to point out some very definite relationships of some of them, which will aid in a better understanding of the problem and certainly be of value from the standpoint of practice.

One of the fallacious notions nearly as ancient as horticulture itself is embodied in the statement that any condition which seriously threatens the life of a plant, induces a realization in such an individual that it is about to die, and therefore it becomes markedly reproductive in order to perpetuate itself. This point is brought out here merely because such ideas are still being taught and perpetuated and actually made the basis for investigation and recommended practices. In any case, in deference to any possible vitalistic ideas, it may be said that whatever may be the conception of a plant. 
its responses are readily modifiable and any preconceived determination on its part may be altered by environmental change.

One frequent error in much of the experimental work relating to productivity in plants, has been the attempt to interpret an external response in the light of the specific external conditions imposed with but little or, in many instances, no attempt to discover or analyze the internal changes concerned. Frequently important factors have been neglected entirely. In some experiments the apparent limiting factor, or factors, under investigation have played a lesser part in determining the final result than others which were unobserved or given no consideration. Now it is more than probable that there may be groups of external influences, any one or all of which produce much the same internal response, and other groups which may produce diametrically opposite results. In other words, external conditions may either augment or largely destroy the effect of each other. It might be difficult, then, without knowing the medium through which action has been transmitted, to determine any specific cause merely from the evidence of some external effect frequently associated with it. That this is the case is apparent in plenty of published accounts, though they need not be considered here. All this means that it is absolutely essential to have a thorough knowledge of the internal changes, conditions, or compounds developed in response to the several external conditions or factors to which plants may be subjected, then the correlation of these, and finally a determination of the external response to these internal conditions.

In this connection it is worth while to consider the oft-repeated objection to the carrying on of experiments under abnormal conditions. Really after all the idea of just what constitutes normality frequently varies with the experince of the individual experimenter. The normal state is generally the average condition, and the conception of what constitutes the average condition too frequently is based on what is most valuable from an aesthetic, applied, or commercial standpoint. The effect of an essential element or factor in any set of imposed conditions can best be studied only by varying it from the average, greater and less, and noting the changes or responses induced. The growing of plants under "abnormal" conditions must remain one of the most valuable experimental methods.

Coming then to a consideration of the factors concerned in fruit setting, it is well worth while to examine briefly a few of the reports of experiments in various fields that are designed to provide an insight into the problem. These experiments will be examined largely from the viewpoint of the relations existing between the nitrate-carbohydrate-moisture conditions within the plant and the associated vegetative or reproductive responses as detailed in the introductory paragraphs.

\section{RELATIONS TO PRACTICE}

I. Cultivation and Companion Cropping. Two of the principal effects claimed to be the result of tillage are the retention of moisture in the soil and the increase in the amount of available plant foods, including nitrogen. 
It is particularly interesting to consider certain orchard practices and note the absurdity of attempting to follow any specific practice universally, without due regard to local conditions, or a knowledge of the factors operating. It is now realized quite generally that fruit plantings under very diverse cultural conditions may be equally productive. The idea that the soil must be kept in a state of intense cultivation each succeeding year is not valid for all conditions. There are plenty of instances in which no cultivation, and even sod mulch have proved to be the best commercial practices to induce and maintain the fruiting condition. Plantings on so-called rich moist lands of ten tend to remain vegetative, if thorough summer tillage is given and leguminous cover crops are grown, but become abundantly fruitful if cultivation is lessened, or a crop of grain, or other non-leguminous crop, is grown between the trees. In one region, the most successful practice to bring the trees into bearing at an early age may be to interplant with corn or other crops; whereas, in another, clean cultivation supplemented with leguminous cover crops turned into the soil or even the addition of animal or mineral fertilizers, may be considered to be the best orchard management. Thus there are many and varied recommendations, each has its supporters, and of course its application. It is unnecessary even to attempt to record all or a considerable portion of them. The point is just this, through every one of these practices some condition is changed and that change is either an increase or a decrease of some substance or substances in its relative proportion to others. It is not so much the absolute amounts as the proportions. If, then, it is possible to determine what internal relationships are required for one type of response and what for another, what factors operate and how they operate to modify such relationships, then the correlation of these findings will aid in establishing rational agricultural practices. Thus on the one hand it may be desirable to increase nitrates and moisture, within the plant; whereas in another it may be essential to decrease one or both of them. This general idea is not new, but seems to be lost sight of all too frequently. It is quite as essential to know what is present in the body of the plant itself, its extent and environment, as to know what nutrients are in the soil. As a simple example, light and temperature conditions suited to a rapid photosynthesis, on the one hand, or a slow one, on the other, with identical soil conditions, will result in widely different responses in the plant. Or, again, identical conditions influencing photosynthesis with different soil conditions will result in equally wide variations. All conditions are operating all the time. It is not easy to be sure of every environmental condition and interpret an external result as a response to some one particular external condition imposed.

Since the moisture and nitrate relations particularly are being considered in this article, reference is made to the findings of several investigators. Pickering (3) reports on a comparison of trees growing in sod and tilled land. In general his results favor cultivation, though on the whole the moisture is greater under grass by $3 \%$. There is no record of the condition of nitrates. He attributes the injurious effects to toxins from the grass rather than to soil nutrients. 
Hedrick (17) recordsexperiments which show an appreciable gain in moisture in favor of cultivated plots in comparison with those in sod. He considers the amount of moisture removed by the grass an active agency in decreasing moisture under sod. "As a consequence of the reduced water supply in the sod plot, there is a reduced food supply; for it is only through the medium of free water that plants can take in food. Analyses show that the differences between the actual amounts of plant food in the two plots are very small."'

Gourley (13)has determined both soil nitrates and moist ure in his experiments on trees in sod as compared with those in clean culture. He found that on the average there was about $3 \frac{1}{2} \%$ greater moisture under sod, but on the reverse that nitrates were appreciably higher under conditions of tillage than under sod. The trees receiving clean culture were superior in growth and fruit production. One plot (IX), which received nitrate fertilizer, averaged higher both in nitrates and moisture but did not show a greatly inereased yield over another plot (V) showing less nitrates and less moisture. The nitrate fertilizer was applied in June. It is therefore a fair question to ask whether the nitrate really was available to the trees, and whether indeed there was sufficient moisture for its utilization by the trees. This will be considered further under the discussion of fertilizers and irrigation.

In a later report (14) by the same writer, particular attention is called to a third treatment; namely, tillage and cover crops, under which treatment there is an increase in moisture and nitrates in the soil and in the annual average growth, though it is stated that the increase in moisture content is "scarcely sufficient to account for the difference in growth." The yield of the sod plots is less than half that of the other two. It is concluded that; (1) "under a good system of tillage nitrates were usually present in excess of the needs of the trees," and (2) "moisture was not the limiting factor in the sod plots."

It would be of considerable interest to know if the yield in the plots high in nitrates could be increased by the application of additional moisture and to determine the effect of a nitrate application to the sod plots early in the season.

A great array of tillage experiments with various crops and with varying results might be adduced; the purpose in citing those above has been to give an example of the studies which are being made with orchard fruits relative to soil treatments and the changes in relations of moisture and nitrates. Now, it is not argued for a moment that other nutrients and sanitary conditions are not important in relation to growth studies. The point with which we are concerned is the fact that certain vegetative and reproductive responses are closely associated with a variation in the nitrate and moisture relations. Thus the means of regulation of these two factors and a knowledge of their function within the plant, are of prime importance. On the one hand it may be commercially advantageous to increase one or both of them in order to render the ultimate crop more abundant or profitable, while on the other hand, it may be desirable to decrease them for the same purpose. Much depends on the type of response desired, it might be vegetative or it might be reproductive, depending on the crop grown and upon its state of development. Furthermore, an intercrop or cover crop might be of such a nature 
that through shading and reducing the light intensity, the photosynthetic activities of any specific crop might be profoundly changed, a condition certainly as fundamentally important in interpreting plant response as soil environment. The kind of tillage, intercrop or cover crop adopted, therefore, will be determined by its influence on any one or all these factors at least.

Gourley gives some analyses of the plants in bis experiments, more especially the carbohydrates. "In alternate-bearing trees we find a heavier deposition of reserve food material in the storage tissues when the tree has formed fruit buds. As starch, this is mainly found in the medullary rays and pith." No determinations of the nitrates within the plant tissues are given but, "It appears in this soil that nitrate formation of from 20 to 40 parts per million of dry soil as an average for the growing season is essential for the maximum vigor of the trees and abundant fruit-bud formation, and that above this an excess will not of itself increase the growth or number of fruit buds formed." It would be interesting to know what would be the result of increasing nitrates and moisture simultaneously, or of an application of nitrates very early in the season.

In this connection, it is a common experience to find very great increases in yield or in the number of fruit buds formed during the first one or two seasons of tillage following the sod-mulch system, provided of course that the tree roots have not been severely injured. This may be due to the fact that excess carbohydrates are frequently stored in plants suffering from lack of nitrates, the plants being in the fourth condition previously enumerated; namely, feebly vegetative and low in fruit production. When nitrates and moisture were rendered available and taken into the plant, the stored carbohydrates would be drawn upon and utilized in vegetative extension and the production of fruiting parts. This is the third condition described. Theoretically by further additions of nitrate and moisture the second condition could be attained, and practice has often shown this to be the case. By artificially restricting the available carbohydrates or preventing their formation, the first condition can be induced. While this condition is not generally likely to be met with in practice, yet one means of producing it is through heavy pruning. This situation is discussed at length in connection with pruning practices.

II. Nitrogenous Fertilizers. It is not the purpose of this paper to enter into the discussion of the use of fertilizers. A vast amount of experimentation has been done, much is still required. One cannot question that each and every one of the essential elements is a limiting factor in crop production; they are that by definition. The main criticism to be offered on much of the work, however, is that it has concerned only external results, sometimes with but little indication of how they were produced. It is absolutely essential that future work shall take into account internal changes and the relations of these to observed results. Much more information is needed on the role of any essential element in its varied relations to processes of water absorption, respiration, carbohydrate formation, translocation and storage, protein synthesis, and any number of other plant functions. Such determinations will 
come closer really to answering fundamental questions than a record of pounds of fertilizer applied and yield in bushels per tree or per acre, no matter of how great practical or local significance such records may be.

Here it is our purpose merely to note a few experiments which are of interest from the viewpoint of a nitrate-carbohydrate relationship as previously proposed. Russel (39) concisely sums up the general effects of nitrogen as follows:

"The normal nitrogenous food of plants is, however, a nitrate, and there is a close connection between the amount supplied and the amount of plant growth, which is well shown in Hellriegel and Wilfarth's experiments.

"The increasing effects produced up to a certain point by successive increments of nitrogen may be due to the circumstance that the additional nitrate not only increases the concentration of nitrogenous food in the soil, but also increases the amount of root; i. e., of absorbing surface, and of leaf; i. e., assimilating surface. The process thus resembles autocatalysis, where one of the products of the reaction acts as a catalyser and hastens the reaction. The increase does not go on indefinitely because some limiting factor steps in.

"The effect of nitrogen supply on the grain is very marked. (In the experiments cited), it is seen that the grain formed, when nitrogenous food is wholly withheld, is only two-thirds of the normal weight per individual. The first addition of nitrate causes a marked rise in the weight per grain and the proportion of grain to total produce, but successive additions show no further rise. Indeed other experiments prove that excess of nitrogenous food causes the proportion of grain to fall off somewhat. The leaf and the general character of growth are affected to a much greater extent. Nitrogen starvation causes yellowing of the leaf, especially in cold spring weather, absence of growth, and a poor starved appearance generally; abundance of nitrogen, on the other hand, leads to a bright green color, to a copious growth of soft, sappy tissue, liable to insect and fungoid pests (apparently because of the thinning of the walls and some change in composition of the sap) and to retarded ripening; the effects resemble those produced by abundant water supply. A series of plants receiving varying amounts of nitrate are thus at somewhat different stages of their development at any given time, even though they were all sown on the same day those supplied with large quantities of nitrate being less advanced than the rest. If they could all be kept under constant conditions till they had ripened, this difference might finally disappear; but in crop production it is not possible much to delay the harvest owing to the fear of damage by autumn frosts, so that the retardation is of great practical importance. Seed crops like barley that are cut dead ripe are not supplied with much nitrate, but oats, which are cut before being quite ripe, can receive larger quantities. All cereal crops, however, produce too much straw if the nitrate supply is excessive, and the straw does not commonly stand up well, but is beaten down or "lodged" by wind and rain. Swede and potato crops also produce more leaf, but not proportionately more root or tuber, as the nitrogen supply increases; no doubt the increased root would follow, but the whole process is sooner or later stopped by the advaneing season-the increased root does in fact follow in the case of the late-growing mangold. Tomatoes, again, produce too much leaf and too little fruit if they receive excess of nitrate. On the other hand, crops grown solely for the sake of their leaves are wholly improved by increased nitrate supply.

" . . The actual increase of growth brought about by successive increments of nitrogenous food depenc's on the amount of water and other nutrients, on the temperature, and so on; any of these may act as limiting factors."

Hartwell (15), in reporting on starch congestion accompanying certain factors which retard plant growth, states that many different factors, correlated in 
each case with retarded growth, were found to be associated with an accumulation of starch in the above-ground portion of plants. The omission from the manures of nitrogen, as well as of phosphorous, was associated with a marked depression in the growth of vines, and it may be seen that in general this was accompanied by a greater accumulation of starch than where the complete manure was used. A deficiency of available potassium in the soil was usually accompanied by an accumulation of starch in the potato vines." In general, an increase in the amount of the available nitrogen caused an increase in growth but a decrease in the average amount of starch in the vines. In one experiment, comparing the various amounts of nitrogen applied with the starch stored, the results were not uniform throughout the growing season, starch storage being greater in late July and very appreciably less, especially in the heavily nitrogen-fertilized plots, in August and September. No explanation is given; but a statement of the condition of growth at this time would have been very desirable.

It seems as unnecessary to account for the accumulation of starch as a pathological condition, as it does to assume that its absence could be considered such a condition in highly vegetative plants. Though the author suggests it as an improbability, yet it is as legitimate to assume that the lack of utilization of stareh, or the substances from which it is synthesized, is just as much the cause of retarded growth as that the retarded growth causes the starch accumulation, though why this should be referred to as a pathological condition is not entirely clear. Retarded growth and starch accumulation would be the expected results if the carbohydrates were not utilized in vegetative extension or the production of reproductive portions.

The nitrate fertilizer experiments of Lewis and Allen (29) are of especial interest when considered from the viewpoint previously expressed. Their work consisted in applying to apple trees in declining vigor nitrate of soda, either as a spray on the trees themselves or as crystals or a spray on the ground. There was little difference in result in relation to the method of application, but a very decided difference depending upon the time of application. To quote:

"Orchards in a somewhat run-down, or devitalized condition; namely, those which are making very little vegetative growth, either in twig or leaf, those which have thin, yellow leaves and weak fruit buds-are greatly benefited by the use of nitrogen. In such cases this fertilization produces a vigorous wood growth, causes the leaves to become thicker and greener, produces more and larger fruit, and thus restores the trees to normal vitality. There is an indication that some of the so-called pollination troubles have been due to the fact that while the fruit buds and spurs might have sufficient energy to blossom, they did not reserve food enough to mature fruit. One of the most striking results obtained from the use of nitrogen has been in the increased percentage of set.

"It has been startling to notice the rapidity with which nitrogen in an available form gives results. Nitrogen added in March causes a larger percentrge of set of fruit in April, an immediate change in the character of the foliage, and a stimulation of the wood growth.

"With about six pounds of nitrate of soda applied to the ground around each mature fruit tree, one secures about a pound of actual nitrogen. Such 
an amount is sufficient to restore the trees to their natural vigor. Indications are that in many cases this amount of nitrogen added two years in succession, causes an over stimulation, shown by too heary a foliage derelopment, too strong wood growth, and a production of too many over-large specimens of fruit.

"The experiments in 1915 indicate clearly that the fertilizer should be applied during the early part of March-that if we wait until May, which has been the custom in applying nitrates, we recieve very little benefit from such fertilization the year the nitrates are applied. 'This is due to the fact that the seasons are too dry to cause the proper dissolving of these fertilizers in time to be of assistance. The fact that the nitrogen has such a marked effect on the percentage of set means, moreover, that it should be applied before the trees bloom.

"Our experiments in 1915 indicate clearly that the best method of applying nitrate of soda to orchards is to spread the dry crystals broadcast on the ground under the trees, harrowing soon after applying. In 1914 the indications were that it paid to spray the nitrate on the trees, but investigations this year showed that the real reason why we secured better results from spraying in former years was due to the fact that nitrogen sprayed on the trees was dissolved and reached the roots, whereas the nitrates spread on the ground were added in May instead of March, and were therefore of little value. We believe that this year's experiments indicate very strongly that the nitrogen will be of value to the trees only when it reaches the roots. Further experiments will be conducted, however, to confirm these conclusions."

Further experiments as reported by Lewis and Brown (30) have tended to confirm these conclusions. While no chemical analysis of the plant tissues has been made either before or since the nitrate applications, yet the general observed responses are so precisely similar to those in the tomato experiments, to be detailed later in this article, that some suggestions may not be out of place. It is more than likely that the trees described as lacking in vegetative vigor and possessing small yellowish leaves and weak, slender fruit buds were very low in nitrates and high in carbohydrates, especially starch. Brief examinations of the twigs and branches of trees of similar appearance and from the same locality show this to be the case. This being true, the trees would be in a state of low vegetation due to a lack of nitrates sufficient to permit the utilization of the carbohydrates in any extensive formation or development of vegetative or reproductive parts. This accumulation of carbohydrates, however, when nitrates are added to the soil and sufficient moisture is available to permit their being taken into the trees, is drawn upon and is made over into other compounds and structures. Depending, then, upon the amount of nitrates and moisture available in relation to the stored carbohydrates and those subsequently synthesized, the type of growth response would vary. Very large amounts of available nitrate, moisture, and carbohydrates would thus result in vigorous vegetative extension; proportionately smaller amounts of moisture and nitrates, in varying degrees of vegetative extension and reproduction; and very small amounts, in feeble vegetation and feeble fruit production. On the other hand, if the carbohydrate supply was very limited, even though nitrates and moisture were abundant, then the growth might be expected to be weakly vegetative and scarcely or not at all reproductive or fruitful. 
In the experiment just previously cited and in many others dealing with nitrate fertilization, the above range of final results in growth and yields has actually been recorded. Unfortunately, in the majority of these experiments, no analyses of the plant tissues themselves are available; so that it is not possible directly to analyze the results aceording to the foregoing suggestions. It may be hoped, however, that in some of the future experiments analyses may be made in order to test these suggested relationships.

III. Pruning. A consideration of the factors involved in pruning in relation to fruit setting is particularly interesting, since by pruning, the organism itself is profoundly altered in its relation to its general environment, which usually is not greatly modified. It may be supposed that a plant at any particular time represents the result of all the environmental forces acting upon it, and it is either in a state of equilibrium with such forces or in a state of becoming so adjusted. The response following pruning is largely a process of regeneration. The type of such regeneration, whether of simple vegetative parts or parts closely associated with reproduction, is of the greatest practical significance, and any knowledge leading to a possible control of such responses is highly desirable. Top pruning is a most direct and speedy method of influencing the carbohydrate conditions in a plant.

Pruning practices are almost as many and as varied as the number of individuals who grow plants. While there are almost endless varieties of types and combinations of types, yet through all run two fundamental ideas, the one to direct, maintain, decrease, or increase the vegetative extension of the plant, the other to maintain or increase flowering or fruitfulness. Frequently vegetation and fruitfulness are regarded as opposing plant functions. While at first thought this seems to be the case, it can hardly be the true situation; rather, vegetative extension and fruitfulness are intimately associated one with another. Reproduction may be vegetative or gametic. Beginning with clearly vegetative parts used for reproductive purposes, a closely graded series may be constructed, through slightly modified parts such as off-shoots, bulbs, and the like, sporophytic budding, apogamy to parthenogenesis (if in the limited use of the term this really occurs in plants) and true gametic reproduction. The main point to be borne in mind is that there are not two entirely antagonistic functions, but rather extremes of possible expression, and that between these extremes, all sorts of gradations may exist. To say that a plant becomes markedly reproductive because its life is threatened is indeed begging the question.

Pruning practices concern both roots and tops of plants. Much more work has been done and many more results recorded regarding the latter than the former, probably because of the ease of handling and observation. The comparatively limited experiments on root pruning, for the most part have been recorded and interpreted on the basis of the responses of the tops. Lacking an abundance of specific chemical analyses of the plant tissues in connection with pruning experiments, much of the following discussion must be based on inference. The conditions imposed and responses recorded, however, agree so closely with similar circumstances and results in the 
experimental work detailed later in this article that the specific, suggested explanations seem worth presenting.

One of the most general statements regarding pruning of fruit trees is that heavy dormant pruning increases vegetation, that trees should be pruned to cause them to grow more vigorously. The inaccuracy of this general statement has been pointed out, particularly in three reports. The Duke of Bedford and Pickering, found in comparing trees 12 years of age that heavily pruned trees were 16 pereent lighter than moderatly pruned trees, while those unpruned were 20 percent heavier than those moderately pruned. Alderman and Auchter (1) found that young trees lightly winter pruned as compared with those heavily pruned were taller and broader, made longer total growth, grew branches which were longer and larger, had larger trunks, and exhibited a tendency toward earlier bearing as indicated by flower-bud formation. Gardner (11) in experiments in winter, winter-and-summer, and no pruning on young trees found that on the average the unpruned tree increases in size as rapidly as, if not a little more rapidly than, the tree that is winter pruned only or both winter and summer pruned.

In the case of the older trees, "not in a very vigorous condition," Alderman and Aucher report, as a result of heavy and light pruning, an exact reversal of fruiting habits from those in the younger trees. "Both the Arkansas and the York Imperial varieties produced distinctly larger crops on the heavily pruned blocks than on the lightly pruned blocks. This sharp distinction in bearing habits between vigorous young trees and middle-aged trees of subnormal vigor is of interest. Middle-aged is only a relative term. In New York where apples are still in their prime at thirty-five years of age, fifteen-year old trees would be considered young. In the Shenandoah Valley the commercial orchards generally start their decline at twenty-five to thirty years of age and fifteen to twenty years is truly middle age. We know that neglected orchards which have not produced crops of any consequence for years will frequently be greatly benefited and stimulated into fruit production by a heavy pruning. To be sure such trees are abnormal, but it will be noticed that the trees in this orchard made but four inches of terminal growth in the year before the experiment began, and that since that time they have averaged from seven to nine inches for one variety and from four to five for the other. This result would indicate that at the beginning the trees were somewhat below normal in vigor, but under better cultural methods their average condition had improved. The writers are of the opinion that, from the standpoint of fruit production, vigorously growing trees would have made a somewhat different response to the treatment than did the ones in the test."

Both Kraus (27) and Gardner (10) have pointed out that the thimning out of old massive spurs in pears, apples and prunes, results in a much greater tendency of the fruit buds to mature fruit. In brief, to prune "judiciously" in order to maintain the desired balance between fruiting and vegetation, is a very general recommendation, but how many of those who make the recommendation understand what factors are involved in producing the results?

Now, why these apparently diverse results from similar practices? An 
analysis of some of the internal conditions affected and their relation to external response may aid in obtaining a clearer view of the situation. In the first place whatever may be the character of the storage in the top under any condition, it is self evident that some will be removed from any future use by the tree if any pruning whatsoever is practiced. Considering now the responses during the growing season on the basis of the suggested idea of a moisture, carbohydrate, nitrate relationship, it may be assumed that at the actual time of pruning the soil moisture and nutrients themselves would neither be increased nor decreased whatever the practice, though the amount utilized later by the tree would be profoundly modified. On the contrary, any pruning practice would certainly mean a decrease in the amount of storage materials actually remaining as a part of the plant, and in large measure also the future synthesis of such material, so that the relation of the nutrients in the plant to those in the soil about it have been profoundly disturbed. That is to say, top pruning, whatever its nature, would decrease particularly the available carbohydrates and other stored substances in relation to the soil moisture and nutrients; root pruning would not only do the same thing but in addition would tend to prevent, in considerable degree, the possibility of absorption of materials from the soil. As will be pointed out later also, in the more detailed experiments on tomatoes, the amounts of moisture and nitrates which are absorbed and used in growth are dependent upon the available carbohydrates either in storage or those being derived from photosynthetic activity.

Thus, as previously pointed out, the four general types of response related to the varying nutrient conditions, could be expected from pruning practices as well as any other practice which would tend to modify them. If, for example, either because of lack of storage or photosynthetic activity, the carbohydrate supply were greatly reduced, even though there were an abundance of available moisture and nitrates, then blooming and fruit production are very greatly decreased, and vegetation is also restricted. The suppression of vegetation in itself is absolutely no reason why fruitfulness should follow. ${ }^{*}$

Again, if moisture, nitrates, and carbohydrates all are abundant, these would be utilized in rapid vegetative extension, with little tendency toward the formation of specialized reproductive parts or the storing up of large quantities of carbohydrates, as long as growth was active. This condition differs from the preceding in the availability of the carbohydrates. If, then, a pruning of any type were given to trees or plants with meager carbohydrate reserves or means for their continued synthesis, even though the nitrogen and moisture conditions are unchanged, there would be a tendency for decreased vegetation and fruiting. That this is the actual situation is evidenced by the recorded results of many investigations, especially those dealing with young or so-called vigorously growing plants.

A third condition exists when there are available nitrates, moisture, and carbohydrates, but the latter are synthesized in excess of the quantities which

* (The effects of etiolation naturally suggest themselves, but these seemingly must be rather sharply separated from the discussion at hand.) 
are utilizable in simple vegetative extension. In such cases growth is expressed both as vegetative extension and specialized reproductive parts, either as a sort of balance or as an expression in favor of the one type or the other. Compared with the preceding condition, actual vegetative extension is apparently less. It is this condition which is of greatest commercial interest to fruit growers. It is an ideal condition to have trees making some vegetation each year, thus increasing and maintaining bearing area coupled with abundant fruit production. This nicety of balance can be and is maintained through many orchard practices, expecially such soil treatments as will regulate nitrogen and moisture conditions, and such top treatments as can be managed through pruning. Sometimes no cutting whatsoever may be needed, but generally some is required. The desired results of such cutting might be to suppress all growth in one portion, encourage growth in another, or to maintain a balance between purely vegetative parts and reproductively modified parts in still others. These conditions could be regulated by severe or light cutting depending upon the relative abundance of the carbohydrates, nitrates, and moisture, pruning furnishing the most ready practical means of regulating the form.

A fourth condition is most frequently encountered in very old trees, in those which are growing in impoverished or dry soils, or in those which have sustained certain types of injury which virtually amount to a ringing or girdling. In these cases vegetative extension is notably depressed, the foliage small and generally light colored, and there is usually an increased tendency toward flowering, accompanied or not, as the case may be, with fruit development. In many instances there is actually a relative decrease in the production of flowers. If this condition is due to a relative lack of nitrates or moisture or both in proportion to the available carbohydrates, then it might be expected that if the former were increased, there would be first a tendency toward increased vegetation and fruiting, but on increasing these amounts more and more, a response wholly vegetative would finally result. Such increase could be brought about either by some top pruning which directly removes stored carbohydrates, or by increasing the available nitrates and moisture by the application of nitrogenous fertilizers and cover crops with or without irrigation, as the case may be. Both these methods and their gross results are well known and established in practice. In general, it may be added that for most tree fruits, a combination of the two is most useful, since if the available nitrogen is very low, to secure results by pruning alone, the potential bearing area must be so greatly reduced that the trees are no longer commercially profitable. On the other hand, the application of fertilizers or cover crops only without some pruning may result in a loss of some of the most profitable bearing area by over-crowding or the development of fruit of a poor commercial grade.

With this viewpoint and suggestions as a starting point, it is of interest to consider the recorded results of several investigations.

There is a wide range of opinion among horticulturists in general regarding the response due to summer pruning; that is, pruning when the plants are in 
actual foliage. Formerly it was stated that summer pruning induced fruitfulness. This view is changing, due to the accumulation of results of accurate experimentation. One might expect much the same results from summer pruning as from winter pruning, and such is not far from the true situation. There is absolutely no question but that growth or vegetation may be decidedly decreased by cutting in full leaf but it must be remembered also that fruitfulness is not a necessary accompaniment of reduction of vegetation. It may be quite as much associated with an increase as with a decrease, as previously pointed out.

Summer pruning differs in one marked essential from dormant pruning, especially when the plant in question is leafless in its dormant stage, in that the former removes not only whatever nutrients are in the portion cut away, but also removes an appreciable portion of the carbohydrate synthesizing area. It must be remembered, however, that while some leaves are removed entirely, yet in some portions of the tree, other leaves may be exposed to the light to a greater extent. In other words the decrease in synthesizing power may or ray not be entirely equal to the leaf area removed. Again, moisture and nitrates are apt to be present in smaller quantities during the mid-summer growing season than in spring, so that they, as well as a restrietion of carbohydrates, would act as limiting factors to growth. With these facts in mind, whatever else has been said of dormant pruning in the ratios of nitrates and moisture to carbohydrates in relation to growth, applies equally forcibly in summer pruning.

The term summer pruning has been used to include a wide variety of pruning practices followed out during the summer months, such as a thinning out and heading back relatively early or late in any given season or at several times during the season, removing water sprouts or large limbs, or merely pinching the tips of branches. At times it has been employed in connection with winter pruning. Much of the disagreement between the interpretations of investigations is because of different methods employed. Actually, so far as can be deduced from the data available, the results are remarkably well agreed.

Batchelor and Goodspeed (2) have reported on summer-pruning practices. The data recorded permit only a suggested interpretation of the results. 'There are many possible combinations of causes operating. The greater average length of 100 twigs in each case, does not indicate whether the winter and summer pruned trees actually accumulated more total volume of growth than the unpruned trees. The mere weight of the fruit produced also leaves doubt as to the general fruit-bud situation, the percentages of blossoms setting fruit, where the functioning spurs occur, and other points. It is quite probable that as the authors suggest, the decreased fruit production is due to a reduced area of fruit-bearing wood removed by the summer pruning. 'At least, if fruit buds were stimulated as a result of the thinning (pruning), they were not sufficient in number or quality to compensate for those removed. It is not possible to judge these results as they stand on the nitrogen, moisture, carbohydrate relations, for lack of sufficient data. 
Alderman and Auchter (1) report on summer-pruning experiments, which in net result of fruit production approximate those just previously discussed. The experiments included heavy, moderate, and light pruning in the form of a heading back and thinning out. The light pruning evidently was almost entirely in the nature of thinning. A proper relation, however, was always maintained between the heavy, moderate, and light pruning. In one orchard the degrees of difference in pruning were secured entirely by varying the amount of branch thinning.

"In all orchards dormant pruning took place between March 20 and April 4 of each year. The summer pruning practiced was of virtually the same type as the dormant pruning and in amount of wood removed corresponded closely with the moderate dormant pruning. The early summer pruning was performed in 1912 between May 25 and May 31, but in the last two years was shifted to June 9 to 11, as the earlier pruning seemed to be much too early. The midsummer pruning took place each year between July 8 and 15 , while the repeated summer pruning was simply a combination of the early and midsummer prunings and took place on the dates mentioned. In this region fruit-bud formation in the apple begins from June 20 to July 1. Early summer pruning was performed just previous to this period and midsummer pruning just following it after the period of most rapid growth was completed . . In the case of the winter and summer pruning, the trees were headed back in the winter and about one-half of the wood was thinned out. In the summer time, the other half of the wood was thinned out and the suckers were removed. In the case of the repeated summer pruning it was attempted to do the same amount of pruning at each date. The sum of these two prunings made about the same as the moderate dormant pruning and left the trees pruned in about the same condition as regards shape, etc."

The results of the experiment to test the effects of seasonal pruning upon the first five years' growth of trees "show that the trees pruned heavily in the dormant season made by far the longest average terminal growth. The summer-pruned trees made a longer growth than the trees pruned lightly in the dormant season, but did not make quite as much growth as did the moderately pruned trees." But the authors made a measurement of the total as well as "average" growth produced in the year 1915 and the result "shows that summer pruning has checked decidedly the growth of the trees as regards total amount of new wood produced." In general the authors concluded that in this experiment, summer pruning has checked tree growth and has delayed and decreased fruit production. Other experiments on trees five and six years old showed that "on young trees bearing their first crops summer pruning has reduced both vigor and fruitfulness."

These results are not at all out of harmony with the general ideas expressed regarding dormant pruning. The thinning out of the branches in summer in all probability removed more in the way of potential fruit-bud area, stored nutrients, and the potential carbohydrate synthesizing area, than was compensated by admitting light and air into the remaining leaves and branches. Naturally a decreased total growth should be expected since it is also quite likely there was less available nitrate and moisture at the time of summer pruning as compared with the amounts present earlier in the season. The greater average length of terminal growth in the heavy dormant and the summer- and winter-pruned trees is not out of keeping with the general idea, 
but as the authors themselves pointed out, this does not mean greater total growth, but rather the contrary. In fact, quite a point is made of the fact that lightly pruned trees showed a strikingly greater increase in trunk diameter, branch diameter, size of top, and total annual growth than those which received annual heavy dormant pruning. This result could readily be explained as the result of limiting the available carbohydrates in the pruned trees. The moisture and nitrate conditions in the soil would not be materially changed by the mere removal of branches in itself, and if these were in excess of what would be utilized in increasing growth in the heavily pruned tree because of the limiting of the carbohydrates, then in the unpruned tree where such limit had not been imposed, total growth should be greater. If, however, the carbohydrates synthesized were in excess of the amount which might be utilized in simple vegetative extension, it might be expected that the character of growth would be progressively changed toward the reproductive type, as already pointed out.

It is in experiments of this kind that the value of the study of the parts remaining after pruning, and the conditions and changes induced in them becomes apparent and are of even greater importance than what has been removed. Any attempt to measure vigor by growth response alone is unsafe. One of the greatest hindrances to advance in the study of the whole pruning problem has been segregation of growth, blooming and fruiting responses as if they belonged in different categories or were due to ant agonistic fundamental causes. It seems much more helpful to an understanding of the problem to regard these responses as being due not so much to many distinct and separate causes, but rather to modifications or different combinations of a few, of ten closely associated or even inter-dependent.

Some recent work reported by Gardner (11) deals with a somewhat different phase of summer pruning in apples. The work was done on young trees, not yet in bearing. The summer pruning consisted of a more or less severe heading back and thinning out in early summer, removing from 55 to 78 percent of the season's growth. The winter pruning of these same trees removed from 53 to 72 percent of the late short growth formed for any particular year. From the winter-pruned trees 64 to 79 percent of the growth of any current year was removed. Some trees were unpruned. This type of summer pruning generally results in a putting forth of branches below the cut. These branches may attain a length of but a fraction of an inch or of many inches before the dormant season. If not of such length that they would interfere with the future ideal form of the tree, these shoots are not headed back in winter. If this secondary growth is profuse, it is often thinned out. Evidently this type of pruning is not quite the same as that reported by Batchelor and Goodspeed or by Alderman and Auchter.

"The data relating to shoot growth indicate that on the average the unpruned tree increases in size a little more rapidly than the trees that are winter pruned only, or that are both winter and summer pruned. Its average annual shoot growth is less but it loses none of this by pruning and hence its net increase is greater. Broadly speaking there is but little difference in increase in size between trees that are winter pruned only, and those that are 
both winter and summer pruned. The summer-pruned trees lose more shoot growth from pruning, but they produce nearly enough more to compensate for the additional loss."

The greater size of the unpruned tree is in keeping with the results of Alderman and Auchter. The same suggestions as were made on their experiments are entirely applicable here.

"While there is considerable variation between individual trees in the units of shoot growth they made in 1915 for each unit of 1914 shoot growth, there is shown no general tendency for the more severely pruned trees to produce more shoot growth for each unit of last year's growth than the less severely pruned trees. In fact, the average for the varying degrees of severity of pruning shows a slight tendency in the opposite direction. In other words, the evidence tends to show that at least in the case of young apple trees that have not yet produced many spurs, the amount of shoot growth they produce one season is much more closely correlated with the amount they made the preceding season than with the amount removed by winter pruning."

"Study of the data presented indicates that on the average there is little or no relation between the severity of the early summer pruning given these trees and their subsequent response in shoot growth. Individual trees of any of the varieties might be selected for comparison that would seem to show that heavy early summer pruning results in a more rapid shoot growth than a lighter summer pruning. Conversely other individuals might be selected that would seem to indicate an opposite tendency. The averages, however, clearly show that amount of later summer -shoot growth following the summer pruning here described is much more closely correlated with the amount of early shoot growth already possessed by the tree at the time of summer pruning than with the pruning itself. This would indicate that while on the average early summer pruning, like winter pruning, does not check rate of shoot growth, it results in a check to increase in size of tree because rate of growth is not accelerated; and that the heavier the summer pruning the greater is such a check. Attention is called to the fact, however, that the early summer pruning did not check the increase in size of the trees (as measured by shoot growth) to a degree greater than a correspondingly heavy winter pruning."

An examination of the actual figures upon which this statement is based shows some wide departures from this general conclusion; so wide in fact that it is questionable if it is safe to venture an explanation of the results expressed only as a general average. It is essential that something more be known regarding the condition of the individual trees and branches as well as their length. Professor Gardner has told the writers that in his experiments the degree or state of maturity of the branches is a very great factor in determining response from this type of summer pruning. Now degree of maturity is really another way of expressing the evident differences resulting from different conditions of nutrition. Since for the purposes of this discussion the main interest centers in the nitrate, moisture, and carbohydrate conditions, and since no determinations of these substances are at hand, it is only possible to offer conjectures as to the possible causes of the results recorded. The relative state of development of the several trees or branches is an indication of the relative amounts of the substances mentioned which are present or available. How these influence growth has already been pointed out, but a few additional examples may be mentioned here. Now a branch which is very vigorously vegetative at the time of heading back is in itself an indication that it is receiving these nutrients in the proportions which produce such growth, and 
on the other hand one which has made little vegetative extension, and has perhaps already developed a terminal bud indicates totally different proportions. What the response of any branch or tree will be after heading back will depend upon how these relationships are changed. Such heading back during the active growing season will exert its greatest limiting influence in carbohydrate synthesis, in much the same manner as does defoliation. The conclusion naturally follows that if the carbohydrate supply were decreased below the amount that could be utilized in maximum vegetative extension, considering the amounts of other compounds present, then growth would be decreased. If on the other hand the moisture-nitrate relations were such that there was not an active vegetative extension, but a surplus of carbohydrates (simple or complex), then a moderate heading back, which would tend to remove some of the latter, would result in a vegetative response until balanced relations were again restored. But as stated, if such heading back were so extensive that carbohydrate starvation effects were introduced, then vegetative activity would not result because of that fact itself, no matter what the nitrate-moisture conditions. In similar manner the entire range of results, already ascribed to the nitrate-moisture-carbohydrate relationships, might be expected. Actual experiments bear out such expectations remarkably well.

Several other results reported by Gardner are of interest. All may be interpreted on the general hypothesis previously stated. "There seems to be a close correlation between increase in trunk circumference at any period during the summer and the leaf area possessed by the tree at that particular time." It should be remembered that young actively growing trees were used in the experiments.

"Summer pruning of the type described affords a direct stimulus to fruitspur formation. Some of the buds on the basal portions of the shoots that are left after the summer pruning almost invariably grow out into fruit spurs during the latter part of the summer. Those that remain dormant during the latter part of the summer are just as apt to develop into spurs the following year as similarly situated buds on shoots that are not summer pruned.

"The later summer shoot growth of the summer-pruned trees is very productive of fruit spurs the season following its formation. A high percent age of its buds develop into spurs. Herein, apparently, lies the chief gain in fruitspur production from the summer pruning. On the trees that are winterpruned only, there is no growth to correspond with it. There is little or no relation between the severity of the summer pruning and the number of spurs to each unit of shoot length that remains."

The outstanding facts of particular interest in these experiments are that the winter- and summer-pruned trees are very similar in the amount of growth accumulated, and that the summer-pruned trees produce larger numbers of fruit spurs, more in fact than those which have been winter pruned only. That the unpruned trees average greater total growth than those pruned, is another instance of greater accumulations through non-removal of any reserve. For the most part the type of summer pruning practiced removes only the terminal portions of the branches, the portion which in active growth, as most of these branches are at the time, contains least of the storage carbohydrates, 
if there are any present. But since such a pruning does remove considerabe synthesizing area, it may prove seriously devitalizing in its effects.

That there should be increased fruit spur formation on the summer-pruned trees is in accord with the general ideas expressed, since the new growth is only slightly or not at all cut back. There would be little or no removal of stored materials, so that the adjustment for fruit buds is more quickly established. (It should be borne in mind, however, that fruit spurs and fruit buds are not one and the same thing, and that the mere development of fruit buds does not necessarily mean fruit development.)

Magness (31) has also called attention to the fact that in this method of summer heading "the form of the summer-pruned shoot, which allows many axillary buds to be left at the time of the following winter pruning, accounts for the greatly increased number of spurs in trees that have received regularly an early summer heading back." In a later report on defoliation experiments, Magness (32) gives more concrete evidence bearing on the cause of such increased fruit-spur production. His summary is so suggestive that it is worth repeating in full:

"The study of the relation of fruit-bud and leaf-bud formation and development of leaf area, as shown by the results following the removal of leaves, may be summarized as follows:

"1. Fruit-bud initiation will not take place, and fruit buds will not form in most varieties in the absence of a fair amount of leaf area in the tree.

"2. Leaf area in one part of the tree will usually not supply food material to the buds in another part to the extent necessary to cause them to become fruit buds. Defoliating one-half of a tree has little influence upon the undefoliated portion, but that part which is defoliated functions as it would if all the leaves had been removed from the whole tree.

"3. Food material stored in the tree through the dormant season is apparently stored largely in the tissue adjacent to the leaves in which it was manufactured. This is shown by the fact that the defoliated portion of a tree does not develop as strongly and well during the spring following the treatment, as does the undefoliated portion.

"4. Removing the same number of leaves, without any pruning, has practically the same effect upon the fruit-bud formation for the immediate year following, that a summer pruning, removing leaves from the same position would have.

"5. Buds on one-year wood, in areas from which the leaves have been removed are slower in starting out into growth, and make a weaker growth the following spring than do other buds on the same shoots not defoliated This is more noticeable in some varieties than in others.

" 6 . One shoot seems to be very largely independent of other shoots about it so far as fruit-bud formation is concerned. It is apparently largely dependent upon its own leaves for nourishment.

"7. Removing leaves from individual spurs tends to prevent the formation of fruit buds upon those spurs, although it does not entirely check the development of flower parts.

"8. On those spurs which form fruit buds, notwithstanding defoliation, the blossoms are, on the average, considerably later in opening in the spring.

" 9 . Axillary buds of the Wagener seem to be almost entirely dependent upon the immediate subtending leaf for the carbohydrate supply with which they are nourished. Removing the subtending leaf entirely prevents fruit-bud formation. Buds so treated either remained entirely dormant during the 
following growing season or pushed out into very weak growth. Very few of them showed a development approaching normal.

"10. Microscopic examination of buds, both defoliated and undefoliated, taken at intervals during the summer, show little influence of the defoliation so far as development is concerned. No buds were studied that were taken later than September 12.

"11. There is very decided decrease in the number of calcium oxalate crystals deposited in the tissues of defoliated as compared to undefoliated buds. This may be indicative of a small supply of soluble carbohydrates and general slow metabolism in the bud tissue.

"12. Injury to the bark on the trunk of the tree very greatly stimulated fruit-bud formation. This injury brings about very different conditions of nutrition in the tree from those produced by defoliation, for by preventing the normal flow of elaborated foods to the roots, the supply in the top of the tree is greatly increased by the injury of the bark."

The evidence as to the influence of carbohydrates on fruit-bud formation is particularly direct. The extremely close relation between the behavior of any bud relative to its immediate leaf area emphasizes such an influence still further, and is of great practical significance. It is unfortunate that no direct measurements of the various nitrogenous compounds are available, but it should be recalled that, for the most part, young vegetative trees were used, so located that there was a copious supply of soil nitrates. One tree of the Glowing Coals variety which had a severe trunk injury developed a little more than one-third as many fruit buds on the defoliated half as on the nondefoliated half, though the former produced much weaker bloom clusters the following spring. Magness has suggested that the conditions of nutrition in this tree caused an initiation of floral primordea somewhat in advance of the defoliation because of the relation of the elaborated foods in the tops. This is no doubt true, and the elaborated foods were probably carbohydrates for the most part. Of course this behavior resembles that of artificially girdled individuals, but the contrast in performance of the defoliated and nondefoliated halves bears out the general conclusion even more clearly.

One other set of results reported by Drinkard (7) is particularly significant, when examined from the viewpoint previously expressed regarding growth behavior and fruit production. Some of his conclusions together with a suggested analysis follow:

1. "Spring pruning of the branches of the trees at the time of growth resumption had a tendency to discourage the formation of fruit buds, but there was apparent stimulation of wood growth in the trees."

An explanation for this result has already been given. The apparent stimulation resulting from severe heading back is an indication that nitrogen rather than carbohydrates was a limiting factor to vegetation.

2. "Summer pruning of the branches of the trees the latter part of June, when fruit buds normally begin to show differentiation, checked wood growth the year in which the summer pruning was done, and greatly stimulated the formation of fruit buds as was shown by the bloom and crop of fruit the following year."

Without more complete data on the exact location of fruit buds and the full behavior of these trees, a complete explanation of the results is impossible. Still it is interesting to note some of them. Compared with the check trees and the spring- and fall-pruned trees, the average circumference of these 
summer-pruned trees was less, the number of fruit buds formed was not greatly in excess of the checks, though decidedly greater than the spring-pruned trees. It may be suggested that the carbohydrates were present or being manufactured in proportions relative to the available nitrogen, sufficient for coprous fruit-bud initiation and development in those trees which received no pruning treatment. If so, then an early spring pruning would tend to reduce these from the standpoint of storage and subsequent synthesis. At this time, also, soil moisture and nitrates could be expected to be somewhat higher than at the time of summer pruning. The natural growth expression would be vegetative, provided that lack of carbohydrates were not a limiting factor, and the results indicate that they were not. It certainly would have been possible to make them so. A pruning given later in the summer would likewise remove some stored carbohydrates and of course synthesizing area, but at that time soil nitrates and moisture were probably relatively less so that a strong vegetative response would not be anticipated. Increased fruit-bud formation over the checks would be expected in this particular case only if the carbohydrate supply were relatively greater, which might have been the case, since the amount of leaf area removed may have been compensated by the admission of more light to the parts remaining, and by the new leaves developed. Such carbohydrates as were synthesized were not used up in vegetative extension, since these trees made very short growth in annual shoots. This is a particularly interesting case in which it would be extremely desirable to know something of the relative proportions of the several substances under consideration. Under the present circumstances they can only be surmised. These suggestions should be considered in connection with the next point.

"Root pruning on April 23, at the resumption of growth in the absence of spring pruning, did not give as much stimulation to fruit-bud formation as the same treatment applied at later dates. Apparently this was too early for the full effects to be felt by the trees. Root pruning when the foliage was fully developed, and when the fruit buds began to become differentiated, in the absence of spring pruning of the tops, produced very marked stimulation in fruit-bud formation. At these three times the treatment retarded wood growth and foliage development in the current and succeeding year and the trees suffered from the treatment.

"Severe root pruning at the time of growth resumption in the spring (April 23), at the time the leaves were well developed (May 31), and at the beginning of fruit-bud differentiation (June 23), when accompanied by or preceded by spring pruning of the branches, produced some stimulation in fruit-bud formation. Another series of experiments showed that the spring pruning did much to off-set the effects of the root pruning. The root-pruning treatment retarded wood growth in the current and succeeding year; the leaf area of the trees was reduced and the trees showed injury from the treatment."

The results expressed in the two preceding puragraphs can best be analyzed together. A root pruning would be expected to reduce the intake of moisture and of mineral nutrients including nitrates. Of course the earlier in the season performed, the earlier some result would be produced in the top, though the results might not be quite the same under the two conditions. A root pruning when the foliage is fully developed and the fruit buds are beginning to become differentiated would mean decreased moisture and nitrate intake, whereas 
carbohydrate synthesis would continue, assuming of course that such pruning is not so severe as to result in actual death of the tops. Without sufficient moisture and nitrates to utilize the carbohydrates in forming other compounds or in vegetative extension, they would tend to accumulate, with the resultant types of expression of vegetation and fruiting already enumerated from scarcity to marked fruit-bud production, even to the suppression of fruit-bud production, fruiting, and vegetation. On this basis it readily follows that, other conditions of root pruning and the like being the same, a spring pruning of the branches, which would decrease the materials already in storage and to a degree the subsequent amount of foliage developed, should tend to influence fruit-bud formation to the same extent that it modifies the relations of the carbohydrates to the moisture and nitrates. In the experiments under consideration fruit-bud formation for the most part was greater when the root pruning was not accompanied by branch pruning, but not necessarily so. Theoretically there should be a point where fruit-bud formation on rootpruned branch-pruned trees should be relatively greater than on those which had been root-pruned only. That is, such a condition would exist when the root removal had so reduced the possibilities of absorption that it would be necessary to decrease the carbohydrates in proportion to the nitrates in order to promote growth. In the scheme already proposed this would mean a change from the fourth to the third condition. Such a situation is actually indicated in the fruit-setting records in the experiments under consideration. It should be brought out also, that a branch pruning removes many buds likely to develop into fruit spurs, whereas these remain when no pruning is given, so that a comparison based on numbers of fruit buds only, seems hardly a just one.

"Ringing at different seasons when accompanied or preceded by spring pruning of the branches produced no noticeable stimulation of fruit-bud formation.

"Ringing at the time growth was resumed in the absence of spring pruning did not stimulate fruit-bud formation. The treatment was given too early. Ringing at the time the foliage was fully developed in the absence of spring pruning gave the best results; however, when the treatment was given at the time the fruit buds began to become differentiated, there was some stimulation of fruit-bud development."

All these results would be expected in accordance with the general ideas proposed. There is little question that ringing would result in an accumulation of carbohydrates above the girdle, if they are being manufactured in excess of the amount utilizable in connection with the moisture and nitrates available. The same series of results would be expected as from root pruning or as from limiting the nitrate or nitrate and moisture supply. The situation is just the reverse of root pruning in which nitrate and moisture intake were limited through reducing the absorbing medium, but the same net result in the relation of carbohydrates to nitrates is gained by holding the carbohydrates in the top even though the root conditions are not mechanically changed. It would seem that if moisture and nitrate intake were not limited that growth should be little changed. A question may be raised here, however, in regard to the possibilities of moisture and general mineral intake when the carbohydrate supply is prevented from reaching the roots. There are reasons and 
evidence for believing that the actual root extension is decidedly diminished by such carbohydrate limitation, and there is also quite likely a change in the power of the roots to absorb mineral nutrients. In any case such analyses as have been made do show an aceumulation of carbohydrates above a girdle, generally in direct proportion to the severity of the ringing, whether there is also a limitation of nitrate intake remains to be determined. Thus a ringing when the trees were in full leaf might be expected to result in a more rapid accumulation of carbohydrates and in larger quantities than when such leaf surface were small or if the girdle healed before the leaf surface became larger. The relative amounts of moisture and nitrates available in the soil earlier or later in the growing season are also important factors to be considered. It is easily possible to make a girdling so se vere that fruit-bud formation, blooming, fruiting, and growth are all seriously diminished. The whole range of growth responses resulting from the nutrient relations as previously proposed can be produced.

"Stripping at different seasons when accompanied by or preceded by spring pruning, had no stimulative effect on fruit-bud formation. The effects of stripping were offset by those of spring pruning. Stripping at the three seasons already mentioned, in the absence of spring pruning stimulated fruitbud formation uniformly."

Stripping in its effects, is like ringing or girdling, except that it is less severe. What has been said for the latter will apply equally well to stripping.

\section{HISTORICAL}

There are many references in botanical and general agricultural literature dealing with a suggested relationship between plant responses and the availability of elaborated or non-elaborated food. Some of these make no further explanations or suggestions regarding the particular nature of these foods, others roughly classify these compounds as mineral or organic nutrients, while still others fix upon specific compounds as related to specific responses. In addition to specific references already mentioned in this article, several others are of special interest. Up to the present time, at least, Klebs $(21,22,23)$ has been one of the most active contributors to definite knowledge on this subject. He has worked with algae, fungi, and the higher plants. In the lower forms he has shown that by controlling the envirommental conditions it was possible: to cause the plants to remain in a vegetative condition, to produce zoospores or to reproduce sexually. He has demonstrated that much the same results could be secured in the higher plants as, for example, Sempervivum Funckii. (24). In a more recent paper (25) he has brought together the results of numerous investigations which have shown that the environmental conditions very largely determine whether a plant shall remain in a vegetative condition or become sexually reproductive. The controlling factors were found to be a reduction in the supply of nutritive salts (especially those which are nitrogenous) and an increase in the intensity of light, the efficiency of the illumination being responsible for the formation of organic substances, such as carbohydrates. 
It has been observed for a long time that most tropical trees show an alteration of growth and a rest period. This has quite often been attributed to some inherent heredity character. Klebs, (26) however, has regarded this condition as a result of external conditions acting upon the specific hereditary character of the plant. Each plant is supposed to possess certain hereditary possibilities in the way of expression of growth and reproduction, and the probable form which results will depend upon the surrounding conditions. Klebs has concluded that, since growth depends upon a large number of factors, any one of which may be a limiting factor, rest ean be secured by suppressing any one of these factors to a minimum. Intense photosynthesis, producing a large supply of carbohydrates in case salts are not present in sufficient amounts, may result in rest.

Crocker (5) in reviewing the foregoing work by Klebs, has stated the following: "It seems that Klebs has established his general contention of the dual determination of periodicity in these forms, but there are some minor conceptions that are less happy.

"He classifies all nutrient salts together as if they all have the same effect upon the course of development, while agriculturists have fully demonstrated that nitrates and phosphates in some respects have opposite effects. He implies that salts have their effects mainly as nutrients (building materials), while the extensive work on antagonism probably deals with general physical or colloidal effects, and there is evidence that metallic ions are of importance in catalysis. Moreover, it is not yet known whether high nitrate supply induces vegetation and succulence through materials, (proteins, ete.) built from it, or through its lyotropic effects, and whether the partly contrasting effects of phosphates depend upon the first or second condition. Periodicity in salt absorption which has been observed in trees and grains is also minimized. It seems evident that to get far back of the general proposition which Klebs has apparently proved, there is need of a careful study of internal conditions of the plant, anatomical, chemical, and microchemical, as well as the application (by injection or otherwise) of various salts and carbohydrates and products manufactured from them to be sure of the effective agents."

This summary very accurately defines the present status of the whole problem and opens up the field of future attack. Some other references are of special significance in furnishing additional facts for interpretation of the nutrient relations in the plant itself.

Fischer (8) has studied the starch and sugar transformations in a wide range of plants taken at various periods during the year. He did not differentiate between vigorous and non-vigorous individuals, but has distinguished between starch storeres and fat storers. He found that the stored starch underwent marked changes, and that such transformations are closely associated with the formation of glucose.

Leclerc du Sablon (40) has investigated the carbohydrate reserves in the stem, root, and leaves of girdled and non-girdled pear trees three or four years of age. He found that by autumn there were greater reserves in the leaves but smaller amounts in the roots of the decorticated trees. Analyses of the stems indicated little difference. The chlorophyll, however, was less abundant in the leaves of the decorticated trees; such leaves were in general recognizable by their yellow color. It was suggested that there seemed to be a sort of regu- 
lation of the assimilatory function; the products of chlorophyll assimilation not having their normal outflow thus encumbering the leaves, and causing a diminution in the production of chlorophyll.

Hedrick (16) has reported ringing experiments with tomatoes and chrysanthemums. Commercially this practice was not a success. There was actually a decrease in the weight of fruit produced on the ringed tomato plants, and the root development of both the tomato and chrysanthemum plants which had been ringed was markedly decreased.

Remy (38) has given results of the analyses of apple and pear trees used in fertilizer tests. Those trees from which nitrogen was withheld were markedly unfruitful. He has stated that a nitrogen content of at least $1.25 \%$ of the dry substance of the leaves is essential to fruit-bud formation, and that the flowering and fruiting condition is far more sensitive to variations in nitrogen supply than to potash, phosphoric acid, or lime.

Petri $(36)^{*}$ has reported experimental studies on fruit setting in the olive. His observations are of particular interest. He has suggested that the abortion of the developing flowers and ovaries in the olive is due in large measure to a lack of sufficient supply of nitrogen in the plant tissues, and that this really constitutes a cause for sterility in that plant. A deficiency of nitrogen relative to the carbohydrate supply represents a stimulus to abundant formation of flowers, but if the available nitrogen supply goes below a certain limit, the flowers remain sterile because of incomplete development of the ovary. Lack of moisture in soil may be a cause of sterility, due to the lack of absorption of nitrates. His investigations are limited, but tend to bear out his conclusions. A later report (37) has confirmed and somewhat extended his former statements. He found that fertile branches of olive contained $2.119 \%$ to $2.370 \% \mathrm{~N}$ of dry weight, whereas those not setting fruit contained from 0.720 to $0.924 \%$. "In normal conditions of vegetation the inception of the reproductive phase coincides with a relative prevalence of the products of assimilation over those that are derived in whole or in part from the mineral nutrients. Naturally this particular nutritive relation may be established both by an increase of the assimilatory function of the leaves and by a diminution of the absorbing roots." Petri has taken special pains to point out that the mere formation of floral parts does not necessarily indicate the capacity of any plant for fruit production, and that the nutritive relations for fruitfulness do not necessarily coincide with the extreme fluctuations under which "the simple differentiation of the reproductive organs" occurs. "The same deficiency of nitrogen which in many cases determines an abundant flowering, may also impede the development of the ovary when it goes beyond a certain limit. Likewise the deficiency of water in the soil may frequently stimulate the formation of abundant flowers and yet constitute a cause of arrest of the growth of the female organs." That sterility may be due to conditions of nutrition as well as heredity was also pointed out.

Hartwell (15) has reported on work with potatoes and mangels in which he attempted to determine the effects of potassium in relation to starch assimila-

*The writers are indebted to Dr. Sophia H. Eckerson, of the Department of Botany of the University of Chicago, for a careful translation of the original articles by Petri. 
tion. He has stated that, "A deficiency of available potassium in the soil was usually accompanied by an accumulation of starch in potato vines," and that "Many different factors, correlated in each case with retarded growth, were found to be associated with an accumulation of starch in the above-ground portion of plants."

Hibino (20) has reported on his investigations in ringing. Among other things he found that in the ringed individuals above the wound there was an increase in organic and inorganic reserve materials. In the case of decortication only these consisted of starch, reducing sugar, ether extract, and ash; if wood ringing was performed these were non-reducing sugar, proteins, crude fiber, and tannins. There were no estimates of nitrates, the total nitrogen determinations having been calculated to proteins.

Recently the relation of nitrogenous fertilizers in connection with mottleleaf in citrus trees has been receiving much attention. Briggs, Jensen, and McLane (4) have reported in connection with their investigations of this subject that "groves which for some years had received only the 'complete' fertilizers in general use in the areas studied were badly mottled in all cases, so far as observed in these studies. This was also the case where sodium nitrate was used alone or as the prineipal fertilizer for some years. . . . No relation was found between the pereentage of leaves mottled and the total nitrogen content in the soil in either the orange groves or the lemon groves studied." MeBeth (33) has found that "mottled orange leaves have a higher moisture content than healthy leaves of the same age from the same tree. The nitrogen content of mottled leaves is also generally higher than healthy leaves. Extreme mottling is frequently associated with a high nitrate content, but the correlation is by no means an invariable one." The relation between nitrates and mottle leaf still remains to be established definitely.

\section{MATERIAL AND METHODS. Experimental.}

In the present work with tomatoes, we were interested mainly in a comparative study of the internal conditions in plants which were setting fruit, and those which were not, particularly with reference to the presence of total nitrogen, nitrates, moisture, and carbohydrates, and the relations between them. Since our work was to deal largely with the conditions within the plant, we made little effort to determine the exact quantities of nutritive or other elements in the soil in which the plants were grown, beyond a knowledge that the supply was abundant or restricted in any particular case.

Materials. The tomato was selected as material for investigation because of the ease with which this plant can be handled and grown under green-house conditions, because it is clean cut in its fruit-setting responses to any set of conditions imposed, and because it is readily available in any quantity. 
All the plants used, with the exception of one lot, were of the Lorillard variety and were raised from seed. The seeds were first sown in loam soil, the seedlings pricked off into individual two-inch pots containing rich potting soil and when they had made a height of some three or four inches, the most uniform plants were selected for transfer to any particular set of conditions which it was desirable to employ. For the most part the plants used were stocky, actively growing, and without external evidences of flower buds when they were selected for transplanting.

For the sand cultures ordinary white quartz sand was used. This was free from organic matter but was not subjected to any particular treatment or washing before being used. It contained considerable quantities of iron. Without added nutrients the plants did not grow in it. This sand was used as a medium in which to grow plants subjected to a very low supply of nitrates. It was not desired in any case completely to eliminate them from the soil. A thin layer of cotton batting was put in the bottom of each pot before filling it with sand so as to prevent the latter from being washed through when the plants were watered. After filling the pots a porous battery cup was sunk into each, allowing about one-half inch to protrude above the surface of the sand. A large, flat cork was fitted into the opening. The nutrient solutions were poured into these cups and allowed to seep out into the sand. In this way the taking up of the nutrient solution by the pot itself and its later appearance as an efflorescense on the rim and sides, was almost entirely avoided. The roots of the growing plants formed a solid mat about the eups.

The nutrient Knop's solution employed in connection with the sand cultures was made up as follows:

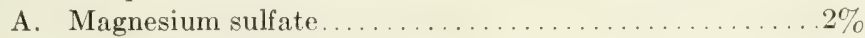

Dibasic potassium phosphate................... $2 \%$

Potassium nitrate.............................. $2 \%$

B. Calcium nitrate........................ $8 \%$

For use, equal parts of $A$ and $B$ were diluted one to seven with tap water and then mixed. Some precipitate was always formed, but this did not in any way seem to interfere in the use of the porous cups. Every three weeks the cups were scraped out with a scalpel and the accumulated sand and precipitate, which is always but little, dug into the sand about the plant. In some cases this was not done; not the slightest difference was observed in the plants in the two cases.

When the plants were transferred to the pots containing sand, all the soil and adhering particles of organic matter were washed from the roots with great care. The plants were then placed in the sand about one-half inch deeper than they stood originally. This is desirable because a large part of the roots present at the time of transfer die back, but new ones are produced very quickly from the stem.

The particular conditions for any particular lot or series of plants are given in connection with the analysis of the same, but there are some general conditions which will apply to all of them. No special precautions were taken re- 
garding the general green-house conditions. So far as possible a temperature suitable for growing tomatoes was maintained, the light conditions of course varied with the season and external conditions, but care was taken that all plants in any lot or series were uniformly subjected to the same general conditions. The plants were grown in ordinary ten-inch to twelve-inch earthenware pots. Every pot, however, was placed in a granite-ware basin, which served the double purpose, first, of preventing the roots which came through the bottom of the pots from coming into contact with any soil in the benches on which the plants stood, or the leeching of any material from such soil into the pots, and second, it was possible to maintain a uniform condition of moisture in the several pots. For the most part our effort was to maintain, in each basin, when the pot was in it, a depth of about one inch of water. Of course immediately after watering this level was of ten higher, and sometimes it was a trifle lower; but the soil was not permitted to become dry in any case, except in the experiment where the soil was intentionally allowed to dry out. Water from the Chicago Municipal supply was used throughout all the experiments and in making up the nutrient solutions.

\section{Chemical.}

Sampling and Preservation of Samples. In order to obtain uniform samples in so far as it was possible, a number of plants were selected from any given lot which was to be sampled. After cutting the plants off just above the surface of the ground the leaves were removed, those from the upper half being kept separate from those of the lower half of the plant. The leaves were then cut into pieces about two inches long, and 100 grams weighed out for each sample. The stems were then cut into two-inch pieces and weighed. The samples were placed in large wide-mouthed glass-stoppered bottles and taken at once to the laboratory.

Enough $95 \%$ alcohol was added to each sample to insure a concentration of about $75 \%$. In all cases except the first few lots of samples $0.25 \mathrm{gr}$. of precipitated $\mathrm{CaCO}_{3}$ was added in order to neutralize any acids which might be present. After heating for one hour on a steam bath at $70^{\circ}$ to $75^{\circ} \mathrm{C}$. the samples were placed away until they could be analyzed.

It might seem as though there would be sufficient loss of moisture to eause error from the time the samples were cut up until they were weighed, but Table I will illustrate that such was not the case. In Table I, samples 1, 2, and 3 were taken without cutting the plants and samples 4 and 5 were weighed from a composite of the plants which had been cut into two-inch pieces. The moisture in sample 6 is calculated from the determinations of series M, upon the basis that there was twice as much green weight in the leaves as in the stem, a ratio which was noted when the samples were taken. The other samples were taken from the same lot and at the same tims as series M.

Extraction of the Samples. After the samples had been allowed to stand for at least several weeks, the alcohol extract was poured off and filtered into a liter flask. The residue was then transferred to a pyrex beaker. Small amounts of 
Table I.-Showing the Determinations for moisture in Whole" Plants and Those Cut into Small Pifees.

\begin{tabular}{|c|c|c|}
\hline Sample & $\begin{array}{c}\text { Character of } \\
\text { Material }\end{array}$ & $\begin{array}{l}\text { Percentage } \\
\text { of moisture }\end{array}$ \\
\hline 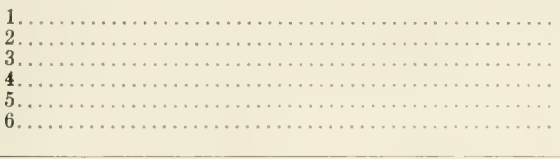 & $\begin{array}{l}\text { Whole plants } \\
\text { Whole plants } \\
\text { Whole plants } \\
\text { Cut into 2-inch pieces } \\
\text { Cut into 2-inch pieces } \\
\text { From sample extracted } \\
\text { Series M }\end{array}$ & $\begin{array}{l}91.17 \\
91.06 \\
91.40 \\
91.61 \\
91.65 \\
91.63\end{array}$ \\
\hline
\end{tabular}

warm $80 \%$ alcohol were added and allowed to cool and then filtered into the liter flask. After repeating this operation until there were about 900 c.c. in the flask the residue was dried upon a steam bath and then transferred to a small weighed beaker. All of the extract remaining in the original beaker was transferred to the filter and the filter paper was washed carefully. The extract in the flask after coming to room temperature was made up to a liter and then stored away in a tightly stoppered glass bottle. After the residue was air dried it was weighed, ground finely in a mill, and then weighed out into one-fifth sample and one-twentieth sample aliquots.

Total Nitrogen. Fifty cubic centimeters of the extract, representing $1 / 20$ of the original sample were placed in a Kjeldahl flask and placed upon a steam bath to drive off the alcohol. An aliquot of the residue representing $1 / 20$ of the sample was then added and the total nitrogen determined by the Kjeldahl method modified to include nitrates.

Nitrate Nitrogen. The nitrrte nitrogen was determined by a modification of the Schulze (42) method very similar to that used by Mitchell, Shonle, and Grindley (34). The method was checked up with a sample of potassium nitrate of known strength.

Carbohydrates. Two hundred cubic centimeters of the extract representing $1 / 5$ of the sample were placed in a beaker and the alcohol driven off upon a steam bath. An aliquot of the residue representing $1 / 5$ of the sample was placed upon a filter paper and extracted with 200 e.c. of warm water $\left(30^{\circ}-40^{\circ} \mathrm{C}\right.$.) in successive small portions. Such an extraction completely removed all the free-reducing substances and sucrose. The extract of the residue was used to transfer the extract from the alcohol solution to a 250 c.c. volumetric flask. The extract was then neutralized when necessary with $\mathrm{NaOH}$ and cooled to room temperature. The solution was cleared with just sufficient basic lead acetate, then made up to volume and without standing Ionger than to allow the precipitate to settle, was filtered through a dry filter paper into a dry vessel. Two hundred cubic centimeters of the filtrate were placed in a 250 c.c. volumetric flask and sufficient saturated $\mathrm{Na}_{2} \mathrm{SO}_{4}$ solution was added to precipitate any very slight excess of lead. This solution was made to volume and after standing until the lead was completely precipitated was filtered through a dry filter paper into a dry flask. This solution was used for the determination of free reducing substances and the easily hydrolyzable non-reducing disaccharides 
(sucrose*). The residue from the water extraction was used for the determina tion of polysaccharides ( starch*). $^{*}$.

Free-Reducing Substances. Twenty-five or fifty cubic centimeters of the cleared extract were used for the determination of the free-reducing substances.

Sucrose. Seventy-five cubic centimeters of the extract were placed in a 100 c.c.volumetric flask. Five cubic centimeters of $\mathrm{HCl}$ (sp.gr.1.19) were added slowly and then the flask was placed in a water bath at $70^{\circ}$ so that the solution reached $65^{\circ}$ to $70^{\circ}$ at the end of $31 / 2$ minutes and was kept at $69^{\circ} \mathrm{C}$. for $6 \frac{1}{2} \mathrm{~min}$ utes longer. The flask was then removed, cooled, neutralized, cooled to room temperature, and made up to 100 e.c. After being filtered through a dry filter paper into a dry flask 25 or 50 c.c. were used for the determination of the reducing power.

Polysaccharides. The residue from the water extraction was boiled with 150 c.c. of water and 15 c.c. of $\mathrm{HCl}$ (sp. gr. 1.125) in a two-liter flask with a reflux condenser for two and one-half hours. After neutralizing to litmus with $\mathrm{NaOH}$ the solution was transferred to a 250 c.c. flask. After clearing with basic lead acetate and deleading with $\mathrm{Na}_{2} \mathrm{SO}_{4}, 25 \mathrm{c} . \mathrm{c}$. of the solution was used for the determination of the reducing power.

The reducing power of all of the carbohydrate solutions was determined by a combination of the Munson and Walker method and the Bertrand method. The reduction was carried out under the conditions of the Munson and Walker method and the tables of this method were used (43). The determinations of the amount of reduced copper were carried out by the Bertrand method.

The results have all been calculated and expressed as dextrose. While this does not give absolute results for the different carbohydrates, such results are none the less comparative. Any reliable method for a more definite differentiation of the carbohydrates would have consumed so much time that it would have been impossible to cover so wide a range of material. It seemed wiser, therefore, to make a general survey now and to defer a more minute study until a later time.

General Statement. The free-reducing substances represent the total reducing power of the extract before hydrolysis, expressed as dextrose. Sucrose represents the increase in reducing power due to the hydrolysis under the conditions given for the determination of sucrose. The results are expressed as dextrose. While this may not give absolute results for the amount of sucrose it does give the relative amounts of sucrose or substances which are hydrolyzed with the same degree of ease. A sample of pure maltose was subjected to the same method of hydrolysis and no measurable increase of reduction due to the hydrolysis was detected. Starch is expressed in terms of dextrose. Although the method used for the determination of stareh is not absolute and includes any polysaccharides which are hydrolyzed under the conditions imposed with the production of reducing substances, it should be kept in mind that the term is used with that significance. The substances included in addition to the starch are those which are hydrolyzed with about the same

"The terms "sucrose" and "starch" are used throughout this discussion with the significance indicated in the paragraphs under the "general statement." 
degree of ease. Micro-chemical tests show an abundance of starch grains where the determinations for starch are high and scarcely any starch where the quantitative methods show very low amounts. It is quite probable that the polysaccharides hydrolyzed by this method are made up of starch in a large part.

Moisture and Dry Weight. One hundred cubic centimeters of the alcohol extract were evaporated to dryness upon a steam bath and then dried to constant weight in a vacuum oven at $78^{\circ} \mathrm{C}$. From this weight the total dry weight of the extract was ealculated. The total dry weight of $1 / 5$ of the residue was determined by drying under the same conditions as mentioned above. The moisture was then determined by difference.

\section{Microchemical.}

The principal substances tested for microchemically in all the experiments were free-reducing substances, starch, and nitrates, to a lesser extent determinations of calcium, potassium, oxalates, and chlorides were also made. All the analyses were made immediately after cutting the fresh material and bringing it into the laboratory. All tests were made in triplicate, at least.

The following were the three principal tests employed:

Free-reducing Substances. Flückiger's Reagent made up of a minute quantity of copper tartrate placed in a drop or two of $15 \%$ to $20 \% \mathrm{NaOH}$ was used. When the copper tartrate was completely dissolved and mixed with the sodium hydrate, thin sections were cut from the material to be tested, immediately placed in the solution, and a cover glass added. The preparations were then placed on a water bath at about $90^{\circ} \mathrm{C}$ for one hour. Comparisons were based on the relative number and size of the dark brown granules of copper oxide precipitated.

Tests based on osazone formation were entirely unsatisfactory for the tomato tissue.

Nitrates. The reagent used was made by dissolving 0.1 grams diphenylamine in 10 grams $75 \%$ sulfuric acid. Fresh sections were placed on a slide, covered, and the reagent run in from the side of the cover. A blue color indicated the presence of nitrates. Very satisfactory comparisons were obtained by noting the intensity of the coloration.

Starch. The well-known test, iodine-potassium iodide solution was employed, and the peculiar granular nature of the starch noted.

\section{Anatomical Methods.}

For the anatomical studies both fresh and preserved material was used. Some of the stems were cut in parafine though for the most part material hardened in alcohol was cut sufficiently well on a sliding microtone without previous imbedding of any kind. For the more detailed studies the material was stained in Safranin and Grübler's Lichtgrün and mounted in balsam. 


\section{PRESENTATION OF DATA \\ Chemical.}

Experiment II. The plants from which samples of Series A and E were taken were of the variety Ponderosa. They were grown in ordinary greenhouse soil in $21 / 2$-inch pots, and at the time of transplanting were about five inches tall, slender, somewhat yellowed, and showing flower buds.

On June 14, 1916, they were transplanted in the greenhouse to a ground bed about two feet in depth, of fresh cow manure which contained considerable hay and straw but without the admixture of any soil whatsoever. Ordinarily these conditions would be considered wholly unfitted for the growing of tomato plants, but within several days, the young plants took on a healthy green color and began to grow vigorously, though most of the blossom buds fell off before or immediately after blooming.

The samples constituting series A were taken July 25 at $9: 30 \mathrm{a}$. m. on a clear day. The plants were then about four feet high, had a good green color, were flowering fairly well but had failed to set fruit.

The samples constituting series $\mathrm{E}$ were taken September 8, at 9:30 a. m. during fairly clear weather. The plants were still distinctly vegetative, about five to six feet high, beginning to turn somewhat yellow, and although they blossomed freely, scarcely any fruit was produced. The analyses are given in Tables II, III, IV, and V. Because the variation in dry matter of the plants grown under different conditions and in different parts of the plant is great, it seemed wise to give the results calculated to both the dry weight and to the green weight.

These plants of this series were high in moisture, total nitrogen, and nitrate nitrogen and low in total dry matter, sucrose, and polysaccharides, and fairly high in free-reducing substances. In the stem, going from the top to the bottom, the total nitrogen decreased and the polysacchrides, free-reducing substances, and total dry matter increased. In the leaves this relation of total nitrogen and nitrate nitrogen to free-reducing substances is the opposite, but with the polysaccharides the same relation holds as was found in the stems.

TABle II.-SERIES A.

All results computed to a dry-weight basis except moisture and dry matter.

\begin{tabular}{|c|c|c|c|c|c|c|c|c|}
\hline \multirow{2}{*}{ Material } & \multicolumn{2}{|c|}{ Upper leaves } & \multicolumn{2}{|c|}{ Lower leaves } & \multicolumn{2}{|c|}{ Upper stems } & \multicolumn{2}{|c|}{ Lower stems } \\
\hline & $\begin{array}{l}\text { First } \\
\text { deter. }\end{array}$ & $\begin{array}{l}\text { Second } \\
\text { deter. }\end{array}$ & $\begin{array}{l}\text { First } \\
\text { deter. }\end{array}$ & $\begin{array}{l}\text { Second } \\
\text { deter. }\end{array}$ & $\begin{array}{l}\text { First } \\
\text { deter. }\end{array}$ & $\begin{array}{l}\text { Second } \\
\text { deter. }\end{array}$ & $\begin{array}{l}\text { First } \\
\text { deter. }\end{array}$ & $\begin{array}{l}\text { Second } \\
\text { deter. }\end{array}$ \\
\hline 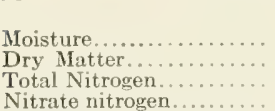 & $\begin{array}{r}0 \\
90.11 \\
9.89 \\
5.02\end{array}$ & $\begin{array}{l}\% \\
\% \\
5.06\end{array}$ & $\begin{array}{r}\% \\
91.25 \\
8.75 \\
3.36\end{array}$ & $\begin{array}{r}\% \\
90.88 \\
9.12 \\
3.41\end{array}$ & $\begin{array}{r}\% \\
93.29 \\
6.71 \\
1.81\end{array}$ & $\begin{array}{c}\% \\
\cdots \\
1.76\end{array}$ & $\begin{array}{r}\% \\
91.70 \\
8.30 \\
1.74\end{array}$ & $\begin{array}{c}\% \\
1.78\end{array}$ \\
\hline Free-reducing substances. & 1.92 & 1.97 & 2.21 & 2.73 & 2.08 & 2.20 & i.ii & 1.11 \\
\hline $\begin{array}{l}\text { Sucrose } \ldots \ldots \ldots \ldots \ldots \ldots \\
\text { Starch................... }\end{array}$ & $\begin{array}{l}0.00 \\
6.90\end{array}$ & $\begin{array}{l}0.00 \\
\cdots\end{array}$ & $\begin{array}{l}0.00 \\
7.59\end{array}$ & $\begin{array}{l}0.00 \\
\cdots \cdots\end{array}$ & $\begin{array}{l}0.53 \\
7.90\end{array}$ & $\begin{array}{l}0.70 \\
7.90\end{array}$ & 8.43 & 8.26 \\
\hline
\end{tabular}


Thabe III.-Series A.

All results computed to a green-weight basis.

\begin{tabular}{|c|c|c|c|c|c|c|c|c|}
\hline \multirow{2}{*}{ Material } & \multicolumn{2}{|c|}{ Upper leaves } & \multicolumn{2}{|c|}{ Lower leaves } & \multicolumn{2}{|c|}{ Upper stems } & \multicolumn{2}{|c|}{ Lower stems } \\
\hline & $\begin{array}{l}\text { First } \\
\text { deter. }\end{array}$ & $\begin{array}{l}\text { Second } \\
\text { deter. }\end{array}$ & $\begin{array}{l}\text { First } \\
\text { deter. }\end{array}$ & $\begin{array}{l}\text { Second } \\
\text { deter. }\end{array}$ & $\begin{array}{l}\text { First } \\
\text { deter. }\end{array}$ & $\begin{array}{l}\text { Second } \\
\text { deter. }\end{array}$ & $\begin{array}{l}\text { First } \\
\text { deter. }\end{array}$ & $\begin{array}{l}\text { Second } \\
\text { deter. }\end{array}$ \\
\hline 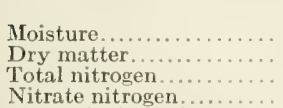 & $\begin{array}{l}\% \\
90.11 \\
9.89 \\
0.496\end{array}$ & $\begin{array}{l}\% \\
0.500\end{array}$ & $\begin{array}{l}\quad \% \\
91.25 \\
8.75 \\
0.294\end{array}$ & $\begin{array}{c}\% \\
90.88 \\
9.12 \\
\cdots\end{array}$ & $\begin{array}{c}\% \\
93.29 \\
6.71 \\
0.121\end{array}$ & 0.118 & $\begin{array}{l}\% \\
91.70 \\
8.30 \\
0.144\end{array}$ & $\begin{array}{c}\% \\
\cdots \cdots\end{array}$ \\
\hline $\begin{array}{l}\text { Free-reducing substances. } \\
\text { Sucrose................... }\end{array}$ & $\begin{array}{l}0.189 \\
0.000\end{array}$ & $\begin{array}{l}0.194 \\
0.000\end{array}$ & $\begin{array}{l}0.238 \\
0.00\end{array}$ & 0.00 & $\begin{array}{l}0.139 \\
0.055\end{array}$ & $\begin{array}{l}0.147 \\
0.027\end{array}$ & 0.092 & 0.092 \\
\hline Starch $\ldots \ldots \ldots \ldots \ldots \ldots$ & 0.682 & $\ldots \ldots$ & $\cdots \cdots$ & $\cdots \cdots$ & 0.5301 & 0.5301 & 0.699 & 0.685 \\
\hline
\end{tabular}

Experiment V. For this experiment seeds of the Lorillard variety were sown July 29, 1916. The young plants when large enough to handle were transplanted to a rich loam soil in $2 \frac{1}{2}$-inch pots, watered as required, and forced along rapidly until they were from six to eight inches high. By September 1, the plants were thrifty and healthy and just beginning to show flower buds. On this date most of them were taken out of the pots in which they were growing and the soil washed earefully from the roots. They were then transplanted to three different conditions of nitrogen supply.

1. Those from which the samples of series $\mathrm{G}$ and $\mathrm{B}$ were taken were transplanted to ten-inch pots containing a soil mixture of one-half clay loam, onefourth sand, one-fourth well-rotted manure. They were given an abundance of moisture, and well exposed to the light. They grew rapidly, were dark green and succulent and produced many blossoms, most of which fell off soon after opening.

Series G was collected on September 28 at 10:00 a. m. on a fairly clear day. At this time, the plants were about three feet tall, decidedly vigorously vegetative and yet somewhat fruitful. The foliage was large and dark green, the stems of large diameter and succulent, particularly the upper two-thirds.

Series B was collected on October 12, at 10:00 a.m. on a slightly cloudy day. These plants were still dark green and vigorous, had set a few more fruits than those in series $\mathrm{G}$ above, were somewhat taller, the foliage not quite so dark green and the stems were more firm and less succulent.

$$
\text { Table VI.-Series G. }
$$

All results computed to a dry-weight basis except moisture and dry matter.

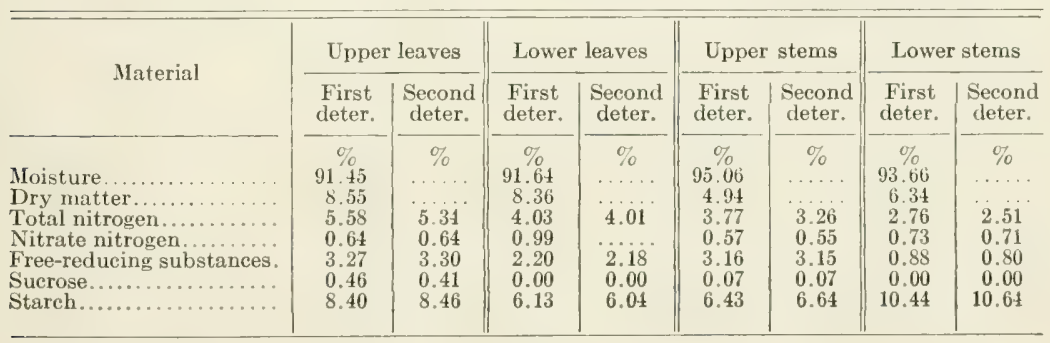



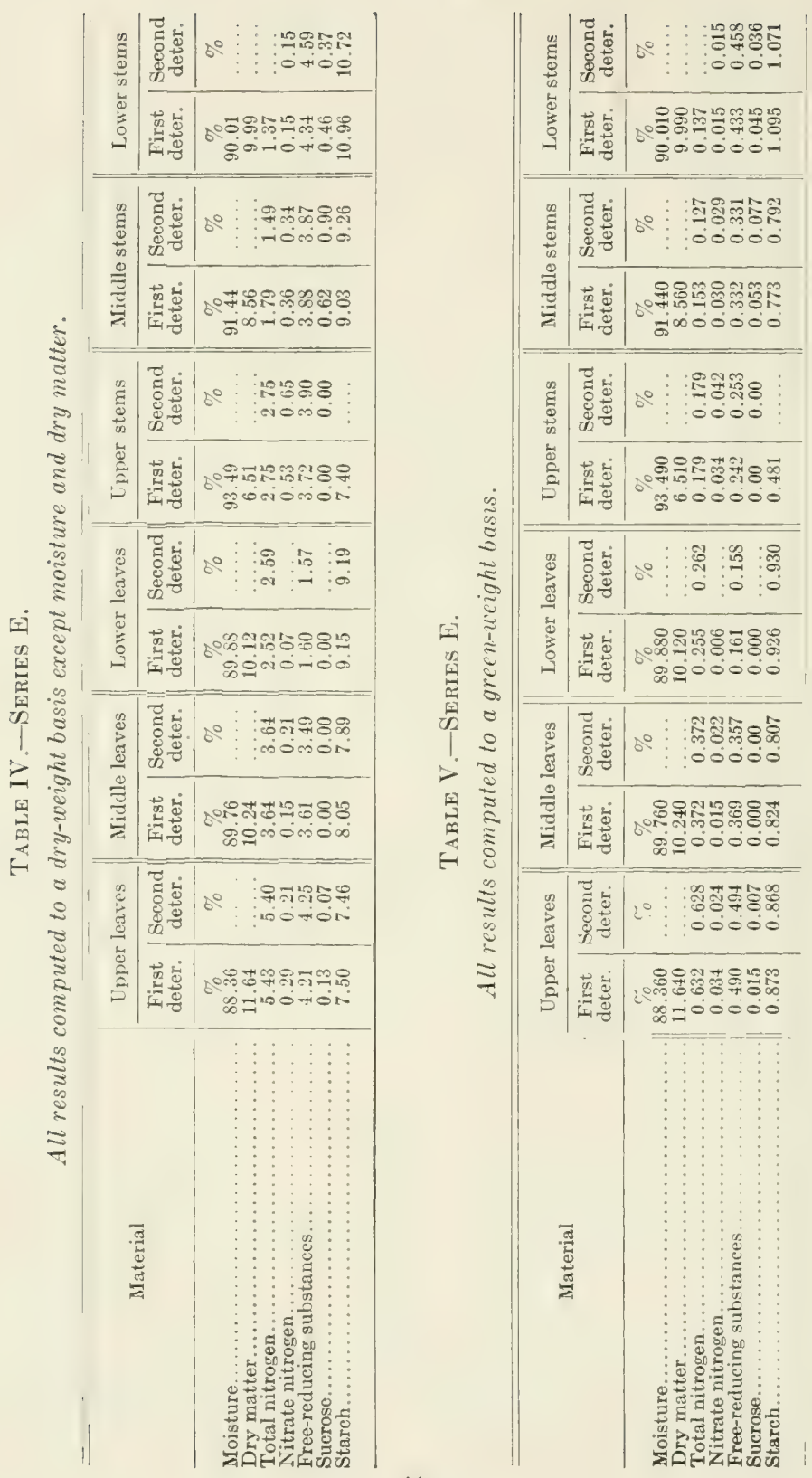
'TABle VII.-Series G.

All results computed to a green-weight basis.

\begin{tabular}{|c|c|c|c|c|c|c|c|c|}
\hline \multirow{2}{*}{ Material } & \multicolumn{2}{|c|}{ Upper leaves } & \multicolumn{2}{|c|}{ Lower leaves } & \multicolumn{2}{|c|}{ Upper stems } & \multicolumn{2}{|c|}{ Lower stems } \\
\hline & $\begin{array}{l}\text { First } \\
\text { deter. }\end{array}$ & $\begin{array}{l}\text { Second } \\
\text { deter. }\end{array}$ & $\begin{array}{l}\text { First } \\
\text { deter. }\end{array}$ & $\begin{array}{l}\text { Second } \\
\text { deter. }\end{array}$ & $\begin{array}{l}\text { First } \\
\text { deter. }\end{array}$ & $\begin{array}{l}\text { Second } \\
\text { deter. }\end{array}$ & $\begin{array}{l}\text { First } \\
\text { deter. }\end{array}$ & $\begin{array}{l}\text { Second } \\
\text { deter. }\end{array}$ \\
\hline Moisture... & $91 \%$ & $\%$ & $91 \%$ & $\%$ & $\begin{array}{c}\% \\
95.060\end{array}$ & $\%$ & $\begin{array}{c}\% \\
93.660\end{array}$ & $\%$ \\
\hline Dry matter.......... & 8.550 & & 8.360 & & 4.940 & & 6.340 & \\
\hline Total nitrogen..... & 0.477 & 0.456 & 0.336 & 0.335 & 0.186 & 0.161 & 0.201 & 0.159 \\
\hline Nitrate nitrogen........... & 0.054 & 0.055 & 0.083 & & 0.028 & 0.027 & 0.046 & 0.045 \\
\hline Free-reducing substances. & 0.279 & 0.282 & 0.183 & 0.182 & 0.156 & 0.155 & 0.055 & 0.050 \\
\hline Sucrose................. & 0.039 & 0.035 & 0.00 & 0.000 & 0.007 & 0.000 & 0.000 & 0.000 \\
\hline Starch $\ldots \ldots \ldots \ldots \ldots \ldots$ & 0.718 & 0.723 & 0.512 & 0.505 & 0.317 & 0.328 & 0.661 & 0.674 \\
\hline
\end{tabular}

TABle ViII.-Series B.

All results computed to a dry-weight basis except moisture and dry matter.

\begin{tabular}{|c|c|c|c|c|c|c|c|c|}
\hline \multirow{2}{*}{ Material } & \multicolumn{2}{|c|}{ Upper leaves } & \multicolumn{2}{|c|}{ Lower leaves } & \multicolumn{2}{|c|}{ Upper stems } & \multicolumn{2}{|c|}{ Lower stems } \\
\hline & $\begin{array}{l}\text { First } \\
\text { deter. }\end{array}$ & $\begin{array}{l}\text { Second } \\
\text { deter. }\end{array}$ & $\begin{array}{l}\text { First } \\
\text { deter. }\end{array}$ & $\begin{array}{l}\text { Second } \\
\text { deter. }\end{array}$ & $\begin{array}{l}\text { First } \\
\text { deter. }\end{array}$ & $\begin{array}{l}\text { Second } \\
\text { deter. }\end{array}$ & $\begin{array}{l}\text { First } \\
\text { deter. }\end{array}$ & $\begin{array}{l}\text { Second } \\
\text { deter. }\end{array}$ \\
\hline Moisture ................. & $\begin{array}{c}\% \\
86.77\end{array}$ & $\%$ & $\begin{array}{c}\% \\
89.44\end{array}$ & $\%$ & $91 \%$ & $\%$ & $\begin{array}{c}\% \\
89.76\end{array}$ & $\begin{array}{r}\% \\
\ldots\end{array}$ \\
\hline 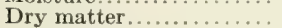 & 13.23 & & 10.56 & & 8.83 & & 10.24 & \\
\hline Total nitrogen............ & 3.31 & 3.30 & 2.24 & 2.14 & 2.08 & 2.07 & 0.96 & 1.16 \\
\hline Free-reducing substances. & 3.26 & 3.21 & 3.66 & 3.65 & 8.06 & 8.03 & 6.67 & 6.65 \\
\hline 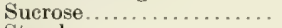 & 0.00 & 0.00 & 0.00 & 0.00 & 1.84 & 1.88 & 4.01 & 4.05 \\
\hline 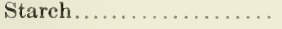 & 12.04 & 12.27 & 7.00 & 7.12 & 7.37 & 7,33 & 8.54 & 8.41 \\
\hline
\end{tabular}

TABLE IX.-Series B.

All results computed to a green-weight basis.

\begin{tabular}{|c|c|c|c|c|c|c|c|c|}
\hline \multirow{2}{*}{ Material } & \multicolumn{2}{|c|}{ Upper leaves } & \multicolumn{2}{|c|}{ Lower leaves } & \multicolumn{2}{|c|}{ Upper stems } & \multicolumn{2}{|c|}{ Lower stems } \\
\hline & $\begin{array}{l}\text { First } \\
\text { deter. }\end{array}$ & $\begin{array}{l}\text { Second } \\
\text { deter. }\end{array}$ & $\begin{array}{l}\text { First } \\
\text { deter. }\end{array}$ & $\begin{array}{l}\text { Second } \\
\text { deter. }\end{array}$ & $\begin{array}{l}\text { First } \\
\text { deter. }\end{array}$ & $\begin{array}{l}\text { Second } \\
\text { deter. }\end{array}$ & $\begin{array}{l}\text { First } \\
\text { deter. }\end{array}$ & $\begin{array}{l}\text { Second } \\
\text { deter. }\end{array}$ \\
\hline Moisture... & $\begin{array}{c}\% \\
86.770\end{array}$ & $\begin{array}{r}\% \\
\ldots\end{array}$ & $\begin{array}{c}\% \\
89.440\end{array}$ & $\%$ & $\begin{array}{c}\% \\
91.170\end{array}$ & $\%$ & $\begin{array}{c}\% \\
89.760\end{array}$ & $\%$ \\
\hline Dry matter.... & 13.230 & & 10.560 & & 8.830 & & 10.240 & \\
\hline Total nitrogen.......... & 0.437 & 0.436 & 0.236 & 0.226 & 0.183 & 0.182 & 0.098 & 0.118 \\
\hline Free-reducing substances. & 0.431 & 0.424 & 0.386 & 0.385 & 0.711 & 0.709 & 0.683 & 0.681 \\
\hline Sucrose..................... & 0.000 & 0.000 & 0.000 & 0.000 & 0.163 & 0.166 & 0.410 & 0.414 \\
\hline 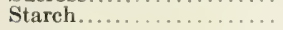 & 1.593 & 1.623 & 0.739 & 0.751 & 0.650 & 0.647 & 0.874 & 0.861 \\
\hline
\end{tabular}

2. Those from which series $\mathrm{H}$ and $\mathrm{C}$ were taken were transplanted to twelve inch pots containing quartz sand. Each pot received 350 c.c. of diluted Knop's solution at each of five applications as follows: September 2, September 8, September 28, (after sampling), September 30, October 9. Following the transplanting the plants soon began to grow fairly rapidly, but the leaves were grayish green in color, stood out stiffly from the stems, folt firm and harsh rather than succulent to the touch; the stems were erect, small in diameter, tough, and scarcely at all succulent except perhaps at the apical one-sixth. There was an abundance of bloom and many of the earlier flowers set fruit readily, though the later ones failed to do so in as great proportion. 
Series $\mathbf{H}$ was collected September 28 under the same conditions as series $\mathbf{G}$ above. At that time the plants were about two feet tall, blooming abundantly, and setting at least two-thirds of the blossoms, some of the larger young fruits were about one inch in diameter.

Series C was collected October 12 at 10:00 a. m. on a slightly cloudy day. At this ti me the plants were still blooming abundantly but were setting only one-half or less of the blossoms, were more gray in appearance, the lower leaves slightly yellowed, and the stems more stiff and firm. In general, the plants could be characterized as only moderately vegetative.

\section{Table X.-Series C.}

All results computed to a dry-weight basis except moisture and dry matter.

\begin{tabular}{|c|c|c|c|c|c|c|c|c|}
\hline \multirow{2}{*}{ Material } & \multicolumn{2}{|c|}{ Upper leaves } & \multicolumn{2}{|c|}{ Lower leaves } & \multicolumn{2}{|c|}{ Upper stems } & \multicolumn{2}{|c|}{ Lower stems } \\
\hline & $\begin{array}{l}\text { First } \\
\text { deter. }\end{array}$ & $\begin{array}{l}\text { Second } \\
\text { deter. }\end{array}$ & $\begin{array}{l}\text { First } \\
\text { deter. }\end{array}$ & $\begin{array}{l}\text { Second } \\
\text { deter. }\end{array}$ & $\begin{array}{l}\text { First } \\
\text { deter. }\end{array}$ & $\begin{array}{c}\text { Second } \\
\text { deter. }\end{array}$ & $\begin{array}{l}\text { First } \\
\text { deter. }\end{array}$ & $\begin{array}{l}\text { Second } \\
\text { deter. }\end{array}$ \\
\hline 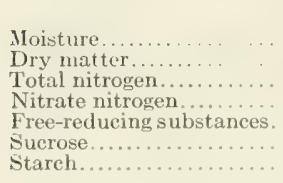 & $\begin{array}{r}\% \\
35.01 \\
11.99 \\
2.31 \\
0.14 \\
3.10 \\
0.43 \\
11.25\end{array}$ & $\begin{array}{r}2.06 \\
0.13 \\
3.21 \\
0.32 \\
11.25\end{array}$ & $\begin{array}{r}\% \\
89.68 \\
10.32 \\
3.16 \\
0.06 \\
0.75 \\
1.53 \\
12.20\end{array}$ & $\begin{array}{r}2.87 \\
0.05 \\
0.73 \\
1.77 \\
11.70\end{array}$ & $\begin{array}{r}\% \\
85.62 \\
11.38 \\
1.65 \\
0.07 \\
6.82 \\
3.15 \\
9.83\end{array}$ & $\begin{array}{r}1.48 \\
0.07 \\
6.73 \\
3.51 \\
10.00\end{array}$ & $\begin{array}{c}\% \\
86.24 \\
13.76 \\
1.36 \\
0.036 \\
4.57 \\
4.58 \\
10.75\end{array}$ & $\begin{array}{r}1.32 \\
4.54 \\
4.37 \\
10.92\end{array}$ \\
\hline
\end{tabular}

3. Those from which series I and D were taken were treated exactly as those in $\mathrm{H}$ and $\mathrm{C}$ except that potassium nitrate was omitted from the nutrient

\section{Table XI.-Series C.}

All results computed to a green-weight basis.

\begin{tabular}{|c|c|c|c|c|c|c|c|c|}
\hline \multirow{2}{*}{ Material } & \multicolumn{2}{|c|}{ Upper leaves } & \multicolumn{2}{|c|}{ Lower leaves } & \multicolumn{2}{|c|}{ Upper stems } & \multicolumn{2}{|c|}{ Lower stems } \\
\hline & $\begin{array}{l}\text { First } \\
\text { deter. }\end{array}$ & $\begin{array}{l}\text { Second } \\
\text { deter. }\end{array}$ & $\begin{array}{l}\text { First } \\
\text { deter. }\end{array}$ & $\begin{array}{l}\text { Second } \\
\text { deter. }\end{array}$ & $\begin{array}{l}\text { First } \\
\text { deter. }\end{array}$ & $\begin{array}{l}\text { S econd } \\
\text { deter. }\end{array}$ & $\begin{array}{l}\text { First } \\
\text { deter. }\end{array}$ & $\begin{array}{l}\text { Second } \\
\text { deter. }\end{array}$ \\
\hline Moisture.. & $\begin{array}{c}\% \\
\text { ss.010 }\end{array}$ & $\%$ & $\begin{array}{r}\% \\
80.650\end{array}$ & $\%$ & $\begin{array}{c}\% \\
88.620\end{array}$ & $\%$ & $\begin{array}{c}\% \\
86.240\end{array}$ & $\%$ \\
\hline Dry matter...... & 11990 & & 10.320 & & 11.380 & & 13.760 & \\
\hline Total nitrogen.............. & 0.277 & 0.247 & 0.326 & 0.296 & 0.187 & 0.168 & 0.187 & 0.181 \\
\hline Nitrate nitrogen............ & 0.017 & 0.015 & 0.006 & 0.006 & 0.009 & 0.009 & & 0.005 \\
\hline Free-reducing substances. & 0.371 & 0.384 & 0.077 & 0.075 & 0.776 & 0.765 & 0.623 & 0.624 \\
\hline sucrose $\ldots \ldots \ldots \ldots \ldots \ldots$ & 0.051 & 0.038 & 0.157 & 0.182 & 0.358 & 0.399 & 0.630 & 0.601 \\
\hline Starch................. & 1.347 & 1.347 & 1.259 & 1.207 & 0.669 & 0.674 & 1.479 & 1.503 \\
\hline
\end{tabular}

solution and instead of calcium nitrate, one-half the amount was substituted with calcium chloride. The nutrient solution therefore was without nitrates except those contained in the water supply.

Series I was collected September 28 under the same conditions as G and H. The plants were twelve to eighteen inches tall, yellowish except at the tips, the lower leaves having fallen or about to fall on many of the specimens, the stems comparatively small in diameter but distinctly firm and woody to the touch. There were no blossoms or fruit, though there was an oceasional weak blossom 
cluster only partly developed. Commonly the plants would be spoken of as distinctly sickly in appearance.

Series D was taken at the same time and under the same conditions as series $\mathrm{B}$ and $\mathrm{C}$. At that time the plants were little or not at all taller than on September 28, light yellow, many were without lower leaves, the stems were more firm to the touch and practically no blossom clusters were present.

Series $\mathbf{F}$ was made up of plants which had been left undisturbed in the small pots in which they were growing and collected for analysis September 8 at 10:00 a. m. on a clear day.

TABle XII.-Series D.

All results computed to a dry-weight basis except moisture and dry matter.

Material

Moisture.

Dry matter.

Total nitrocren

Nitrate nitrogen

Free-reducing substances

Sucrose.

Starch.

\begin{tabular}{|c|c|c|c|}
\hline \multicolumn{2}{|c|}{$\begin{array}{l}\text { Whole plant } \\
\text { First sample }\end{array}$} & \multicolumn{2}{|c|}{$\begin{array}{l}\text { Whole plant } \\
\text { Second sample }\end{array}$} \\
\hline $\begin{array}{l}\text { First } \\
\text { deter. }\end{array}$ & $\begin{array}{l}\text { Second } \\
\text { deter. }\end{array}$ & $\begin{array}{l}\text { First } \\
\text { deter. }\end{array}$ & $\begin{array}{l}\text { Second } \\
\text { deter. }\end{array}$ \\
\hline $\begin{array}{r}\% \\
85.11 \\
14.89 \\
0.93 \\
0.00 \\
6.41 \\
6.52 \\
21.04\end{array}$ & $\begin{array}{c}\% \\
\ldots \ldots \\
\ldots \ldots \\
\ldots \ldots \\
\ldots .43 \\
6.9 \\
20.97\end{array}$ & $\begin{array}{c}\% \\
84.56 \\
15.44 \\
0.98 \\
0.00 \\
4.57 \\
3.98 \\
19.23\end{array}$ & \begin{tabular}{l}
\multicolumn{1}{c}{$\%$} \\
$\ldots \ldots \ldots$ \\
$\ldots \ldots \ldots$ \\
$\ldots$ \\
4.45 \\
$\ldots \ldots$ \\
$\ldots \ldots$
\end{tabular} \\
\hline
\end{tabular}

Table XIII.-Series D.

All results computed to a green-weight basis.

\begin{tabular}{|c|c|c|c|c|}
\hline \multirow{2}{*}{ Material } & \multicolumn{2}{|c|}{$\begin{array}{l}\text { Whole plant } \\
\text { First sample }\end{array}$} & \multicolumn{2}{|c|}{$\begin{array}{l}\text { Whole plant } \\
\text { Second sample }\end{array}$} \\
\hline & $\begin{array}{l}\text { First } \\
\text { deter. }\end{array}$ & $\begin{array}{l}\text { Second } \\
\text { deter. }\end{array}$ & $\begin{array}{l}\text { First } \\
\text { deter. }\end{array}$ & $\begin{array}{l}\text { Second } \\
\text { deter. }\end{array}$ \\
\hline 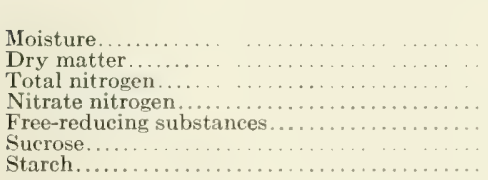 & $\begin{array}{c}\% \\
84.560 \\
15.440 \\
0.151 \\
0.000 \\
0.706 \\
0.615 \\
2.973\end{array}$ & $\begin{array}{c}\%_{0} \\
\ldots \ldots \\
\ldots \ldots \\
\ldots \ldots \\
\ldots .688 \\
\ldots \ldots \\
\ldots \ldots\end{array}$ & $\begin{array}{l}\% \\
85.11 \\
14.89 \\
0.138 \\
0.00 \\
0.954 \\
0.970 \\
3.133\end{array}$ & $\begin{array}{c}\% \\
\ldots \ldots \\
\ldots \ldots \\
\ldots \ldots \\
\ldots .957 \\
\cdots \\
3.122\end{array}$ \\
\hline
\end{tabular}

Table XIV.-Series F, H and I.

All results computed to a dry-weight basis except moisture and dry matter.

\begin{tabular}{|c|c|c|c|c|c|c|}
\hline \multirow{2}{*}{ Material } & \multicolumn{2}{|c|}{$\begin{array}{l}\text { Whole plant } \\
\text { Series F. }\end{array}$} & \multicolumn{2}{|c|}{$\begin{array}{l}\text { Whole plant } \\
\text { Series H. }\end{array}$} & \multicolumn{2}{|c|}{$\begin{array}{l}\text { Whole plant } \\
\text { Series I. }\end{array}$} \\
\hline & $\begin{array}{l}\text { First } \\
\text { deter. }\end{array}$ & $\begin{array}{l}\text { Second } \\
\text { deter. }\end{array}$ & $\begin{array}{l}\text { First } \\
\text { deter. }\end{array}$ & $\begin{array}{l}\text { Second } \\
\text { deter. }\end{array}$ & $\begin{array}{l}\text { First } \\
\text { deter. }\end{array}$ & $\begin{array}{l}\text { Second } \\
\text { deter. }\end{array}$ \\
\hline 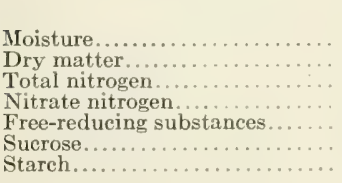 & $\begin{array}{c}\% \\
92.65 \\
7.35 \\
2.88 \\
0.52 \\
2.01 \\
0.00 \\
8.51\end{array}$ & $\begin{array}{c}\% \\
\ldots \ldots \\
\ldots \ldots \\
\cdots \\
0.53 \\
2.15 \\
0.00 \\
8.40\end{array}$ & $\begin{array}{c}\% \\
90.12 \\
9.88 \\
3.00 \\
0.15 \\
0.88 \\
0.17 \\
4.06\end{array}$ & $\begin{array}{c}\% \\
\ldots \ldots . . \\
\ldots \ldots \\
2.99 \\
0.18 \\
0.79 \\
0.26 \\
3.99\end{array}$ & $\begin{array}{r}\% \\
85.95 \\
14.05 \\
1.78 \\
0.00 \\
4.01 \\
1.21 \\
15.66\end{array}$ & $\begin{array}{c}\% \\
\ldots \ldots \\
\ldots \\
1.70 \\
0.00 \\
4.00 \\
1.20 \\
15.70\end{array}$ \\
\hline
\end{tabular}


TABLe XV.-Series F, H, and I.

All results computed to a green-weight basis.

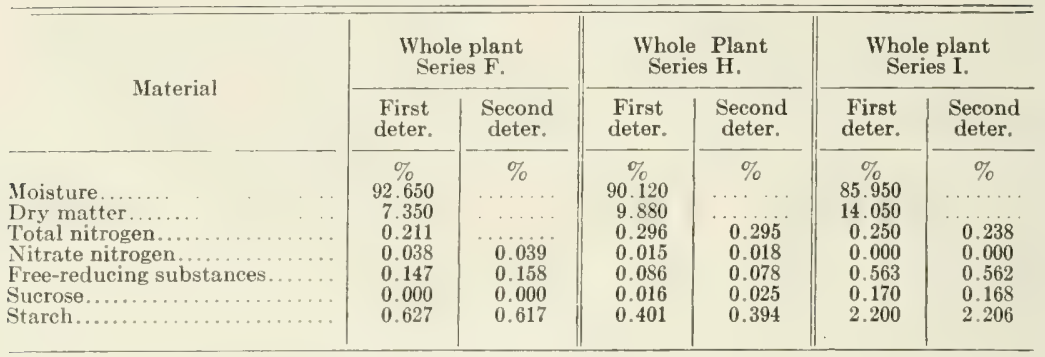

Series $G$. The analyses show that compared with the other two series H and I the plants of series $\mathrm{G}$ were high in moisture, total nitrogen, and nitrate nitrogen, and, compared with series I, are low in free-reducing substances, disaccharides, polysaccharides, and total dry matter. It is difficult to compare with series $\mathrm{H}$ where the differences are not so marked because the whole plant was taken as a sample in the latter case. In the stems of series G going from top to bot tom there is considerable difference in total nitrogen and nitrate nitrogen. There is also an increase in polysaccharides and a decrease in free reducing substances. It is apparent, however, that the plants of series $\mathrm{H}$ are low in moisture, nitrate nitrogen, and total nitrogen and are higher in total dry matter.

Series 1 . Compared with the vegetative plants of series $\mathrm{G}$ they are much lower in total nitrogen. The free-reducing substances, sucrose, polysaccharides, and total dry matter are very much higher than in series G. Here again no comparison can be made upon the different parts of the plant because whole plants were used to make up the sample.

Series B. In composition the plants in series B resemble the plants of series $\mathrm{G}$ except that the stems of the latter are higher in moisture and total nitrogen and lower in disaccharides, and total dry weight. In the stems of the plants themselves in series B there is an increasing gradient from top to bottom in total dry matter, sucrose, and polysaccharides and a decreasing gradient in total nitrogen and free-reducing substances. In the leaves there is no such relation between nitrogen and carbohydrates.

The plants of series $C$ compared with series $B$ were less vegetative and more fruitful. In the stems of series $\mathrm{C}$ there is a decreasing gradient from top to bottom in moisture, free-reducing substances, and nitrate nitrogen, and an increasing gradient in total dry matter, sucrose, and polysaccharides. The total nitrogen is about the same in the upper and lower portion of the stems. In the leaves there is no such relation between nitrogen and carbohydrates.

Series $D$. Compared with series B the plants were low in moisture and total nitrogen and high in sucrose and polysaccharides. Nitrates are absent. Since whole plants were taken to make the samples, no comparisons can be made between the different parts of the plant itself. 
Series $F$. The analyses show that the plants were high in moisture and nitrate nitrogen and fairly high in total nitrogen. The free-reducing substances and polysaccharides were low, and sucrose was absent.

While not recorded for analysis it is worthy of note that at the close of this experiment a few pots containing plants which had received no nitrates still remained. To each of these, 100 c.c. of a one percent calcium nitrate solution was added. Within four or five days the stems of these plants began to turn green, the terminal leaves became darker green and expanded, and terminal axial growth was rapid. This result is of interest more particularly in indicating that the reason for the slow growth previously was the lack of nitrate rather than some other essential element or the presence of some harmful salt in the modified nutrient solution.

Experiment VI. The seed for this lot of plants of the Lorillard variety was sown October 20, 1916. On October 30 the plants were transplanted to threeinch pots of rich, fertile soil and on December 11 the plants were transplanted to the three different conditions of soil nitrogen supply; namely, quartz sand without nitrogenous fertilizer, quartz sand with Knop's solution, and to a rich potting soil composed of clay loam one-fourth, sand one-fourth, well-rotted manure one-half. The analyses were listed under series $\mathbf{J}, \mathbf{K}$, and $\mathrm{L}$. No analyses were finally made of the plants which were transferred to sand and given no nitrogenous fertilizers so they are not listed below.

Series $\mathbf{J}$ is made up of plants collected about 2:00 p. m. December 13, 1916, which were still in the three-inch pots of rich soil. The day was clear. At that time the plants were growing vigorously, about four to six inches tall, dark green, sturdy and succulent, without visible blossom buds. It was hoped to use the analyses of these plants as a basis for study of variation in the later analyses of plants grown with large and small soil-nitrogen supply.

Series $\mathbf{K}$ was collected at the same time and under the same conditions as series L. Following transplanting, the plants had been grown in the rich potting soil noted above, but the moisture supply was limited. Instead of maintaining a constant supply in the granite-ware pans in which the pots had been placed, the pots were watered only at intervals as needs seemed to require in order to keep them above the wilting point. The plants were about three to three and one-half feet tall, growing moderately vigorously, the foliage was large, and dark green. Each plant had two or three blossom clusters of good size and one to several fruits. Compared with series $\mathrm{L}$, the plants were much the same except that they gave the general impression of being greener and more stocky in every way.

Series L was collected February 16,1917 , at 2:00 p. m. on a clear day. The plants had been grown in twelve-inch pots containing quartz sand. To each pot had been added 350 e.c. Knop's solution diluted one to seven on each of the following dates-December 11, 18, January 8, 13, 22, 29. At the time of collection the plants were from three to three and one-half feet tall, moderately vegetative, the leaves large and green, somewhat drooping, those at the base somewhat smaller and lighter in color, the lower two-thirds of stem firm, green, the 
upper one-third succulent. There were several blossom clusters of good size, and two to five fruits to each plant, though a number of blossoms had fallen without setting.

Table XVI.-Series J.

All results computed to a dry-weight basis except moisture and dry matter.

\begin{tabular}{|c|c|c|c|c|}
\hline \multirow{2}{*}{ Material } & \multicolumn{2}{|c|}{$\begin{array}{l}\text { Whole plant } \\
\text { First sample }\end{array}$} & \multicolumn{2}{|c|}{$\begin{array}{l}\text { Whole plant } \\
\text { Second sample }\end{array}$} \\
\hline & $\begin{array}{l}\text { First } \\
\text { deter. }\end{array}$ & $\begin{array}{l}\text { Second } \\
\text { deter. }\end{array}$ & $\begin{array}{l}\text { First } \\
\text { deter. }\end{array}$ & $\begin{array}{l}\text { Second } \\
\text { deter. }\end{array}$ \\
\hline 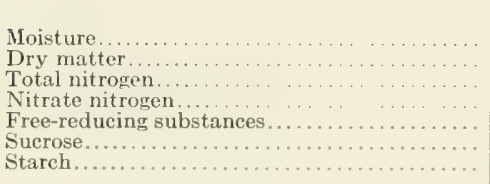 & $\begin{array}{r}\% \\
93.44 \\
6.56 \\
3.36 \\
0.90 \\
1.77 \\
0.87 \\
12.98\end{array}$ & $\begin{array}{c}\% \\
\ldots \\
\ldots \\
12.57 \\
12.62\end{array}$ & $\begin{array}{r}\% \\
93.18 \\
6.82 \\
3.45 \\
1.79 \\
0.75 \\
13.13\end{array}$ & $\begin{array}{c}\% \\
\ldots \ldots \ldots \\
\cdots \cdots \ldots \\
\cdots \cdots \cdots \\
\cdots \cdots \cdots \\
\cdots \cdots \\
13.20\end{array}$ \\
\hline
\end{tabular}

Series $J$. The plants were high in moisture and fairly high in total nitrogen and nitrate nitrogen and low in free-reducing substances, sucrose, and tot al dry matter.

Series $K$. Compared with series $L$, they are higher in moisture and in total nitrogen, but slightly lower in sucrose, polysaccharides, and total dry matter.

Table XVII.-Series J.

All results computed to a green-weight basis.

Material

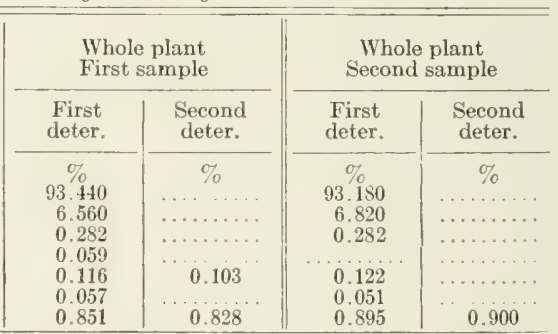

Moisture.

Dry matter.

Total nitrogen.....

Nitrate nitrogen.

Free-reducing substances

Sucrose..... . .

Starch.

0.828

0.895

0.900

TABLE XVIII.-Series K.

All results computed to a dry-weight basis except moisture and dry matter.

\begin{tabular}{|c|c|c|c|c|c|c|c|c|}
\hline \multirow{2}{*}{ Material } & \multicolumn{2}{|c|}{ Upper leaves } & \multicolumn{2}{|c|}{ Lower leaves } & \multicolumn{2}{|c|}{ Upper stems } & \multicolumn{2}{|c|}{ Lower stems } \\
\hline & $\begin{array}{l}\text { First } \\
\text { deter. }\end{array}$ & $\begin{array}{l}\text { Second } \\
\text { deter. }\end{array}$ & $\begin{array}{l}\text { First } \\
\text { deter. }\end{array}$ & $\begin{array}{l}\text { Second } \\
\text { deter. }\end{array}$ & $\begin{array}{l}\text { First } \\
\text { deter. }\end{array}$ & $\begin{array}{l}\text { Second } \\
\text { deter. }\end{array}$ & $\begin{array}{l}\text { First } \\
\text { deter. }\end{array}$ & $\begin{array}{l}\text { Second } \\
\text { deter. }\end{array}$ \\
\hline Moisture. & $\begin{array}{c}\% \\
89.06\end{array}$ & $\%$ & $\begin{array}{c}\% \\
91.26\end{array}$ & $\%$ & 93.16 & $\%$ & $91^{\%} .82$ & $\%$ \\
\hline Dry matter. & 10.94 & & 8.74 & & 6.84 & & 8.18 & \\
\hline Total nitrogen.. & 4.03 & 3.96 & 2.84 & 2.56 & 2.52 & 2.43 & 1.31 & 1.30 \\
\hline Nitrate nitrogen........... & 0.04 & 0.04 & 0.09 & 0.13 & 0.17 & 0.14 & 0.39 & \\
\hline Free-reducing substances. & 3.06 & 3.17 & 1.77 & 1.82 & 11.30 & 11.30 & 3.07 & 3.16 \\
\hline Sucrose $\ldots \ldots \ldots \ldots \ldots \ldots$ & 1.55 & & 0.92 & & 0.82 & & 1.85 & 1.60 \\
\hline Starch $\ldots \ldots \ldots \ldots \ldots \ldots$ & 15.12 & 14.49 & 2.23 & 2.08 & 5.41 & 5.09 & 8.97 & 8.40 \\
\hline
\end{tabular}


Tarle XIX.-Series K.

All results computed to a green-weight basis.

\begin{tabular}{|c|c|c|c|c|c|c|c|c|}
\hline \multirow{2}{*}{ Material } & \multicolumn{2}{|c|}{ Upper leaves } & \multicolumn{2}{|c|}{ Lower leaves } & \multicolumn{2}{|c|}{ Upper stems } & \multicolumn{2}{|c|}{ Lower stems } \\
\hline & $\begin{array}{l}\text { First } \\
\text { deter. }\end{array}$ & $\begin{array}{l}\text { Second } \\
\text { deter. }\end{array}$ & $\begin{array}{l}\text { First } \\
\text { deter. }\end{array}$ & $\begin{array}{l}\text { Second } \\
\text { deter. }\end{array}$ & $\begin{array}{l}\text { First } \\
\text { deter. }\end{array}$ & $\begin{array}{l}\text { Second } \\
\text { deter. }\end{array}$ & $\begin{array}{l}\text { First } \\
\text { deter. }\end{array}$ & $\begin{array}{l}\text { Second } \\
\text { deter. }\end{array}$ \\
\hline Moisture.... & $\begin{array}{c}\% \\
89.06\end{array}$ & $\%$ & $\begin{array}{c}\% \\
91.26\end{array}$ & $\%$ & $\begin{array}{r}\% \\
93.16\end{array}$ & $\%$ & $91 \%$ & $\%$ \\
\hline Dry matter.... & 10.94 & & 8.74 & & 6.84 & & 8.18 & \\
\hline Total nitrogen. & 0.441 & 0.433 & 0.248 & 0.224 & 0.172 & 0.166 & 0.107 & 0.106 \\
\hline Nitrate nitrogen & 0.00 & 0.004 & 0.0 & 0.0 & 0.0 & 0.00 & & \\
\hline Free-reducing substances & 0.333 & 0.347 & 0.154 & 0.159 & 0774 & 0.773 & 0.251 & 0.259 \\
\hline Sucrose................ & 0.16 & & 0.080 & & 0.0 & & & 0.131 \\
\hline Starch......... & 1.654 & 1.585 & 0.195 & 0.181 & 0.370 & 0.348 & 0.734 & 0.687 \\
\hline
\end{tabular}

Table XX.-Series L.

All results computed to a dry-weight basis except moisture and dry matter.

\begin{tabular}{|c|c|c|c|c|c|c|c|c|}
\hline \multirow{2}{*}{ Material } & \multicolumn{2}{|c|}{ Upper leaves } & \multicolumn{2}{|c|}{ Lower leaves } & \multicolumn{2}{|c|}{ Upper stems } & \multicolumn{2}{|c|}{ Lower stems } \\
\hline & $\begin{array}{l}\text { First } \\
\text { deter. }\end{array}$ & $\begin{array}{l}\text { Second } \\
\text { deter. }\end{array}$ & $\begin{array}{l}\text { First } \\
\text { deter. }\end{array}$ & $\begin{array}{l}\text { Second } \\
\text { deter. }\end{array}$ & $\begin{array}{l}\text { First } \\
\text { deter. }\end{array}$ & $\begin{array}{l}\text { Second } \\
\text { deter. }\end{array}$ & $\begin{array}{l}\text { First } \\
\text { deter. }\end{array}$ & $\begin{array}{l}\text { Second } \\
\text { deter. }\end{array}$ \\
\hline Moisture & $\begin{array}{c}\% \\
86.10\end{array}$ & $\%$ & $\begin{array}{c}\% \\
85.50\end{array}$ & $\%$ & $8 \%$ & $\%$ & $\begin{array}{c}\% \\
88 \%\end{array}$ & $\%$ \\
\hline Dry matter........ & 13.90 & & 11.50 & & 10.10 & & 11.73 & \\
\hline Total nitrogen.... & 3.35 & 3.37 & 2.78 & 2.51 & 1.69 & 1.59 & .97 & 1.12 \\
\hline Nitrate nitrogen......... & 0.06 & & 0.16 & 0.13 & 0.06 & 0.07 & 0.52 & 0.47 \\
\hline Free-reducing substances. & 2.47 & 2.46 & 3.00 & 3.00 & 9.22 & 9.20 & 5.20 & 5.40 \\
\hline 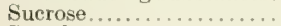 & 1.73 & 2.06 & 1.39 & 1.42 & 3.39 & 3.53 & 4.39 & 4.44 \\
\hline 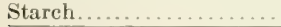 & 18.38 & 18.39 & 4.15 & 4.17 & 8.53 & 8.29 & 13.64 & 13.40 \\
\hline
\end{tabular}

TABle XXI.-Series L.

All results computed to a green-weight basis.

\begin{tabular}{|c|c|c|c|c|c|c|c|c|}
\hline \multirow{2}{*}{ Material } & \multicolumn{2}{|c|}{ Upper leaves } & \multicolumn{2}{|c|}{ Lower leaves } & \multicolumn{2}{|c|}{ Upper stems } & \multicolumn{2}{|c|}{ Lower stems } \\
\hline & $\begin{array}{l}\text { First } \\
\text { deter. }\end{array}$ & $\begin{array}{l}\text { Second } \\
\text { deter. }\end{array}$ & $\begin{array}{l}\text { First } \\
\text { deter. }\end{array}$ & $\begin{array}{l}\text { Second } \\
\text { deter. }\end{array}$ & $\begin{array}{l}\text { First } \\
\text { deter. }\end{array}$ & $\begin{array}{l}\text { Second } \\
\text { deter. }\end{array}$ & $\begin{array}{l}\text { First } \\
\text { deter. }\end{array}$ & $\begin{array}{l}\text { Second } \\
\text { deter. }\end{array}$ \\
\hline Moisture.... & $\begin{array}{c}\% \\
86.100\end{array}$ & $\%$ & $\begin{array}{c}\% \\
88.500\end{array}$ & $\%$ & $\begin{array}{c}\% \\
89.900\end{array}$ & $\%$ & $\begin{array}{c}\% \\
88.270\end{array}$ & $\%$ \\
\hline Dry matter... & 13.900 & & 11.500 & & 10.100 & & 11.730 & \\
\hline Total nitrogen..... & 0.464 & 0.468 & 0.319 & 0.288 & 0.170 & 0.160 & 0.113 & 0.132 \\
\hline Nitrate nitrogen.......... & 0.008 & & 0.019 & 0.015 & 0.006 & 0.007 & 0.061 & 0.055 \\
\hline Free-reducing substances. & 0.343 & 0.342 & 0.344 & 0.344 & 0.930 & 0.929 & 0.610 & 0.633 \\
\hline Sucrose.................. & 0.239 & $0.2 S 6$ & 0.159 & 0.162 & 0.342 & 0.356 & 0.514 & 0.520 \\
\hline Starch.......... & 2.553 & 2.555 & 0.476 & 0.480 & 0.861 & 0.837 & 1.600 & 1.572 \\
\hline
\end{tabular}

Within the stems from top to bot tom there is a decreasing gradient in moist ure, total nitrogen, and free-reducing substances and an increasing gradient in sucrose, polysaccharides, and total dry matter.

Experiment VII. For this experiment seeds of the variety Lorrillard were sown February 2, 1917, and the young plants transplanted to two and one-halfinch pots of rich soil February 14, 1917. On March 10 these plants were from four to five inches tall, stocky, and green, but in need of repotting. Some showed small flower buds clearly. On this date the plants were transferred to teninch pots containing rich soil. Further treatments are described in the series which follow. 
Series M. The plants in the series were grown from March 10 to March 23 in ten-inch pots in a soil mixt ure of clay loan one-fourth, sand one-fourth, well rotted manure one-half, and were copiously watered. Two plants were grown in each pot. At the time of sampling they were eight to ten inches tall, dark green with full heavy foliage, suceulent, vigorous, and usually showed a welldeveloped bud cluster, none of the single buds of which showed any yellow of the corolla. Generally one of the two plants was taken from each pot though in some instances both were removed. (The plants remaining were used in series $Q$ and $R$.) The samples were taken at $2.00 \mathrm{p}$. $\mathrm{m}$. on a clear day. The analyses of these plants are used for comparison with those collected later in the other series of this experiment.

TABle XXII.-Series M.

All results computed to a dry-weight basis except moisture and dry matter.

\begin{tabular}{|c|c|c|c|c|c|c|c|c|}
\hline \multirow{2}{*}{ Material } & \multicolumn{2}{|c|}{$\begin{array}{c}\text { Leaves of whole } \\
\text { plant } \\
\text { First sample }\end{array}$} & \multicolumn{2}{|c|}{$\begin{array}{l}\text { Leaves of whole } \\
\text { plant } \\
\text { Second sample }\end{array}$} & \multicolumn{2}{|c|}{$\begin{array}{c}\text { Stems of whole } \\
\text { plant } \\
\text { First sample }\end{array}$} & \multicolumn{2}{|c|}{$\begin{array}{c}\text { Stems of whole } \\
\text { plant } \\
\text { Second sample }\end{array}$} \\
\hline & $\begin{array}{l}\text { First } \\
\text { deter. }\end{array}$ & $\begin{array}{l}\text { Second } \\
\text { deter. }\end{array}$ & $\begin{array}{l}\text { First } \\
\text { deter. }\end{array}$ & $\begin{array}{l}\text { Second } \\
\text { deter. }\end{array}$ & $\begin{array}{l}\text { First } \\
\text { deter. }\end{array}$ & $\begin{array}{c}\text { Second } \\
\text { deter. }\end{array}$ & $\begin{array}{l}\text { First } \\
\text { deter. }\end{array}$ & $\begin{array}{l}\text { Second } \\
\text { deter. }\end{array}$ \\
\hline 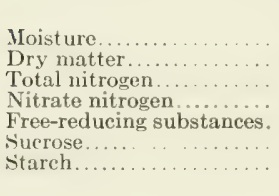 & $\begin{array}{r}\% \\
90.61 \\
9.39 \\
4.11 \\
0.76 \\
2.08 \\
1.15 \\
11.25\end{array}$ & $\begin{array}{l}\cdots \\
\cdots \\
2.05 \\
\cdots \cdots\end{array}$ & $\begin{array}{r}\% \\
90.24 \\
9.76 \\
3.85 \\
0.50 \\
1.30 \\
1.04 \\
10.92\end{array}$ & $\begin{array}{c}\% \\
\ldots \ldots \\
\ldots \ldots \\
\ldots \ldots \\
1.40 \\
\ldots \ldots \\
\ldots \ldots\end{array}$ & $\begin{array}{r}\% \\
94.16 \\
5.84 \\
2.75 \\
1.62 \\
0.80 \\
0.46 \\
0.89\end{array}$ & $\begin{array}{l}\ldots \cdots \\
\cdots \cdots \\
\cdots \cdots \\
\cdots \cdots \\
\cdots \cdots \\
\cdots \cdots\end{array}$ & $\begin{array}{r}\% \\
93.94 \\
6.06 \\
2.94 \\
1.63 \\
1.24 \\
1.06 \\
3.08\end{array}$ & $\begin{array}{l}\cdots \ldots \\
\ldots \ldots \\
3.05\end{array}$ \\
\hline
\end{tabular}

Table XXIII.-Series M.

All results computed to a green-weight basis.

\begin{tabular}{|c|c|c|c|c|c|c|c|c|}
\hline \multirow[b]{2}{*}{ Material } & \multicolumn{2}{|c|}{$\begin{array}{c}\text { Leaves of whole } \\
\text { plant } \\
\text { First sample }\end{array}$} & \multicolumn{2}{|c|}{$\begin{array}{c}\text { Leaves of whole } \\
\text { plant } \\
\text { Second sample }\end{array}$} & \multicolumn{2}{|c|}{$\begin{array}{c}\text { Stems of whole } \\
\text { plant } \\
\text { First sample }\end{array}$} & \multicolumn{2}{|c|}{$\begin{array}{c}\text { Stems of whole } \\
\text { plant } \\
\text { Second sample }\end{array}$} \\
\hline & $\begin{array}{l}\text { First } \\
\text { deter. }\end{array}$ & $\begin{array}{c}\text { Second } \\
\text { deter. }\end{array}$ & $\begin{array}{l}\text { First } \\
\text { deter. }\end{array}$ & $\begin{array}{l}\text { Second } \\
\text { deter. }\end{array}$ & $\begin{array}{l}\text { First } \\
\text { deter. }\end{array}$ & $\begin{array}{l}\text { Second } \\
\text { deter. }\end{array}$ & $\begin{array}{l}\text { First } \\
\text { deter. }\end{array}$ & $\begin{array}{l}\text { Second } \\
\text { deter. }\end{array}$ \\
\hline 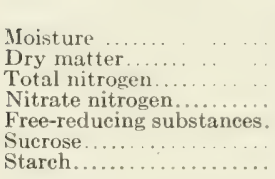 & $\begin{array}{c}\% \\
90.61 \\
9.39 \\
0.385 \\
0.072 \\
0.195 \\
0.108 \\
1.056\end{array}$ & $\begin{array}{c}\% \\
\ldots \ldots \\
\ldots \ldots \\
\ldots \ldots \\
0.192 \\
\ldots \ldots \ldots\end{array}$ & $\begin{array}{c}\% \\
90.24 \\
9.76 \\
0.375 \\
0.046 \\
0.126 \\
0.101 \\
1.066\end{array}$ & $\begin{array}{c}0.136 \\
\ldots \ldots \ldots\end{array}$ & $\begin{array}{c}\% \\
94.16 \\
5.84 \\
0.160 \\
0.095 \\
0.046 \\
0.026 \\
0.051\end{array}$ & $\begin{array}{c}\% \\
\ldots \ldots \\
\ldots \ldots \\
\cdots \ldots \\
\cdots \ldots \\
0.049\end{array}$ & $\begin{array}{c}\% \\
93.94 \\
6.06 \\
0.178 \\
0.098 \\
0.075 \\
0.064 \\
0.185\end{array}$ & $\begin{array}{l}\cdots \\
\ldots \ldots \\
\ldots \ldots \\
0.186\end{array}$ \\
\hline
\end{tabular}

Series O. On March 10, 1916, some of the plants mentioned in series M were removed from the pots in which they were growing, the soil particles carefully and thoroughly washed from the roots, and then they were transplanted to ten-inch pots containing quartz sand. Two plants were put in each pot. On April 11 and April 19 each pot was given 350 c.c. of nutrient solution free from nitrogen. After being transplanted, the plants wilted appreciably but recovered within two days. While there was some continued axial elongation, 


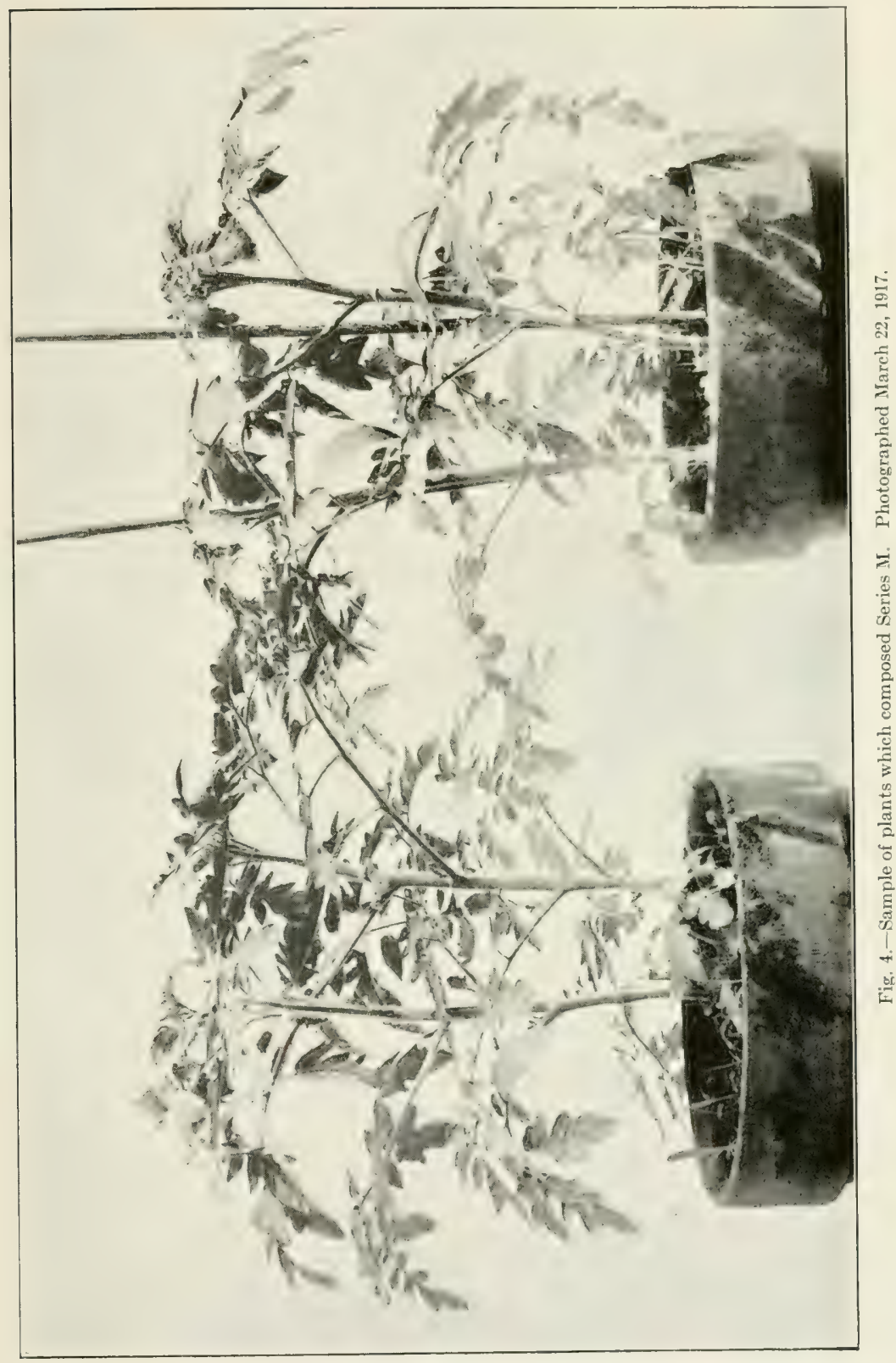


growth was decidedly checked, the lower leaves became yellow and fell, though for the most part the blossom clusters expanded and in some cases set one or two fruits. The stems became yellow, very tough and woody, and stood erect with no tendency to tip over. Samples were collected for analysis April 16 at 2:00 p. m. on a partly cloudy day. At this time the plants were about sixteen inches high, ereet, light green, the lowermost leaves brown and dry, and in some cases already fallen; the upper leaves gray green, small, the stems becoming yellow, woody, even well above the middle, and scarcely at all succulent, the second blossom clusters small and not setting to form fruit.

\section{Table XXIV.-Series O.}

All results computed to a dry-weight basis except moisture and dry matter.

\begin{tabular}{|c|c|c|c|c|c|c|c|c|}
\hline \multirow{2}{*}{ Material } & \multicolumn{2}{|c|}{ Upper leaves } & \multicolumn{2}{|c|}{ Lower leaves } & \multicolumn{2}{|c|}{ Upper stems } & \multicolumn{2}{|c|}{ Lower stems } \\
\hline & $\begin{array}{l}\text { First } \\
\text { deter. }\end{array}$ & $\begin{array}{l}\text { Second } \\
\text { deter. }\end{array}$ & $\begin{array}{l}\text { First } \\
\text { deter. }\end{array}$ & $\begin{array}{l}\text { Second } \\
\text { deter. }\end{array}$ & $\begin{array}{l}\text { First } \\
\text { deter. }\end{array}$ & $\begin{array}{l}\text { Second } \\
\text { deter. }\end{array}$ & $\begin{array}{l}\text { First } \\
\text { deter. }\end{array}$ & $\begin{array}{l}\text { Second } \\
\text { deter. }\end{array}$ \\
\hline 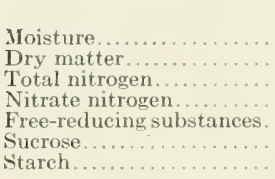 & $\begin{array}{r}\% \\
81.40 \\
18.60 \\
1.70 \\
0.00 \\
3.65 \\
1.05 \\
31.76\end{array}$ & $\begin{array}{c}\% \\
\ldots \ldots \\
1.73 \\
0.00 \\
3.72 \\
0.78 \\
31.85\end{array}$ & $\begin{array}{c}\% \\
86.00 \\
14.00 \\
1.12 \\
0.00 \\
4.02 \\
0.86 \\
16.20\end{array}$ & $\begin{array}{c}\% \\
\ldots \ldots \\
1.20 \\
0.00 \\
4.08 \\
0.80 \\
15.90\end{array}$ & $\begin{array}{r}\% \\
86.98 \\
13.02 \\
0.90 \\
0.00 \\
9.20 \\
4.00 \\
17.98\end{array}$ & $\begin{array}{c}\% \\
\ldots \ldots \\
0.96 \\
0.00 \\
9.23 \\
4.08 \\
18.51\end{array}$ & $\begin{array}{c}\% \\
84.62 \\
15.38 \\
0.80 \\
0.007 \\
9.05 \\
6.31 \\
22.96\end{array}$ & $\begin{array}{c}\% \\
\ldots \ldots \\
\dddot{\ldots} .83 \\
0.002 \\
8.96 \\
5.70 \\
22.51\end{array}$ \\
\hline
\end{tabular}

Series P. On March 10 the plants in this series were taken from the pots in which they were growing, the soil carefully washed from the roots, and, they were then transplanted to twelve-inch pots containing quartz sand. Each pot

TABLE XXV.-Series O.

All results computed to a green-weight basis.

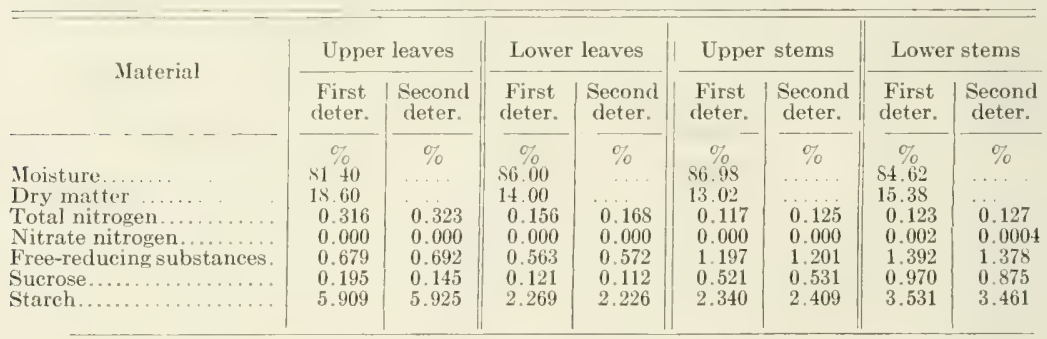

received an application of Knop's solution diluted one to seven on each of the following dates: March 10, March 17, March 24, April 2, April 19. An abundance of moisture was supplied at all times. On April 16 the samples were collected under the same conditions as series $O$. At this time the plants were eighteen to twenty-four inches high, erect, bright green in color, the leaves st anding out stiffly from the stems except the lowermost, which were also somewhat yellowed; each plant had set several fruits. 
Table XXVI.-Sertes P.

All results computed to a dry-weight basis except moisture and dry matter.

\begin{tabular}{|c|c|c|c|c|c|c|c|c|}
\hline \multirow{2}{*}{ Material } & \multicolumn{2}{|c|}{ Upper leaves } & \multicolumn{2}{|c|}{ Lower leaves } & \multicolumn{2}{|c|}{ Upper stems } & \multicolumn{2}{|c|}{ Lower stems } \\
\hline & $\begin{array}{l}\text { First } \\
\text { deter. }\end{array}$ & $\begin{array}{l}\text { Second } \\
\text { deter. }\end{array}$ & $\begin{array}{l}\text { First } \\
\text { deter. }\end{array}$ & $\begin{array}{c}\text { Second } \\
\text { deter. }\end{array}$ & $\begin{array}{l}\text { First } \\
\text { deter. }\end{array}$ & $\begin{array}{l}\text { Second } \\
\text { deter. }\end{array}$ & $\begin{array}{l}\text { First } \\
\text { deter. }\end{array}$ & $\begin{array}{l}\text { Second } \\
\text { deter. }\end{array}$ \\
\hline Moisture..... & $\begin{array}{c}\% \\
\$ 4.02\end{array}$ & $\%$ & 87.72 & $\%$ & $\begin{array}{c}\% \\
90 . \$ 2\end{array}$ & $\%$ & $\begin{array}{c}\% \\
85.12\end{array}$ & $\%$ \\
\hline Dry matter......... & 15.98 & & 12,27 & & $9.1 \mathrm{~s}$ & & 11.85 & \\
\hline Total nitrogen........... & 2.74 & 2.80 & 2.28 & 2.27 & 1.75 & 1.91 & 1.25 & 1.07 \\
\hline Nitrate nitrogen......... & 0.02 & 0.03 & 0.12 & 0.09 & 0.21 & 0.13 & 0.16 & 0.18 \\
\hline Free-reducing substances. & 2.60 & 2.53 & 2.08 & 2.08 & 8.33 & 8.31 & 7.78 & 7.80 \\
\hline 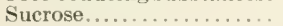 & 0.30 & & 0.26 & 0.27 & 0.85 & 1.06 & 3.58 & 3.45 \\
\hline 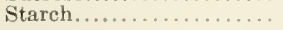 & 25.38 & 25.58 & 12.65 & 12.36 & 8.70 & 8.54 & 11.20 & 11.25 \\
\hline
\end{tabular}

TABle XXVII,-Series P.

All results computed to a green-weight basis.

\begin{tabular}{|c|c|c|c|c|c|c|c|c|}
\hline \multirow{2}{*}{ Material } & \multicolumn{2}{|c|}{ Upper leaves } & \multicolumn{2}{|c|}{ Lower leaves } & \multicolumn{2}{|c|}{ Upper stems } & \multicolumn{2}{|c|}{ Lower stems } \\
\hline & $\begin{array}{l}\text { First } \\
\text { deter. }\end{array}$ & $\begin{array}{l}\text { Second } \\
\text { deter. }\end{array}$ & $\begin{array}{l}\text { First } \\
\text { deter. }\end{array}$ & $\begin{array}{l}\text { Second } \\
\text { deter. }\end{array}$ & $\begin{array}{l}\text { First } \\
\text { deter. }\end{array}$ & $\begin{array}{l}\text { Second } \\
\text { deter. }\end{array}$ & $\begin{array}{l}\text { First } \\
\text { deter. }\end{array}$ & $\begin{array}{l}\text { Second } \\
\text { deter. }\end{array}$ \\
\hline Moisture.... & $\begin{array}{c}\% \% \\
84.02\end{array}$ & $\%$ & $\begin{array}{c}\% \% \\
87.73\end{array}$ & $\%$ & $\begin{array}{c}\% \\
90.82\end{array}$ & $\%$ & $\begin{array}{c}\% \\
\text { SS. } 12\end{array}$ & $\%$ \\
\hline Dry matter...... & $159 s$ & & 12.27 & & 9.18 & & $11.8 s$ & \\
\hline Total nitrogen... & 0.438 & 0.447 & 0.280 & 0.278 & 0.160 & 0.175 & 0.148 & 0.127 \\
\hline Nitrate nitrogen......... & 0.003 & 0.004 & 0.013 & 0.011 & 0.019 & 0.011 & 0.018 & 0.021 \\
\hline Free-reducing substances. & 0.416 & 0.404 & 0.255 & 0.254 & 0.764 & 0.763 & 0.924 & 0.927 \\
\hline Sucrose................ & 0.048 & & 0.103 & & 0.078 & 0.098 & 0.425 & 0.410 \\
\hline Stareh.................. & 4.055 & 4.087 & 1.553 & 1.517 & 0.798 & 0.784 & 1.331 & 1.337 \\
\hline
\end{tabular}

Series Q. The plants of this series were transferred on March 10 from small pots exactly as in series $M$ previously described. In fact, that series simply represents an earlier collection from the same group of plants. An abundance of moisture was provided at all times. The plants grew very rapidly, the leaves became large and green, and the stems of large diameter and very succulent. Samples were taken at the same time and under the same conditions as those in series $\mathrm{O}$. At that time the plants in the present series were eighteen

\section{Table XXVIII.-Series Q.}

All results computed to a dry-weight basis except moisture and dry matter.

\begin{tabular}{|c|c|c|c|c|c|c|c|c|}
\hline \multirow[b]{2}{*}{ Material } & \multicolumn{2}{|c|}{ Upper leaves } & \multicolumn{2}{|c|}{ Lower leaves } & \multicolumn{2}{|c|}{ Upper stems } & \multicolumn{2}{|c|}{ Lower stems } \\
\hline & $\begin{array}{l}\text { First } \\
\text { deter. }\end{array}$ & $\begin{array}{l}\text { Second } \\
\text { deter. }\end{array}$ & $\begin{array}{l}\text { First } \\
\text { deter. }\end{array}$ & $\begin{array}{l}\text { Second } \\
\text { deter. }\end{array}$ & $\begin{array}{l}\text { First } \\
\text { deter. }\end{array}$ & $\begin{array}{l}\text { Second } \\
\text { deter. }\end{array}$ & $\begin{array}{l}\text { First } \\
\text { deter. }\end{array}$ & $\begin{array}{l}\text { Second } \\
\text { deter. }\end{array}$ \\
\hline Moisture......... . . & $\begin{array}{c}\% \\
8 .\end{array}$ & $\%$ & $\begin{array}{c}\% \\
91 \% 2\end{array}$ & $\%$ & 94.79 & $\%$ & $\begin{array}{c}\% \\
93.36\end{array}$ & $\%$ \\
\hline Dry matter......... & 11.52 & & 8.98 & & 5. 21 & & 6.64 & \\
\hline Total nitrogen............ & 4.38 & 4.43 & 3.35 & 3.51 & 3.27 & 3.08 & 2.46 & 2.53 \\
\hline Nitrate nitrogen......... & 0.32 & 0.25 & 0.92 & 0.83 & 2.05 & & 1.54 & 1.56 \\
\hline Free-reducing substances. & 1.04 & 1.04 & 0.68 & 0.50 & 3.25 & 3.18 & 1. 51 & 1.29 \\
\hline Sucrose.................. & 0.34 & $\ldots \cdots$ & 0.47 & 0.30 & 0.17 & 0.24 & 1.43 & 1.65 \\
\hline 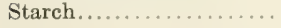 & 12.65 & 12.83 & 4.95 & 5.10 & 1.02 & 1.10 & 1.43 & $\ldots \ldots$ \\
\hline
\end{tabular}




\section{TABle XXIX.-Series Q.}

All results computed to a green-weight basis.

\begin{tabular}{|c|c|c|c|c|c|c|c|c|}
\hline \multirow[b]{2}{*}{ Material } & \multicolumn{2}{|c|}{ Upper leaves } & \multicolumn{2}{|c|}{ Lower leaves } & \multicolumn{2}{|c|}{ Upper stems } & \multicolumn{2}{|c|}{ Lower stems } \\
\hline & $\begin{array}{l}\text { First } \\
\text { deter. }\end{array}$ & $\begin{array}{l}\text { Second } \\
\text { deter. }\end{array}$ & $\begin{array}{l}\text { First } \\
\text { deter. }\end{array}$ & $\begin{array}{l}\text { Second } \\
\text { deter. }\end{array}$ & $\begin{array}{l}\text { First } \\
\text { deter. }\end{array}$ & $\begin{array}{l}\text { Second } \\
\text { deter. }\end{array}$ & $\begin{array}{l}\text { First } \\
\text { deter. }\end{array}$ & $\begin{array}{l}\text { Second } \\
\text { deter. }\end{array}$ \\
\hline Moisture... & $\begin{array}{c}\% \\
88.48\end{array}$ & $\%$ & $91 \%$ & $\%$ & $\begin{array}{c}\% \\
94.79\end{array}$ & $\%$ & $\begin{array}{c}\% \\
93.36\end{array}$ & $\%$ \\
\hline Dry matter.... & 11.52 & & 8.98 & & 5.21 & & 6.64 & \\
\hline Total nitrogen..... & 0.505 & 0.511 & 0.301 & 0.315 & 0.170 & 0.160 & 0.163 & 0.168 \\
\hline Nitrate nitrogen......... & 0.036 & 0.029 & 0.082 & 0.065 & 0.107 & & 0.102 & 0.103 \\
\hline Free-reducing substances. & 0.151 & 0.151 & 0.060 & 0.045 & 0.169 & 0.165 & 0.100 & 0.085 \\
\hline Sucrose.................... & 0.039 & & 0.027 & 0.042 & 0.008 & 0.012 & 0.095 & 0.109 \\
\hline Starch............................. & 1.458 & 1.478 & 0.444 & 0.458 & 0.053 & 0.057 & 0.095 & $\ldots \ldots$ \\
\hline
\end{tabular}

to twenty-two inches tall, very dark green and succulent, the leaves large, soft, and with a decided tendency to droop, the stems green, of large diameter, succulent, and scarcely at all woody to the touch above the lower one-fourth, with the result that the plants required stakes to support them. The plants were blooming freely but at this time none of the blooms had set, all having fallen soon after the fading of the corolla.

Series R. The plants in this series correspond in every way to those in series Q except that each plant when taken for a sample, bore from two to five

Table XXX.-Series R.

All results computed to a dry-weight basis except moisture and dry matter.

\begin{tabular}{|c|c|c|c|c|c|c|c|c|}
\hline \multirow{2}{*}{ Material } & \multicolumn{2}{|c|}{ Upper leaves } & \multicolumn{2}{|c|}{ Lower leaves } & \multicolumn{2}{|c|}{ Upper stems } & \multicolumn{2}{|c|}{ Lower stems } \\
\hline & $\begin{array}{l}\text { First } \\
\text { deter. }\end{array}$ & $\begin{array}{l}\text { Second } \\
\text { deter. }\end{array}$ & $\begin{array}{l}\text { First } \\
\text { deter. }\end{array}$ & $\begin{array}{l}\text { Second } \\
\text { deter. }\end{array}$ & $\begin{array}{l}\text { First } \\
\text { deter. }\end{array}$ & $\begin{array}{l}\text { Second } \\
\text { deter. }\end{array}$ & $\begin{array}{l}\text { First } \\
\text { deter. }\end{array}$ & $\begin{array}{l}\text { Second } \\
\text { deter. }\end{array}$ \\
\hline 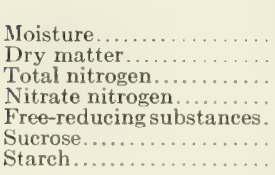 & $\begin{array}{r}\% \\
88.53 \\
11.47 \\
4.13 \\
0.16 \\
1.31 \\
0.58 \\
17.33\end{array}$ & $\begin{array}{r}4.06 \\
0.15 \\
1.39 \\
0.49 \\
17.67\end{array}$ & $\begin{array}{c}\% \\
90.37 \\
9.63 \\
2.90 \\
0.17 \\
0.53 \\
0.12 \\
0.00\end{array}$ & $\begin{array}{l}0.20 \\
0.51 \\
0.14 \\
0.00\end{array}$ & $\begin{array}{c}\% \\
93.50 \\
6.50 \\
2.71 \\
0.76 \\
5.13 \\
0.64 \\
1.16\end{array}$ & $\begin{array}{l}4.91 \\
0.86 \\
1.19\end{array}$ & $\begin{array}{c}\% \\
90.55 \\
9.45 \\
1.61 \\
0.36 \\
4.13 \\
1.47 \\
0.51\end{array}$ & $\begin{array}{l}1.53 \\
0.42 \\
4.10 \\
1.50 \\
0.52\end{array}$ \\
\hline
\end{tabular}

Table XXXI.-Series R.

All results computed to a green-weight basis.

\begin{tabular}{|c|c|c|c|c|c|c|c|c|}
\hline \multirow{2}{*}{ Material } & \multicolumn{2}{|c|}{ Upper leaves } & \multicolumn{2}{|c|}{ Lower leaves } & \multicolumn{2}{|c|}{ Upper stems } & \multicolumn{2}{|c|}{ Lower stems } \\
\hline & $\begin{array}{l}\text { First } \\
\text { deter. }\end{array}$ & $\begin{array}{l}\text { Second } \\
\text { deter. }\end{array}$ & $\begin{array}{l}\text { First } \\
\text { deter. }\end{array}$ & $\begin{array}{l}\text { Second } \\
\text { deter. }\end{array}$ & $\begin{array}{l}\text { First } \\
\text { deter. }\end{array}$ & $\begin{array}{l}\text { Second } \\
\text { deter. }\end{array}$ & $\begin{array}{l}\text { First } \\
\text { deter. }\end{array}$ & $\begin{array}{l}\text { Second } \\
\text { deter. }\end{array}$ \\
\hline Moisture....... & $\begin{array}{c}\% \\
88.53\end{array}$ & $\begin{array}{c}\% \\
\ldots\end{array}$ & $\begin{array}{c}\% \\
90.37\end{array}$ & $\%$ & $\begin{array}{c}\% \% \\
93.50\end{array}$ & $\%$ & 90.55 & $\%$ \\
\hline 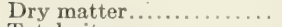 & 11.47 & & 9.63 & $\ldots$ & 6.50 & & 9.45 & \\
\hline Total nitrogen ........... & 0.473 & 0.466 & 0.280 & & & 0.176 & 0.152 & 0.144 \\
\hline Nitrate nitrogen......... & 0.018 & 0.017 & 0.016 & 0.019 & 0.049 & & 0.034 & 0.039 \\
\hline Free-reducing substances. & 0.150 & 0.160 & 0.050 & 0.048 & 0.333 & 0.319 & 0.390 & 0.387 \\
\hline Sucrose................. & 0.066 & 0.056 & 0.011 & 0.013 & 0.041 & 0.056 & 0.138 & 0.142 \\
\hline 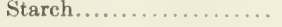 & 1.987 & 2.026 & 0.00 & 0.00 & 0.075 & 0.077 & 0.047 & 0.048 \\
\hline
\end{tabular}



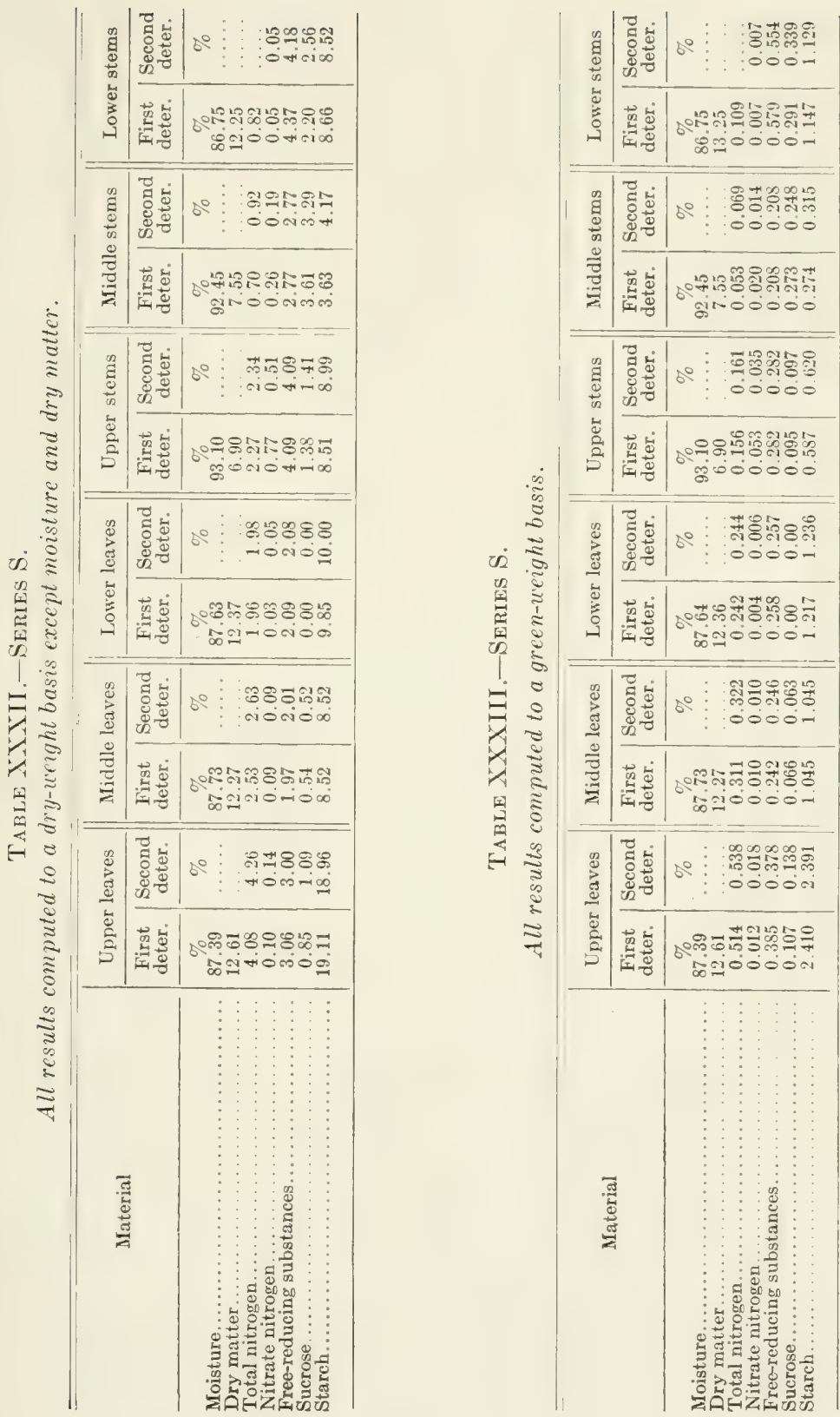
fruits ranging in size from that of large peas to good-sized walnuts. The object in taking this sample was to determine if any differences in analysis could be detected between purely vegetative and vegetative-reproductive plants grown under identical conditions.

Series S. The plants in this series were treated exactly like those described in series $O$. In fact the plants in this lot which are mentioned as having been cut back, are the remaining bases of those which constituted series $\mathrm{O}$, up to April 23, on which date the plants were carefully knocked from their pots and with the least possible disturbance, roots and adhering sand mass were transferred to larger pots in which there was a soil mixture of one-fifth sandy clay loam and four-fifths well-rotted manure. At this time the plants which had not been cut back had changed very little from the condition described for April 16, but those which had been cut back to within an inch or two of the sand surface, in the majority of cases had developed one or two sprouts from onequarter to one and one-half inches long. These sprouts were gray green, slender, and woody. Within three days following the transfer to rich soil, the stems and tip leaves began to assume a much brighter green color. Growth was resumed almost immediately at the tips, the new leaves pushed out vigorously, and became large, soft, and dark green, the stem developed above the tip following the transfer was much larger in diameter than that below it, was dark green, succulent, and more densely clothed with glandular hairs. Later the old lower stems also became very dark green, showed a decided secondary annular growth coupled with a strong tendency to develop adventitious roots. The plants bloomed profusely and began to set some fruit though most of the blooms fell as soon as the corolla faded. Many of the plants developed axillary shoots. In general, plants which had not been cut back, produced much more new growth than those which were cut to stubs. All the samples were of plants which had not been cut back. The samples were taken for analysis on May 12,1917 , at 2:00 p. m. on a clear day. By that date the plants had made from four to six inches of terminal growth which was very succulent and green, were producing many flower clusters, a few of which had begun to bloom, and the whole stem had again become green. The sample was divided into three portions, (1) tips made up of the new growth, (2) middles, which included the upper halves of the plants as they were before transplanting and (3) bases, the lower halves of the same plants.

Table XXXIV.-Series N.

All results computed to a dry-weight basis.

\begin{tabular}{|c|c|c|c|c|}
\hline \multirow{2}{*}{ Material } & \multicolumn{2}{|c|}{$\begin{array}{l}\text { Leaves of first lot } \\
7.195 \mathrm{gr} \text {. dry weight }\end{array}$} & \multicolumn{2}{|c|}{$\begin{array}{l}\text { Leaves of second lot } \\
7.591 \mathrm{gr} \text {. dry weight }\end{array}$} \\
\hline & $\begin{array}{l}\text { First } \\
\text { deter. }\end{array}$ & $\begin{array}{l}\text { Second } \\
\text { deter. }\end{array}$ & $\begin{array}{l}\text { First } \\
\text { deter. }\end{array}$ & $\begin{array}{l}\text { Second } \\
\text { deter. }\end{array}$ \\
\hline 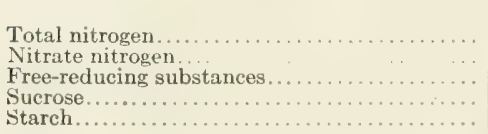 & $\begin{array}{l}\% \\
1.14 \\
0.04 \\
2.07 \\
0.00 \\
5.26\end{array}$ & $\begin{array}{c}\% \% \\
1.02 \\
\ldots .03 \\
2.03 \\
0.00 \\
5.00\end{array}$ & $\begin{array}{l}\% \\
0.81 \\
0.22 \\
3.17 \\
0.94 \\
7.78\end{array}$ & $\begin{array}{r}\% \% \\
0.64 \\
\cdots \\
3.35 \\
7.97\end{array}$ \\
\hline
\end{tabular}




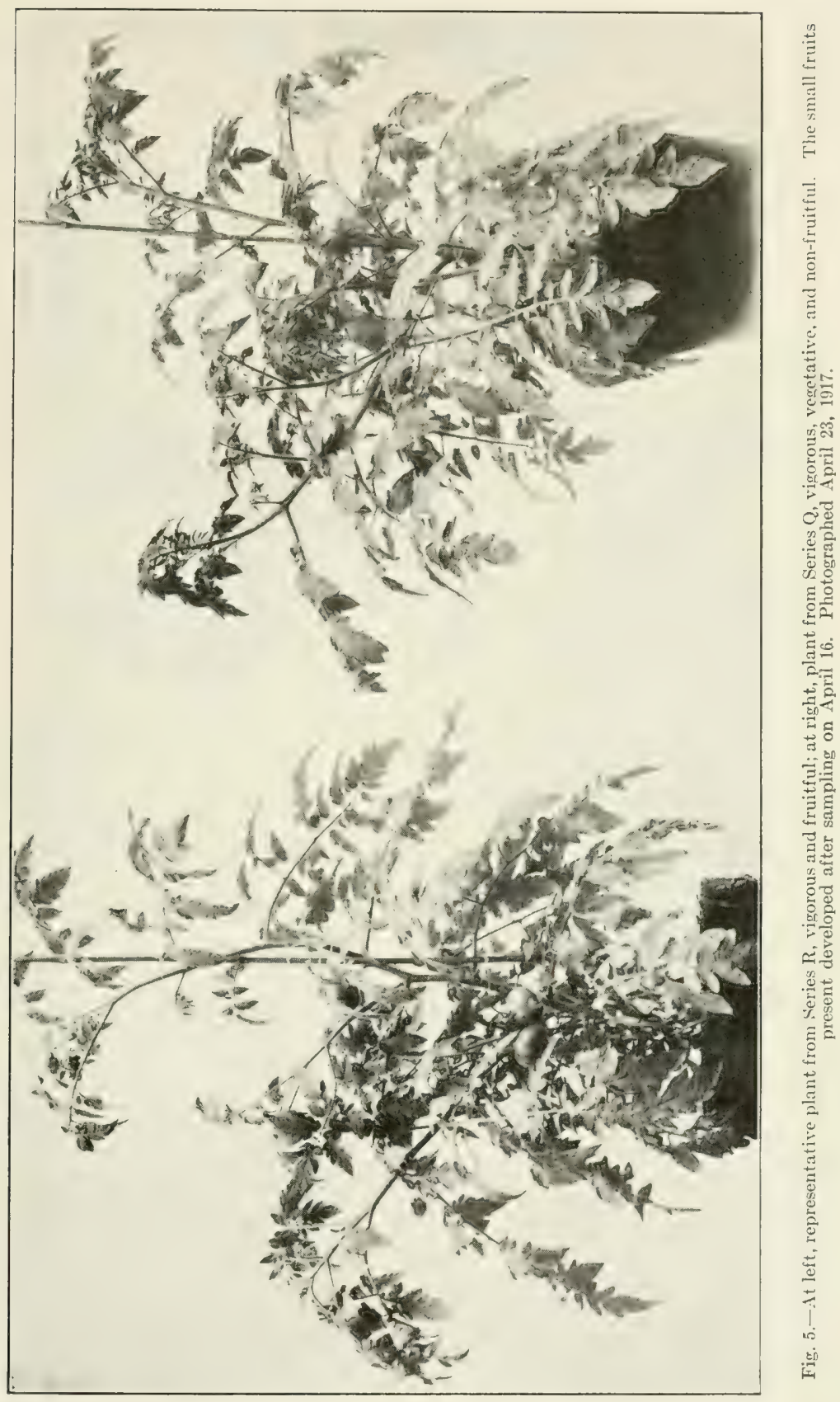




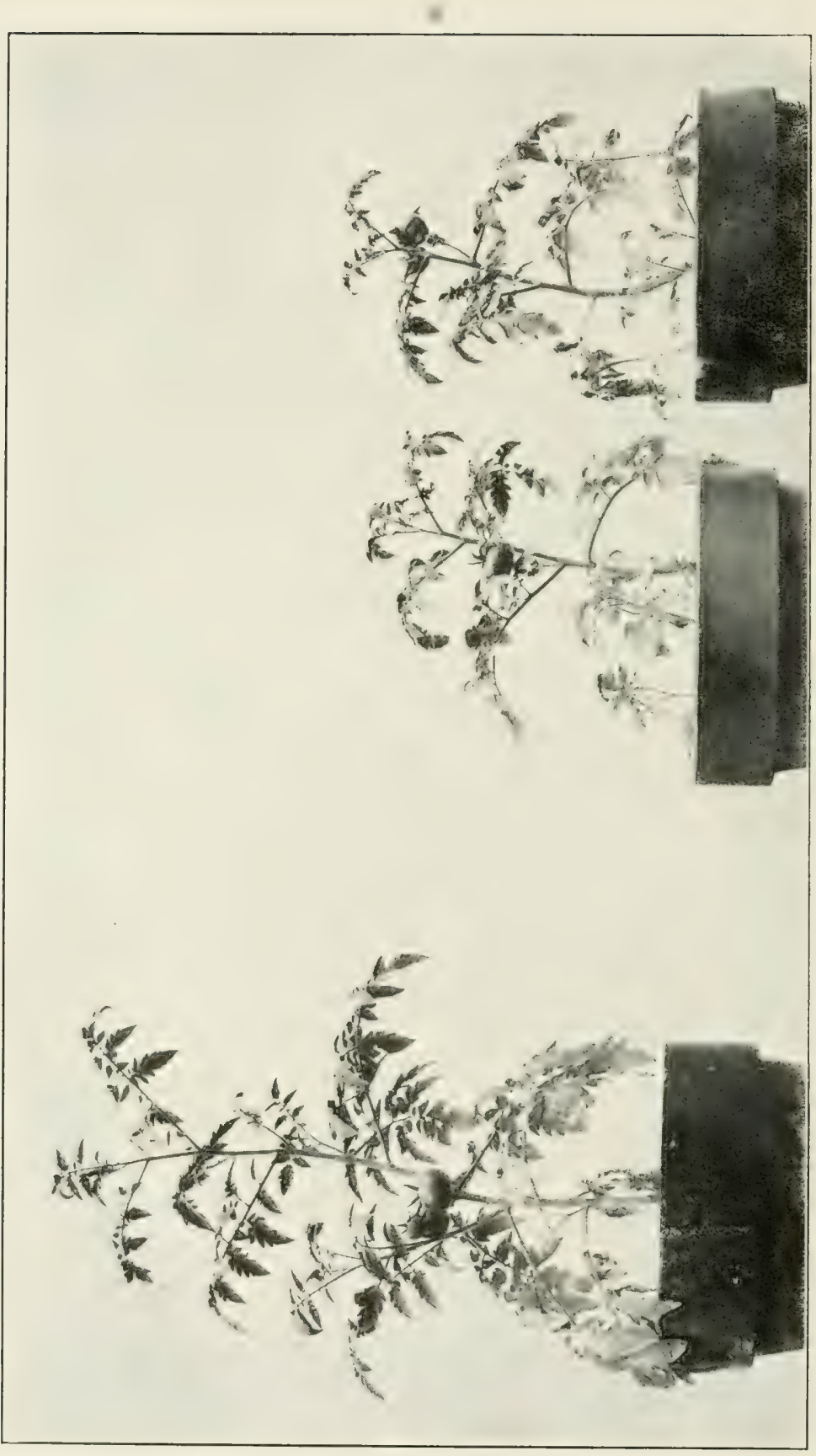

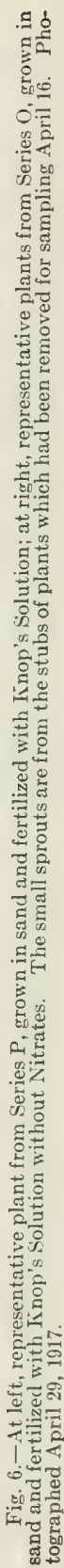


Series N. This series is made up of the leaves which fell from the plants in series O. Sample 1 represents those leaves which fell first and sample 2 a later collection.

The relatively high amounts of nitrate nitrogen present compared with the total nitrogen content is worthy of note.

Series $O$. Compared with series $\mathrm{Q}$ and $\mathrm{R}$ the plants in this series are very low in moisture, fairly low in total nitrogen, and very much higher in free-reducing substances, sucrose, polysaccharides, and total-dry matter. Nitrates were absent with the exception of a trace in the lower stems. Within the stems from top to bottom there is a decreasing gradient in moisture and an inereasing gradient in free-reducing substances, sucrose, polysaccharides, and total-dry matter.

Series $P$. The plants of this series compared with series $\mathrm{Q}$ and $\mathrm{R}$ are lower in moisture, total nitrogen, and nitrate nitrogen and are higher infree-redueing substances, sucrose, polysaccharides, and total-dry matter. Within the stems from top to bottom there is a deereasing gradient in moisture, total nitrogen and free-reducing substances and an increasing gradient in sucrose, polysaccharides, and total-dry matter. Within the leaves this relation does not hold.

Series $Q$. The plants of this series compared with those of series $R$, are slightly higher in moisture, total nitrogen, and nitrate nitrogen, and lower in free-reducing substances, sucrose, and total-dry matter. Within the stems of series $\mathrm{Q}$ from top to bottom there is a decreasing gradient in moisture, total nitrogen, nitrate nitrogen, and free-reducing substances and an increasing gradient in sucrose, polysaccharides, and total-dry matter. In series $R$ within the stem from top to bottom there is a decreasing gradient in moisture, total nitrogen, nitrate nitrogen, and free-reducing substances and an increasing gradient in sucrose and total-dry matter.

Series $S$. The analyses of the plants in this series show that the middle stems and leaves which are comparable to the upper stems and leaves in series $O$ have changed very little in percentage of total nitrogen expressed upon the green weight. They have increased in moisture and nitrate nitrogen and have decreased very much in total-dry matter, free-reducing substances, sucrose, and polysaccharides. Comparing the lower leaves and stems of series $\mathrm{O}$ with those in series $\mathrm{S}$ it is evident that there is a slight increase in total nitrogen, nitrate nitrogen, and moisture and a decided decrease in free-reducing substances, sucrose, and polysaccharides.

\section{DISGUSSION.}

Several points stand out clearly after a study of the foregoing data. It is particularly interesting to note that the interrelation of nitrogenous and carbohydrate substances in the leaves themselves is very variable in the several series and that these relations are frequently quite the reverse of those in the stems. This result might be anticipated perhaps from the general knowledge 


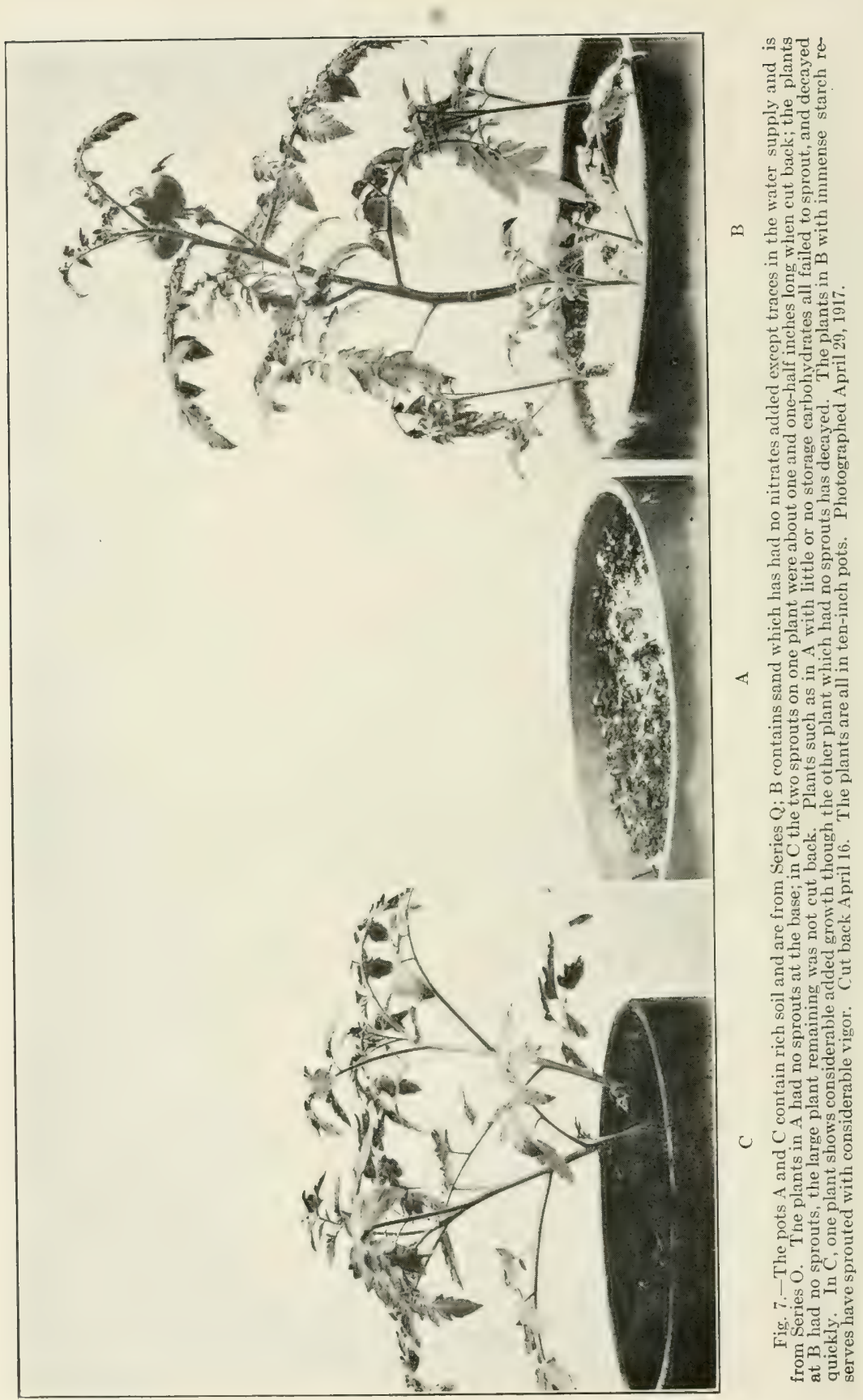


of photosynthesis. It will be better in any future studies of the reserves in leaves to collect samples after the plants have had a period in the dark as well as from plants which have had several hours of exposure to sunshine.

The tomato stem is interesting in its general anatomical makeup. The structure is brought out in the drawings from sections of vegetative and nonvegetative stems, taken from the same general location in both types of plants. In addition to the usual structures there is present an internal phloem and what appears to be an internal xylem. The internal phloem in the average stem is nearly equal in amount to the external, and does not differ greatly whether such stems are vegetative or non-vegetative, whereas the internal xylem cells show decidedly greater thickening in the non-vegetative stems. In one of the later experiments for which we did not secure analyses, a number of the plants were completely girdled by removing a half inch ring of cortex near the base of each. At the time of ringing, these plants were actively growing and the first noticeable change was a vigorous development of a callous-like tissue at various points within the girdled area. The plants did not seem to suffer greatly from this treatment, and after about a week they began to form roots above the girdles. Some of these stems were collected for microscopic examination and it was found that the internal phloem within the girdled area had greatly increased in amount; in some instances being present in from five to ten times as great an extent as in the portions which had not been decorticated. The diagrams (figure 14) also show that the xylem in proportion to the pith, is much greater in the non-vegetative than in the vegetative stems. In fact the greater diameter, succulence, and brittleness of the vegetative stems is due to the very large size of the pith and pith cells in proportion to the xylem tissue, and the tough, woody nature of the non-vegetative stems is due to exactly the reverse conditions.

In connection with the larger size of the leaves and stems of the vegetative plants as compared with the reproductive and the non-vegetative non-reproductive plants, it is worth while to call attention to the work of Gourley (13) and of Heinicke $(18,19)$. Gourley has suggested that larger leaf surface is associated with fruit-bud formation. While this is true to a certain degree, yet it is a matter of common knowledge that the largest leaves are frequently borne on the most vigorous vegetative plants, so that increased leaf area in itself does not necessarily accompany the attainment of the fruiting condition though it may be a correlated factor. That this and several other correlations listed by Gourley are thoroughly appreciated by him, is indicated by the fact that he states that "a good growth is not antagonistic to a good yield but rather they go hand in hand." Heinicke has emphasized the importance of the size and diameter of conducting tissue and sap densities in connection with increased fruit setting. Whether such increase in the percentage of fruit set is due to larger size of conducting tissue is really open to question. No doubt there is a close correlation between them but each is probably dependent upon some other cause back of both of them rather than that the latter follows as a result of the former. It is certain that at least some of the conditions of nutrition which result in the production of the small spurs are likewise those which make 
for decreased fruit setting and development, and the large spur is rather an accompaniment of increased fruitfulness than its cause. Many similar correlations between growth and fruit production have been pointed out by various workers in connection with pruning problems. In the work of Lewis and Allen on nitrate of soda fertilization, the percentage of setting was greatly increased the first season the nitrate of soda was applied, not because there was any immediate appreciable increase in size of the spur, but because of the change in the conditions of nutrition from which greater vegetation followed as an essential consequence. Theoretically and practically this change in nutrition could be so great, that the response is simply vegetative without an increase of fruit production. The means which Heinicke employed, such as sawing partially through limbs, pruning, etc., in order to limit the amount of sap which any given number of spurs could receive, would modify the quality of such sap quite as much as its quantity. Both these factors must be taken into consideration in interpreting the results obtained. In fact, girdling, even such as sawing partly through limbs, has been found to increase fruitfulness and fruit setting in some instances. It has even been recommended in practice as a means of causing over-vigorous trees to become fruitful. These apparently conflicting results are not difficult to interpret. If the carbohydrate factor relative to the nitrogenous factor were already higher than that which would make for maximum fruit setting, then pruning would tend to reduce the carbohydrates and thereby increase fruitfulness; whereas sawing through, as the analyses of Hibino have shown, would tend to increase them still further and a decrease in fruitfulness might be expected. If on the contrary the nitrogenous factor were relatively too high, then exactly the reverse results from the same practices might be expected, since pruning would tend still further to decrease carbohydrates, whereas the sawing would tend to increase them. It would be interesting to know the differences in composition of the sap correlated with the differences in its density, and the relation this has to the development of the abscission layer. How to regulate such composition in practice is of prime importance.

From our experiments with tomatoes and from much corroborative evidence from general observed conditions throughout a wide variety of plants, it seems quite likely that nitrates play a very important part in the development of the abscission layer, especially in vegetative plants; whereas relatively higher carbohydrate content makes for continued development of the vaseular strands of the pedicel and the strengthening of their connection with the fruit spur. This would be in keeping with the finding of greater thickening of the xylem cells in various parts of the plant under the same conditions, and yet, as is well known and was clearly evident in our work, a very marked abscission of fruits and blossoms occurs also when the carbohydrate content is relatively very high. While several possible explanations present themselves, little would be gained by theorizing before much more precise information on the actual chemistry of the abscission of fruits is at hand, for many of the factors apparently involved in foliar abscission seem to differ widely from those connected with the dropping of fruits. 


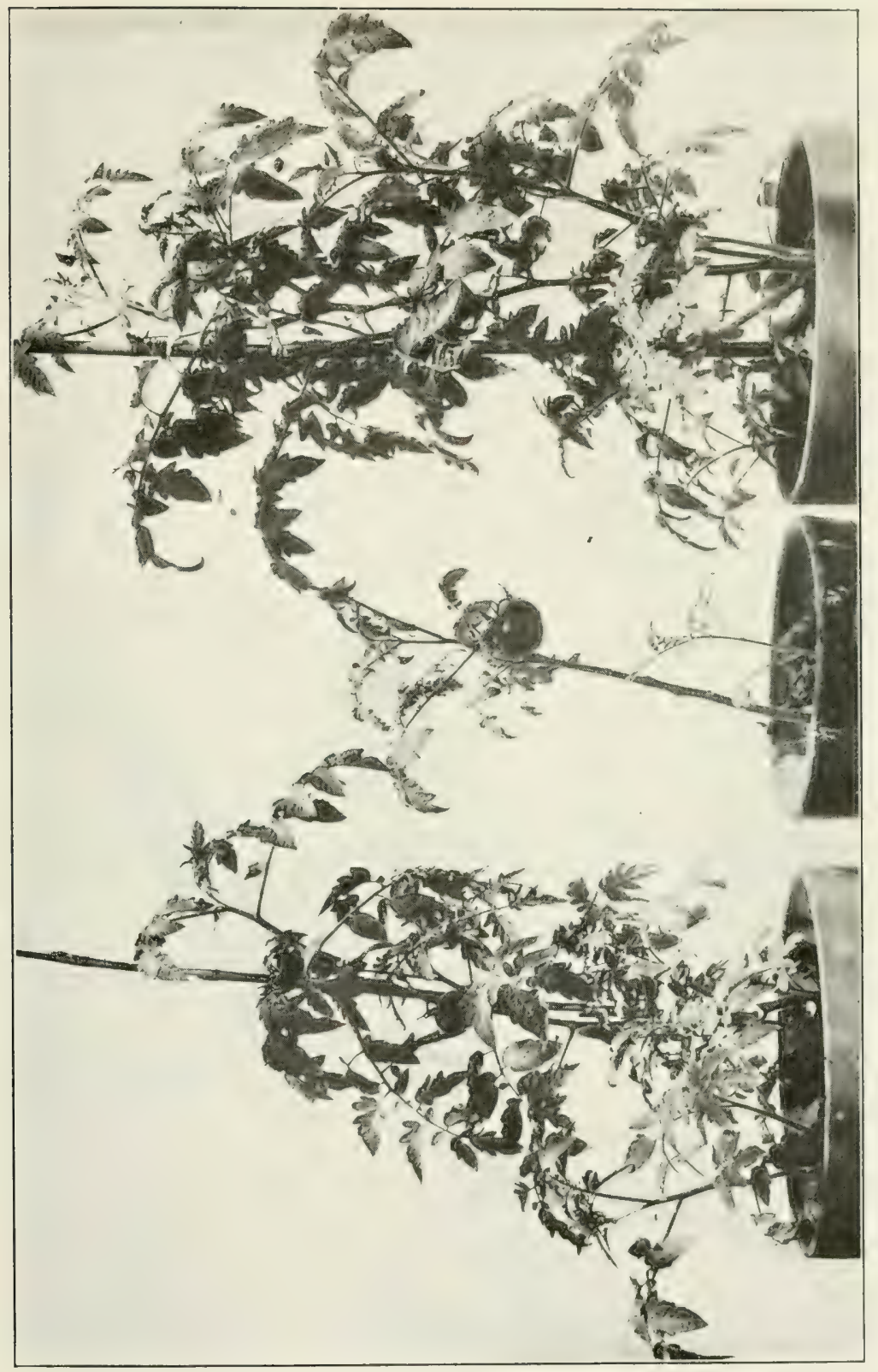




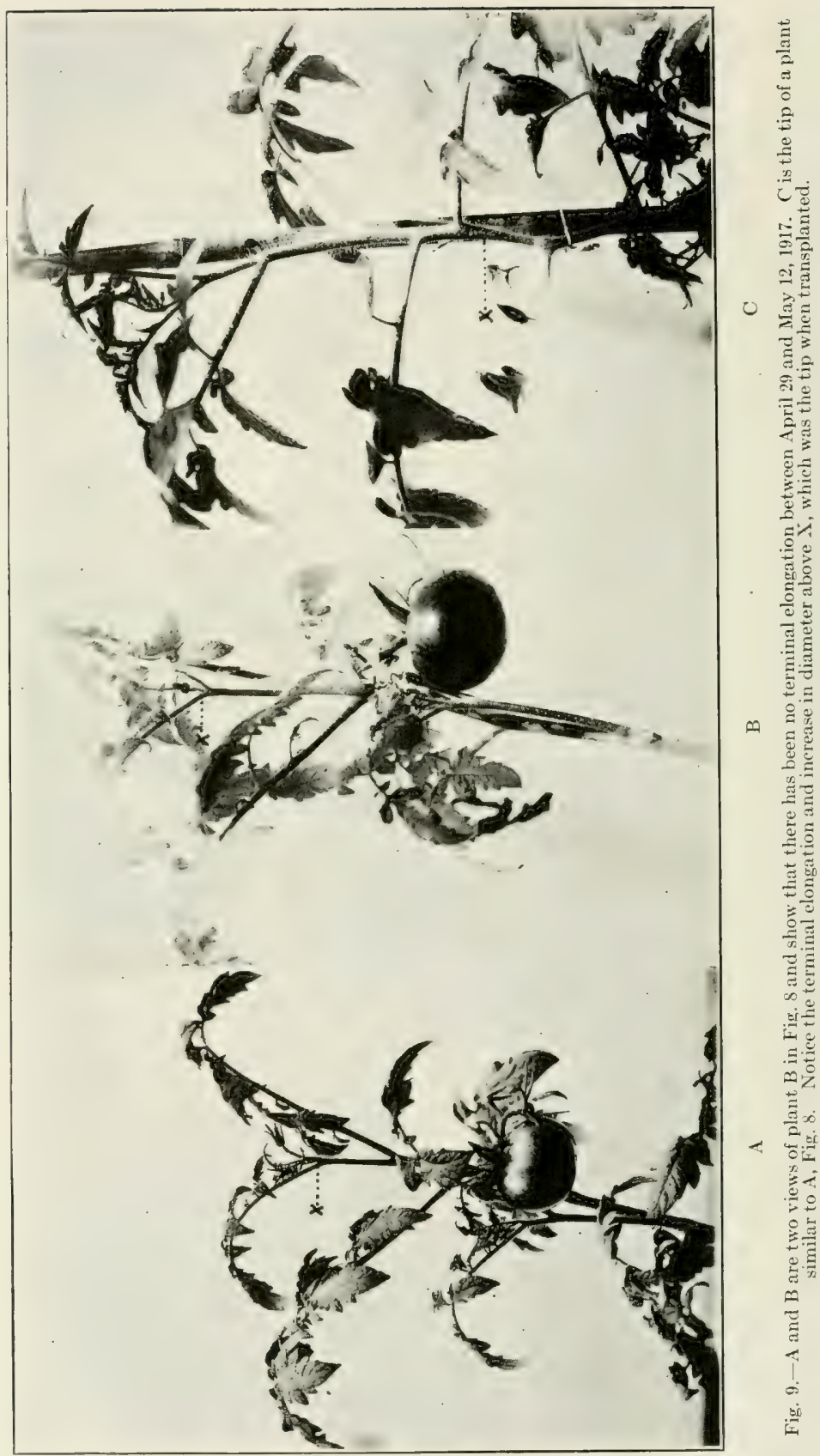




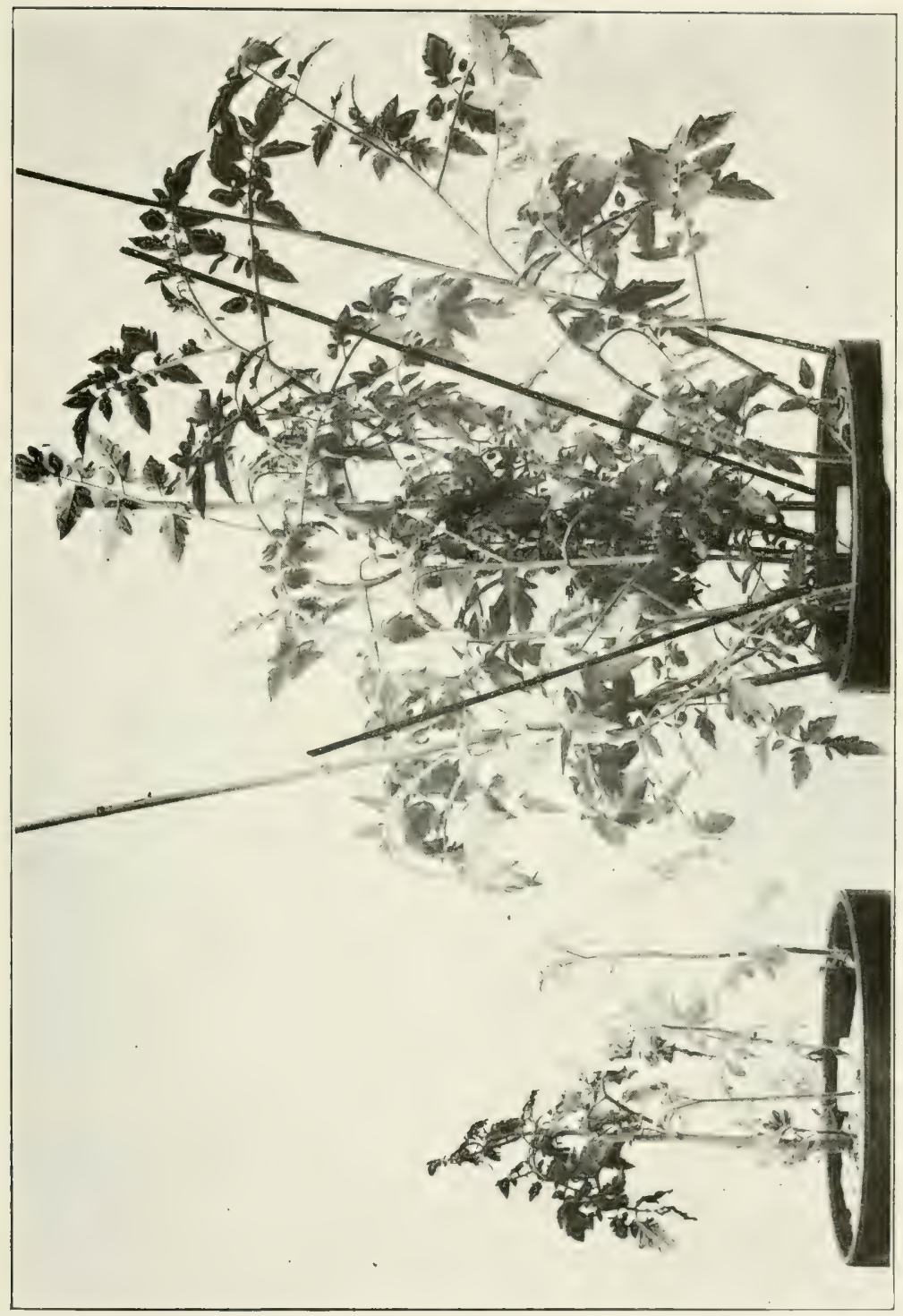

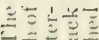

政

政

政

군

政

E.

E

घi

政

政

政

눌

跣

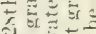

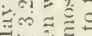

$\forall$ 둥

$\infty$

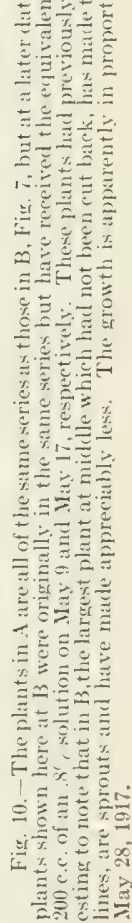




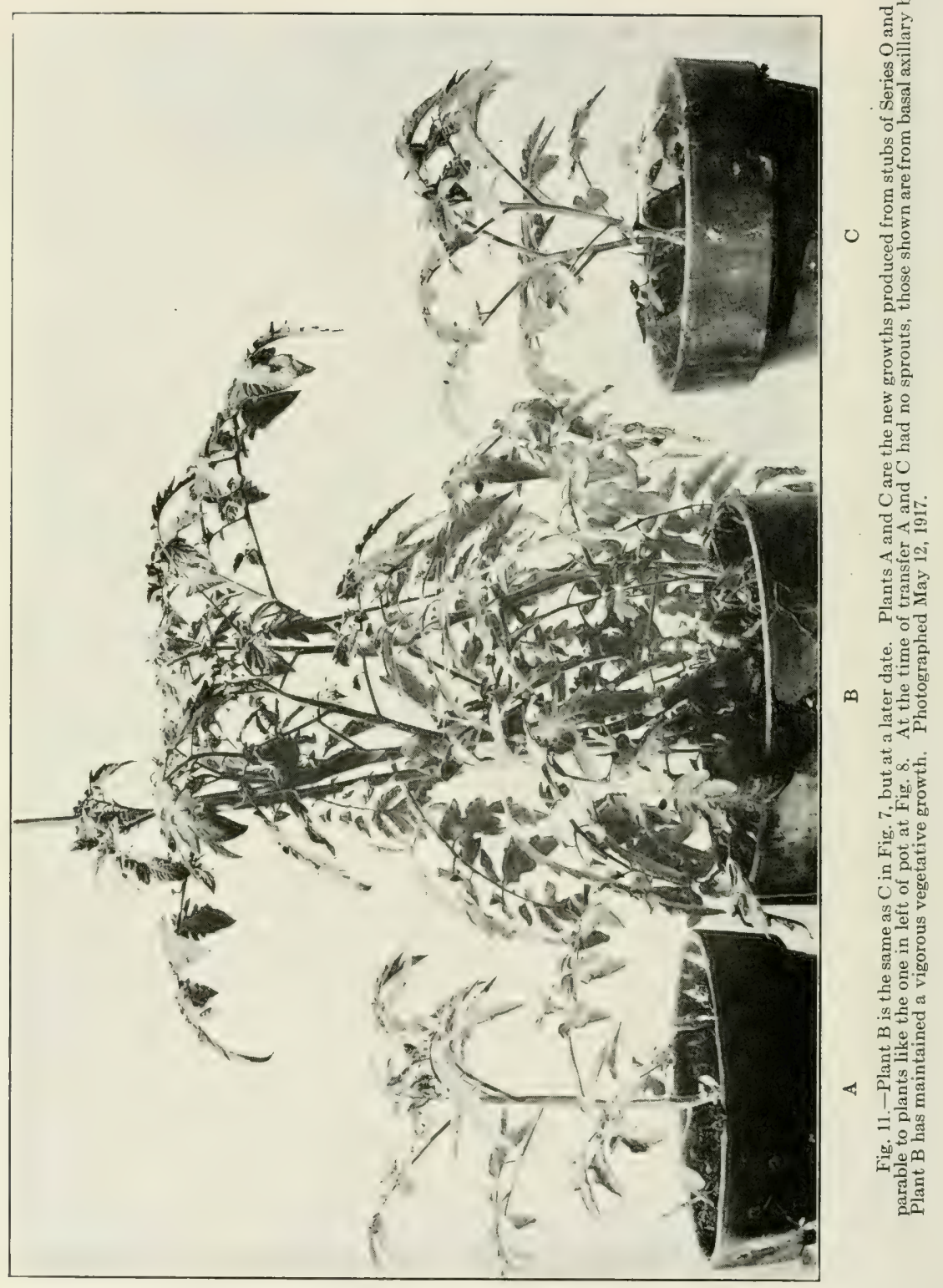




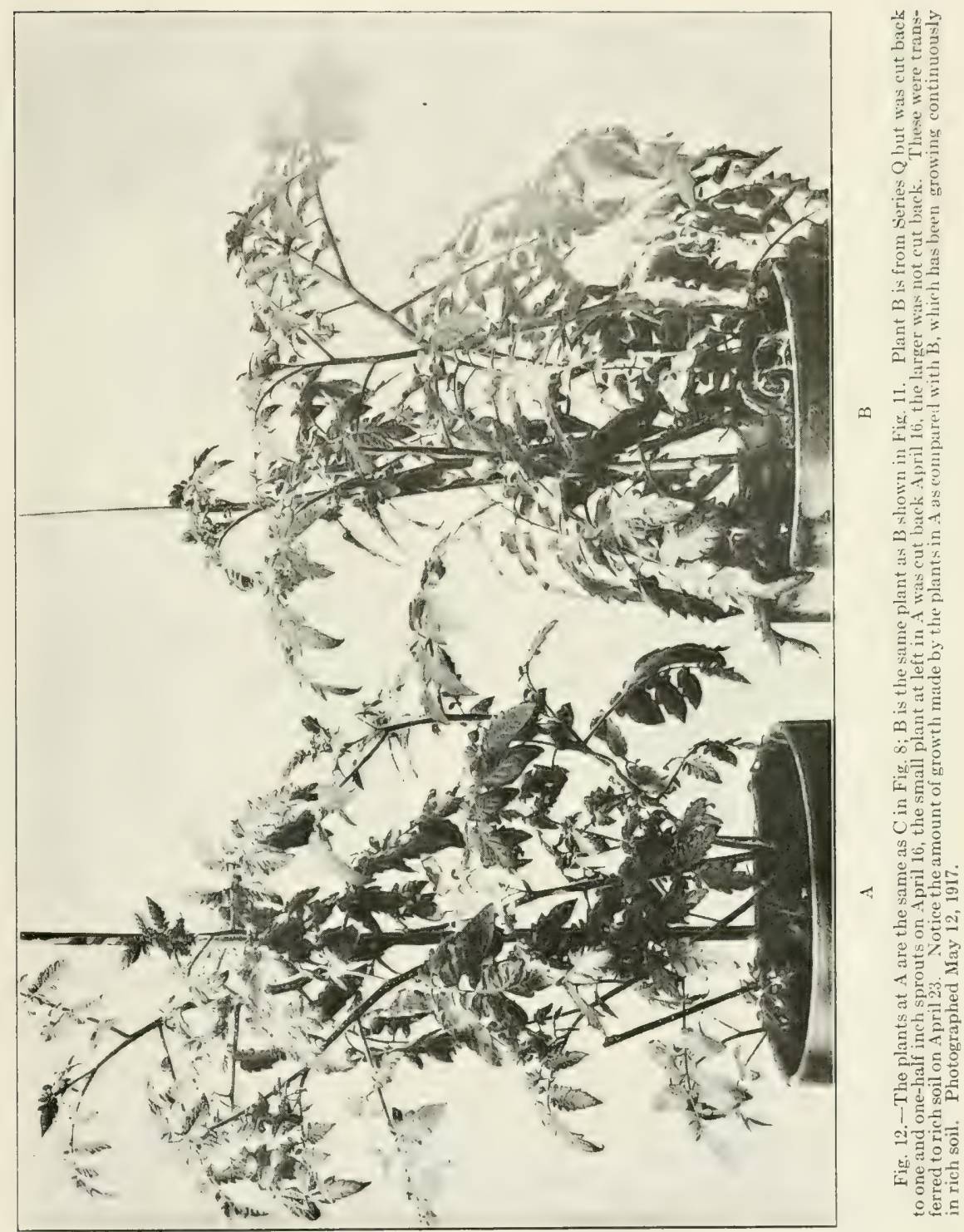




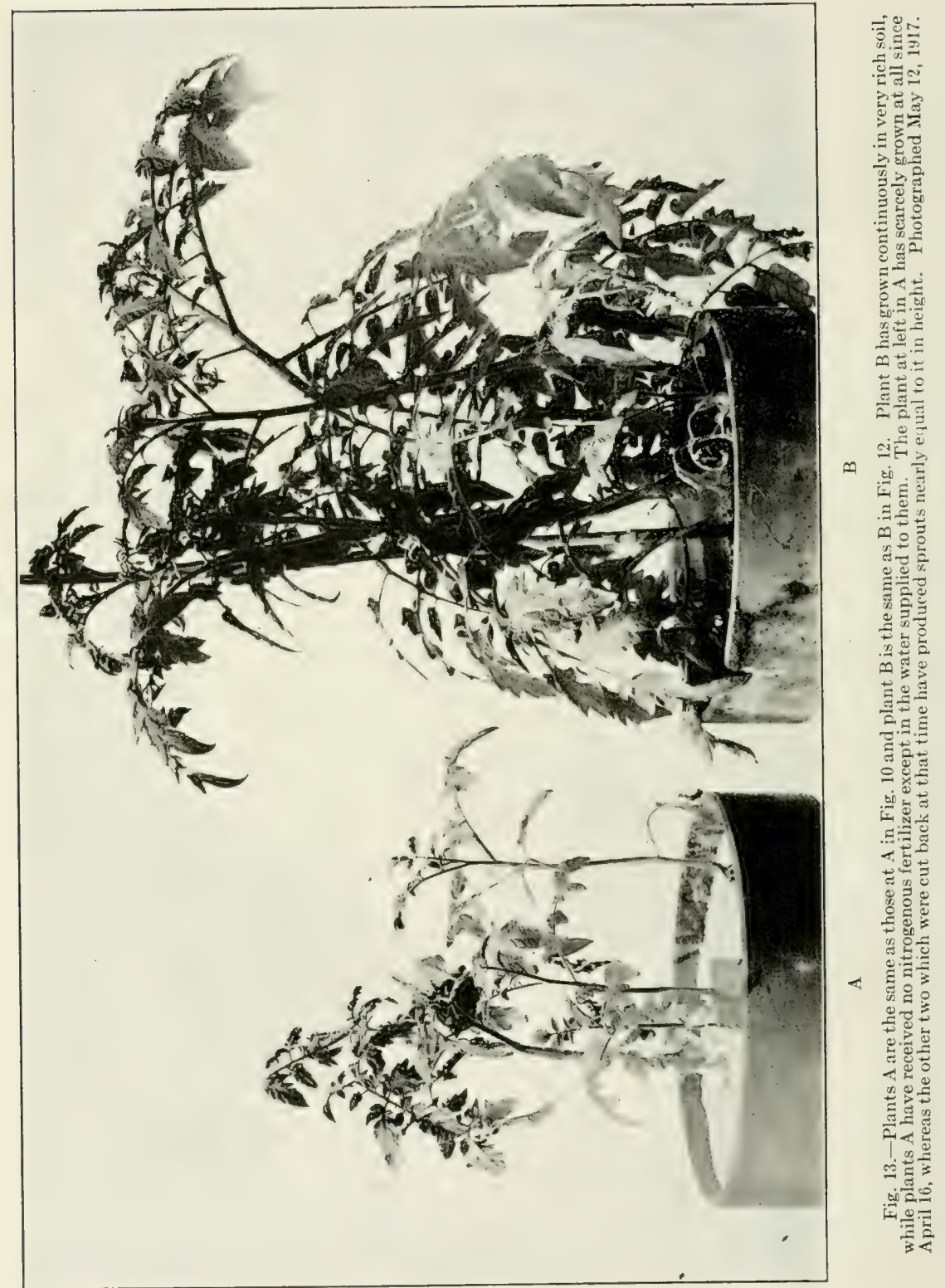


It was observed throughout the experiments that as the plants berame less vegetative, the leaves began to lose their fresh green eolor, to turn gray green and finally yellowish. In spite of this fact, carbohydrate storage in the stems continued. In the very vegetative stems, small plastids containing chlorophyll were to be found in the cortical cells and in the pith cells even to the center of the largest stems and especially toward the tips. When the available nitrogen in the soil was limited, either by drying out the soil or withholding nitrogenous fertilizers, the plants began to turn yellow. This was accompanied by a complete disappearance of the green pigment from the plastids within the cortical and pith cells, and apparently the disappearance of many of the plastids themselves, especially when deposition of starch grains within the cells became rapid. On supplying nitrate to the soil, such plants as were nonvegetative first began active growth at the stem tips. This was associated with a greening of the smaller, younger leaves and a very rapid disappearance of the starch grains from the pith cells of the stem, first near the tip and then progressively down the stem to its very base. Plastids again began to appear in these cells and later took on a bright green color. These plastids were especially abundant in the cells of the newer growth produced after the application of nitrate fertilizer, but also occurred in the cells of the older growth.

Throughout all of our experiments the plants grown with an abundant supply of available nitrogen were distinetly vegetative and non-fruitful. These plants as a whole were higher in total and nitrate-nitrogen and lower in freereducing sugars, sucrose, and polysaccharides than were the distinctly nonvegetative plants. Within any given plant, especially those which were grown most vigorously and rapidly, the nitrate content was generally greater in that part of the stem which was the more vegetative. When the plants were not excessively vegetative, however, the total nitrogen was higher in the more vegetative portions, but the nitrate readings were greater in that portion of the plant where the starch content was also higher. It may be remarked that there was some disagreement between the quantitive chemical analyses and the microchemical analyses for nitrates; by the latter method the greatest quantity of nitrates was always indicated in the most actively growing portion of any given stem; whereas this relation was found to be variable according to the quantitive macrochemical methods. Just how to account for this or what the significance of it may be, must be left for future investigations. The general condition of an association of higher total nitrogen and nitrates with increased vegetation is in most instances valid, especially in the comparison of the stems as a whole in the various series.

There were some wide variations in the amounts of carbohydrate present in the different types of plants. The greatest fluctuation was in the amount of free-reducing substances. These were generally highest in the stems of the less vegetative plants, when considered as a whole, but within the stems themselves they were sometimes more, sometimes less in the more vegetative portions. Disaccharides and polysaccharides were far less variable in relation to any specific vegetative conditions of the stems, either as a whole or in any given portion of it, than were the free-reducing substances. Generally an in- 


$$
\begin{aligned}
& 23 \\
& 23 \\
& 2.2 \\
& \hline
\end{aligned}
$$




$$
3
$$



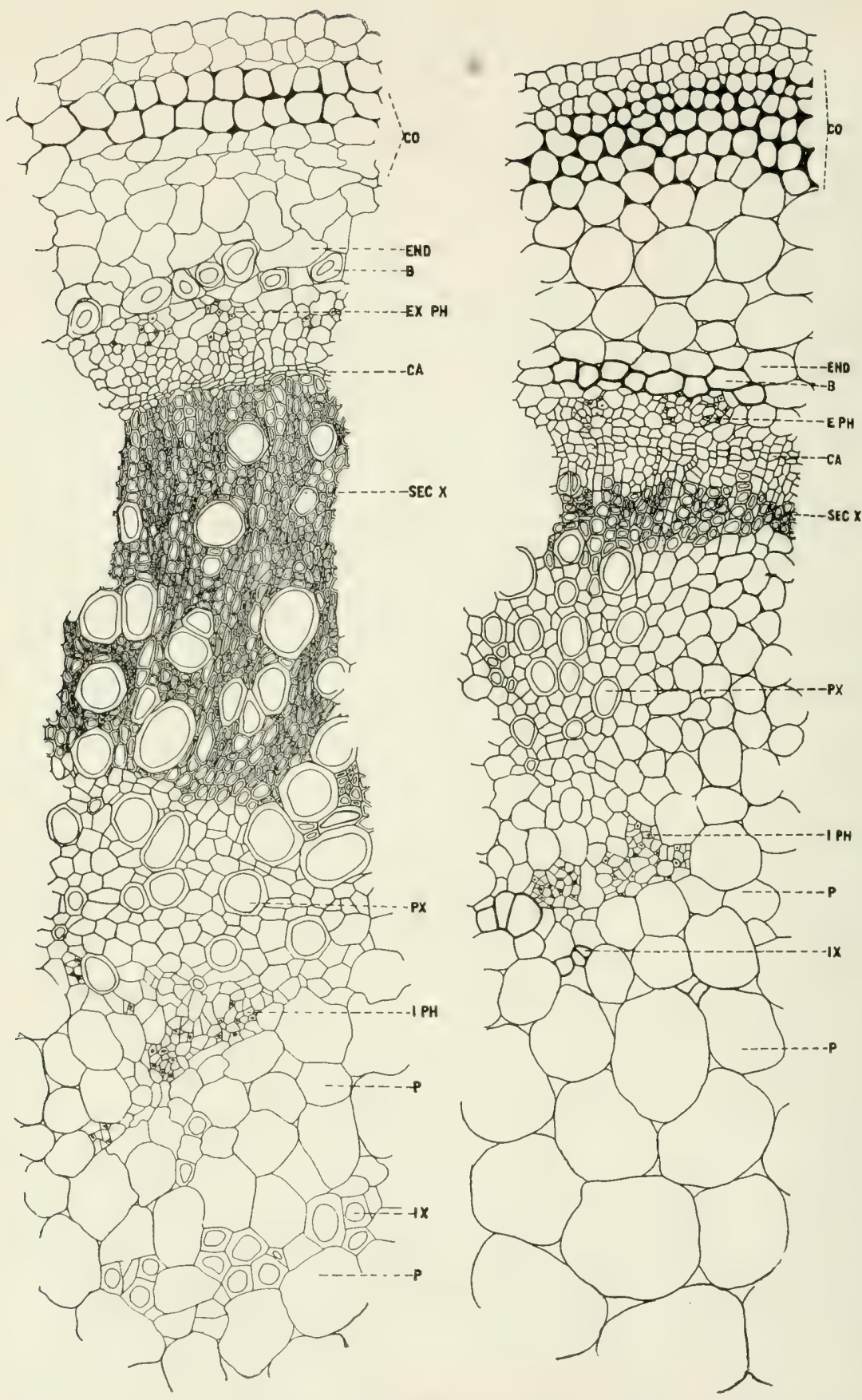

Fig. 14-Cross sections of feebly vegetative (Series $\mathrm{O}$ ) and vegetative (Series $\mathrm{Q}$ ) stems of tomato, The greater development of the xylem tissue in the former is very noticeable. Though not indicated. the development of the pith tissue in the latter was very much greater. CO, collenchyma; END, endodermis; B, bast; Ex PH, external phloem: CA, cambium; SEC X, secondary xylem; PX, primary xylem; IPH, internal phloem; P, pith cells; IX, internal xylem. 


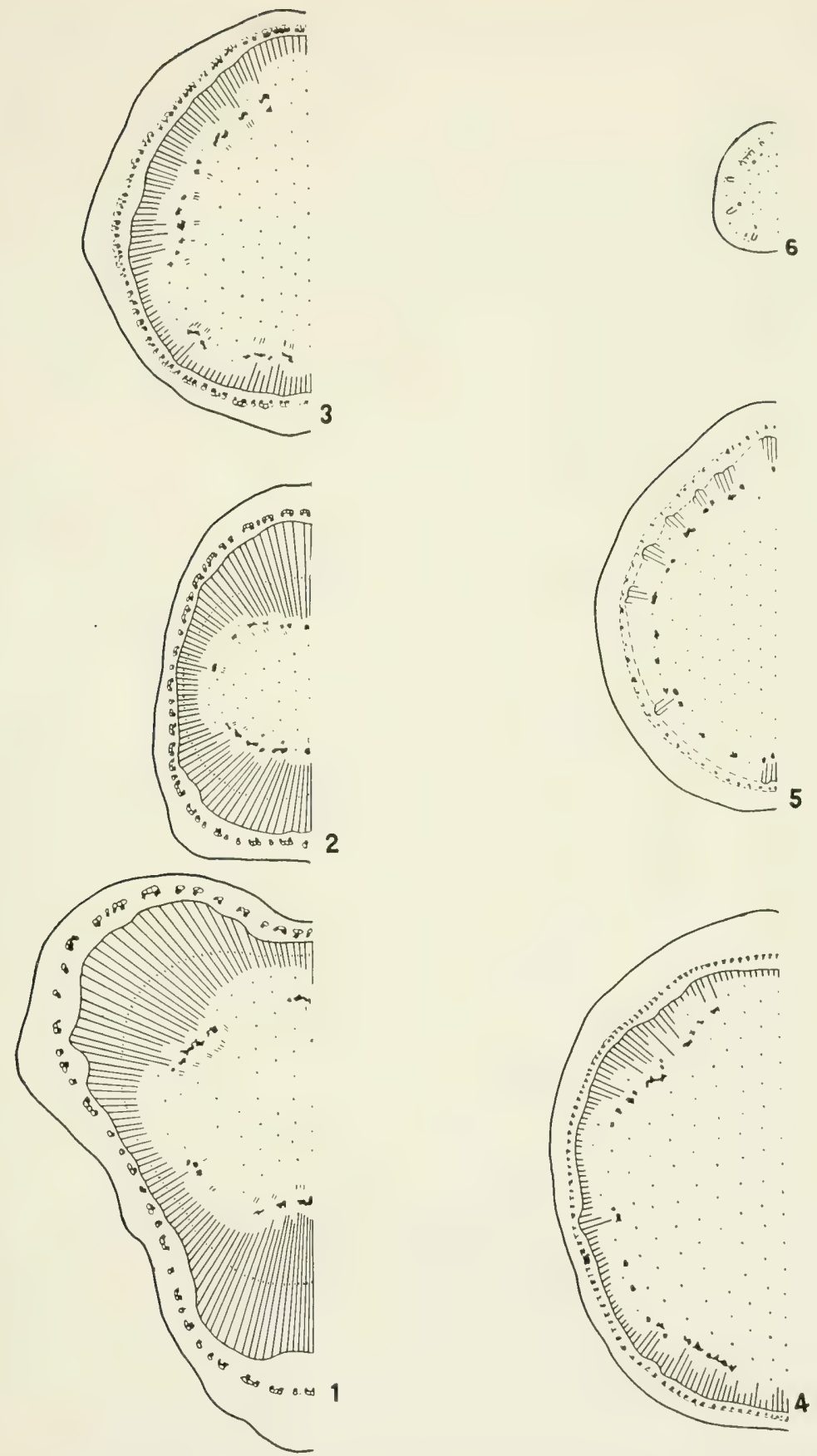

Fig. 17-Diagrammatic cross sections of stem of typical plant from Series S. Sections 1 and 2 are from the base and what was the top of the plant before transferring to rich soil; both show a distinct second growth in the secondary xylem. Sections 3 to 6 are taken at points about five centimeters apart progressively up the stem to within one centimeter of the tip. 
crease in polysaccharides was closely associated with an increase in disaccharides, and both were almost uniformly greater in the less vegetative plants and in the less vegetative portions of any given stem. This association of starch content and condition of vegetation is clearly indicated in figure 18. Associated with greater polysaccharide content was a greater thickening of the walls of the xylem parenchyma cells, and in stems of equal age a far greater proportion of xylem to cortex and especially to pith. This is made clear in figure 14 and the diagrams of entire stems in figures 15 to 17. Starch was always found in the starch sheath or endodermis, even in the most actively vegetative stems, but was not found in any quantity in the pith cells. Frequently in the very vegetative plants, there was no starch storage in the bases of the stems. When nitrogen was limited, that is in those cases where the plants were less vegetative, starch storage was first noticeable in the pith close to the xylem; as more and more storage took place, all of the pith cells, the medullary rays and the wood parenchyma became filled with starch grains.

Our experiments indicate that sucrose is not the first sugar formed by synthesis but that it is present only in those instances where free-reducing substances are high and have been permitted to accumulate. The general situation seems to be a graded series from free-reducing substances through sucrose to polysaccharides. Our observations, therefore, are apparently not in close harmony with those of Parkin (35) on the Snowdrop, for he has stated that in that plant sucrose is the first sugar of synthesis.

The great fluctuation in the amount of free-reducing substances present in the various types of stems may be due to a variation in the extent of their utilization as well as their synthesis, dependent upon the presence of other substances in conjunction with which still other compounds are built from them. If this were the ease, it might be expected that the quantities present at any given time or location would vary directly with the degree of such utilization. At least two alternatives are conceivable, and although neither of them can be proved from the work at hand nor from the various opinions as yet expressed by various workers, still they may be suggested. In the first place, if the simpler carbohydrates do serve as one of the building stones in the synthesis of aminoacids and proteins, or if the synthesis of the latter is conditioned by the available supply of carbohydrates, as well as a suitable nitrogen supply, it might be expected that the carbohydrates would be built over into these compounds more or less rapidly according to the amount of such suitable available nitrogen, and the presence of the other necessary conditions, whatever they may be. In the second place, if a suitable nitrogen supply were not available so that the simple carbohydrates were not utilized in the formation of nitrogen-containing compounds but accumulated as such, then there would be a possibility for their being built into the more complex forms such as disaccharides, polysaccharides, and the like. The tomato plant does not contain or store any considerable quantity of fat, hence estimations of it were not made in our experiments. Because of the close relationship between carbohydrates and fat synthesis, however, it would seem that there was at least a good possibility that similar relations may exist in fat-storing plants. 
Our own experiments give indications that the foregoing ideas on the (arr), hydrate transformations may be correct, for with an abundance of available nitrates in the soil, the plants themselves are relatively high in total nitrogen and nitrate nitrogen, and relatively less in carbohydrates; but when there is a limitation of the nitrates, the carbohydrates, first the simple and then the more complex, accumulate rapidly, provided of course that other conditions for photosynthesis are not prevented. When available nitrogen is added to the soil in which such nitrogen-low, earbohydrate-high plants are growing, however, they very quickly increase in total nitrogen and nitrate-nitrogen content, and become actively vegetative. Associated with such a change is a decrease in the same complex carbohydrates. Microscopic examinations were made of the plants in series $\mathrm{O}$ before transferring to a soil abundant in available nitrogen and it was found that the cells of the pith, cortex, and medullary rays and even those of the xylem parencyma were packed with starch grains. This was true for sections taken up to within one centimeter of the tip. Within three days following such transfer, the beginning of the disappearance of the starch grains from the center pith cells and cortical cells at the tips of the plants was very noticeable. Successive examinations as growth progressed showed an active terminal elongation which contained no storage starch except in the starch sheath, an active development of secondary xylem in the older portion of the stem, and a very rapid, progressive, and finally complete disappearance of the starch from the pith and xylem parenchyma and also the cortical cells even down to the bases of the stems, where it was last to disappear. It may be added that some stems which were thus packed with starch were not given additional nitrates. They finally lost all their leaves except two or three at the very tip about one or two centimeters long. These stems remained alive for over seven months during which time there was a gradual disappearance of the starch in some of them until only traces in the medullary rays and pith could be demonstrated, while some of the others contained large starch reserves at death. Even after this long period a few of these old, yellowed, leafless, apparently dead stems put out new buds at a few of the nodes when calcium nitrate solution was applied to the sand in which they were growing. Every one of the plants which sprouted still contained carbohydrate reserves.

While on this point, it is worth while to consider the behavior of the plants in experiment VII. The results throw some light on the problem of regeneration. When the plants which constituted series Q were collected, they were vigorously vegetative, and the analyses showed that they were very low in the more complex carbohydrates but high in total nitrogen. In taking the samples the plants were generally cut off about one-half or three-fourths of an inch above the surface of the soil. In most cases this left a bare stub of one to three nodes, usually without sprouts but in several cases with sprouts from one-quarter to one and one-half inches long. In every instance in which no sprouts were left the stems rotted without any vegetative response whatsoever, whereas when sprouts were present they usually grew rapidly. In several cases sprouts one-half inch long withered and rotted also. Now the plants in series $\mathrm{O}$ were collected in exactly the same way, and it will be remembered these were 

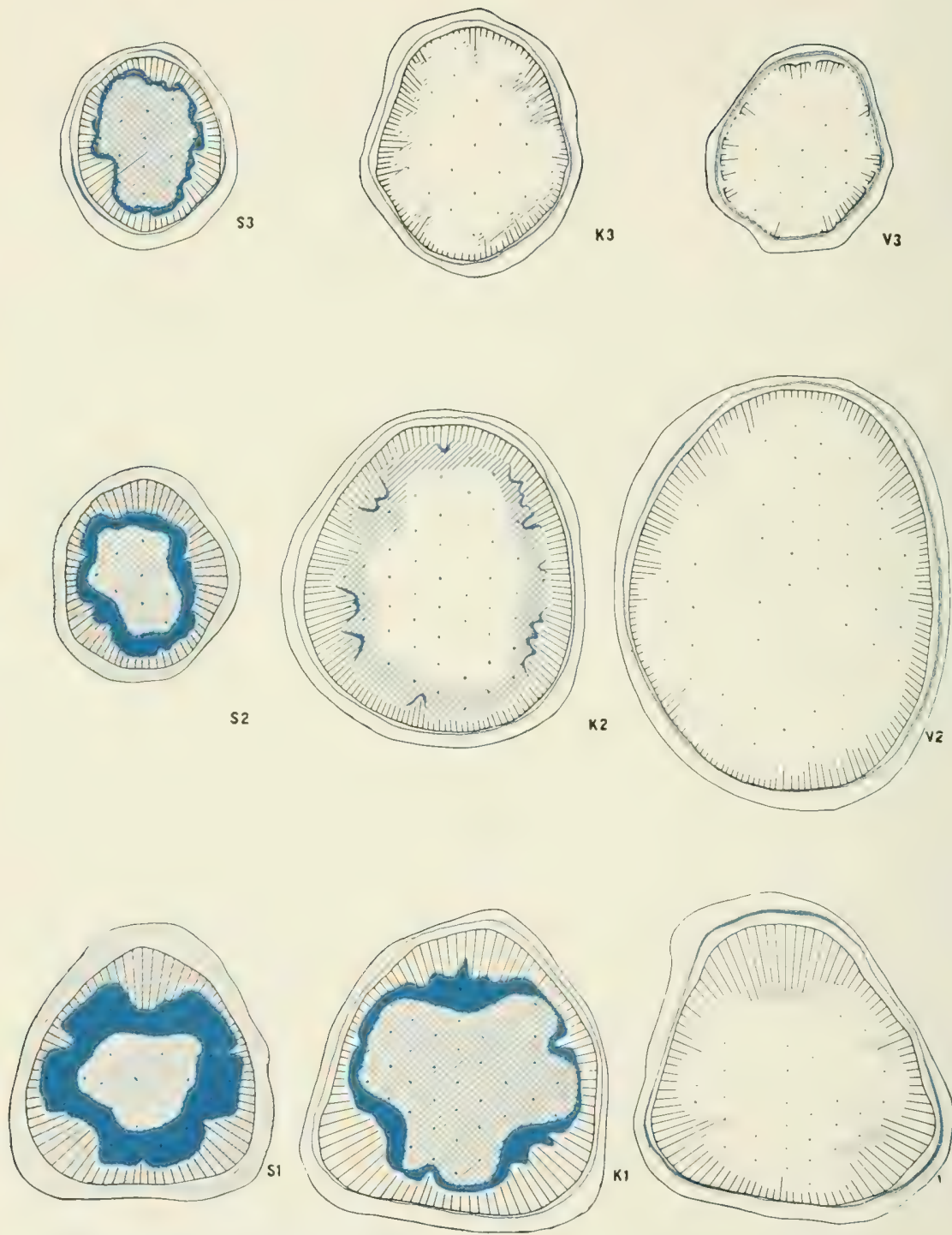

Fig. 18.-Diagrammatic sections, base, middle, and tip, from plants of Serics O (S), Series $\mathbf{P}(\mathbf{K})$, and Series Q $(V)$ to show the range and location (in blue) of starch deposits, as indicated by the Iodine test, and the comparative development of pith and secondary xylem. All drawn to the same scale. 
non-vegetative, and very high in the more complex earbohydrates but relatively low in total nitrogen and almost without nitrate nitrogen. Not one had a sprout at the base, but after cutting back, none of these stubs decayed. Instead, every one without exception produced from one to three new sprouts, which grew vigorously for a short time but ceased before more than one-half the volume of the top which had been cut away had been attained. Provided no additional nitrate was applied to the sand, they again became filled with starch. The rapidity with which these shoots began growth was truly astorishing. What these sprouts did when appreciable quantities of nitrates were added to the soil is clearly indicated in figures 9,10 , and 12.

As previously pointed out, the plants in these two lots differed greatly in carbohydrate reserves, and in total nitrogen. Two suggestions present themselves; first, that without carbohydrate reserves or a means for their synthesis regeneration does not result even though large amounts of nitrates are available; and second, that with a carbohydrate reserve, even though nitrates are very much restricted, regeneration takes place very rapidly. It must be remembered that the sand-culture plants of series $\mathrm{O}$ received traces of nitrates or other nitrogen containing compounds in the water supply. The very slow growth of the plants before eutting back and the early cessation of the vegetative extension of the young shoots indicate that a certain amount of nitrogen is required merely for maintenance, and that without additional quantities vegetative extension cannot take place. What the result may be when the supply of nitrates is increased is well shown in figure 8 and figure 10. The plants shown in the former were grown as series $\mathrm{O}$ and later those which were not eut back analyzed as series S. Two plants had been grown in each pot of sand and fertilized with nitrate-free Knop's solution. When the samples were taken one plant only was collected. Many of these were then transferred, without disturbance, to very rich soil. The plants shown in the latter were treated the same as series $O$, but instead of being transferred to rich soil, calcium nitrate was added to the nutrient solution. The new sprouts had already made considerable growth before the nitrate was added.

The first noticeable feature is, that the plants in the pots which had received additional nitrates, when compared with the plants in those which had not received them, made much greater growth, especially those plants which had not been not cut back; the second, that the difference in the growth of the new sprouts is very much less in the plants which had been cut back; and the third that the unpruned plants made much more growth than the pruned plants in the same pots when available soil nitrogen was increased. In the latter the growth is apparently proportional to the carbohydrate reserve in the stems at the time of transplanting. Even though there were much greater quantities of available nitrates in the nitrate-fertilized pots than in the unfertilized, when the carbohydrate reserves had been greatly limited through cutting back, the growth was not much greater for the first few days. When greater quantities of carbohydrates were made available through synthesis, however, growth was far more rapid in the fertilized pots. In other words, this experiment indieates first, that the limitation of the 
nitrates resulted in the suppression of growth and the accumulation of the more complex carbohydrates; second, that the limitation of the carbohydrates, even with large quantities of available nitrates in the soil, results in a suppression of growth; third, that a rapid vegative extension results from an adjustment of the carbohydrates and nitrates relative to one another so that both may be utilized in the formation and expansion of such structures; and fourth, that such a relationship can be secured either by increasing the nitrates without decreasing the carbohydrates, or by decreasing the carbohydrates without increasing the nitrates. While it is apparent that the amounts of these compounds relative to one another would be the same in both the above cases, the total amounts would be greater in the former and less in the latter, a condition faithfully reflected in the amount of growth produced. These considerations are very important in the problem of pruning and nitrate fertilization, previously discussed in this article.

One more point to be noted was the behavior of the severed stems of the ,lants in the foregoing experiment. Pieces of stems one to four inches long, without leaves, and possessing both nodes and internodes were examined microchemically to learn something of the nature of their content. They were then placed on filter paper moistened with distilled water and placed under a bell jar in the laboratory. These trials were repeated several times, always with the same results. (1) Yellowish stems high in carbohydrates and low in total nitrogen and nitrates pushed forth many roots, particularly along the internodes, to the length of one to four inches. One or two formed tiny yellowish sprouts at the nodes. In ten days to two weeks the roots turned dark and began to decay. (2) Greenish stems containing starch and fairly high in total nitrogen always produced roots along the internodes and sometimes small green sprouts at the nodes. The root production was not so profuse as in the foregoing. Decay began in about the same length of time. The succulent tops of the same plants without starch reserves all decayed without root or shoot production. (3) Green, succulent stems, without starch reserves and very low in free-reducing substances but high in total nitrogen and nitrate nitrogen, all decayed without root or shoot production. These results are of interest in connection with the vegetative propagation of many plants, for which purpose the practical grower prefers the more "hardened" or mature portions. From the general viewpoint expressed in this paper they are also interesting in connection with some other experiments on tomatoes which will not be discussed here, except to state that a decided reduction in the development of the root systems of the plants accompanied a continued removal of leaves from the tops. According to microchemical tests, that practice also resulted in a marked decrease in the carbohydrates in the stems, and a decided reduction in vegetative extension and fruitfulness.

The accompanying diagrams, figures 19 to 22 , show the relation between the percentage of total nitrogen and the percentage of total carbohydrates (free-reducing substances plus sucrose plus polysaccharides) expressed as dextrose. It should be borne in mind that the free-reducing substances, sucrose, and polysaccharides are not absolute determinations, but that these terms are used with 


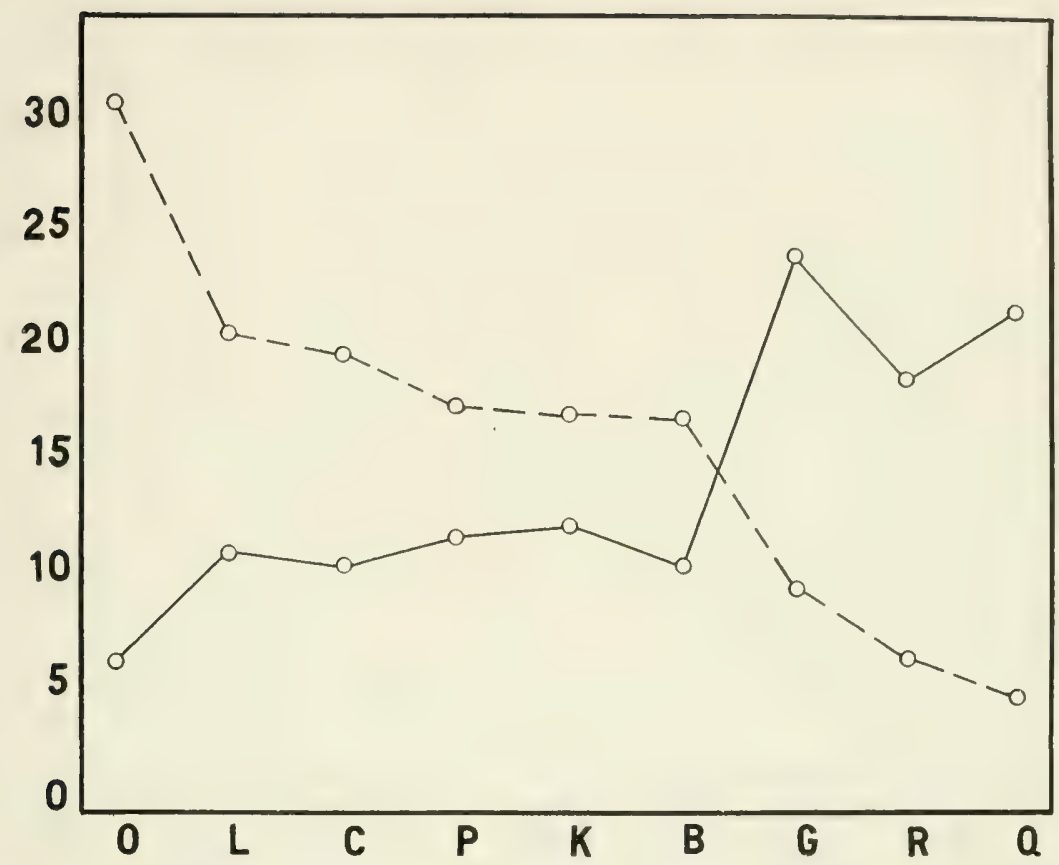

Fig. 19. Diagram to show the comparative quantitative relationships of the total carbohydrates (connected by broken line) and total nitrogen content $x 7$ (connected by solid line) arranged on the basis of the descending values for carbohydrates, in the upper stems of the several series.

the significance given under the methods of determination in an earlier part of this paper. On the base line of the figure at equal dist ances apart are arranged the series of plants and on the vertical lines are arranged the percentages of total nitrogen multiplied by seven and of total carbohydrates, expressed on the dry weight. On account of the wide differences in composition of different parts of any plant grown under a given set of conditions, only similar portions are compared. With but few exceptions increased amounts of total nitrogen are associated with decreased amounts of total carbohydrates. This condition holds fairly uniformly thorughout the plant with the exception of the lower leaves.

This relation between total nitrogen and carbohydrate storage may be due to any one or a combination of reasons, some of which are the following: (1) The presence of the nitrogenous compounds or nitrates may retard assimilation or the formation of the carbohydrates. (2) It may cause increased respiration of the carbohydrates. (3) It may aid in the utilization of the carbohydrates for the synthesis of organic nitrogenous substances. No definite, exact data on any one of these points are available. It is not worth while, therefore, to attempt conclusions coneerning them, though a few suggestions may not be out 


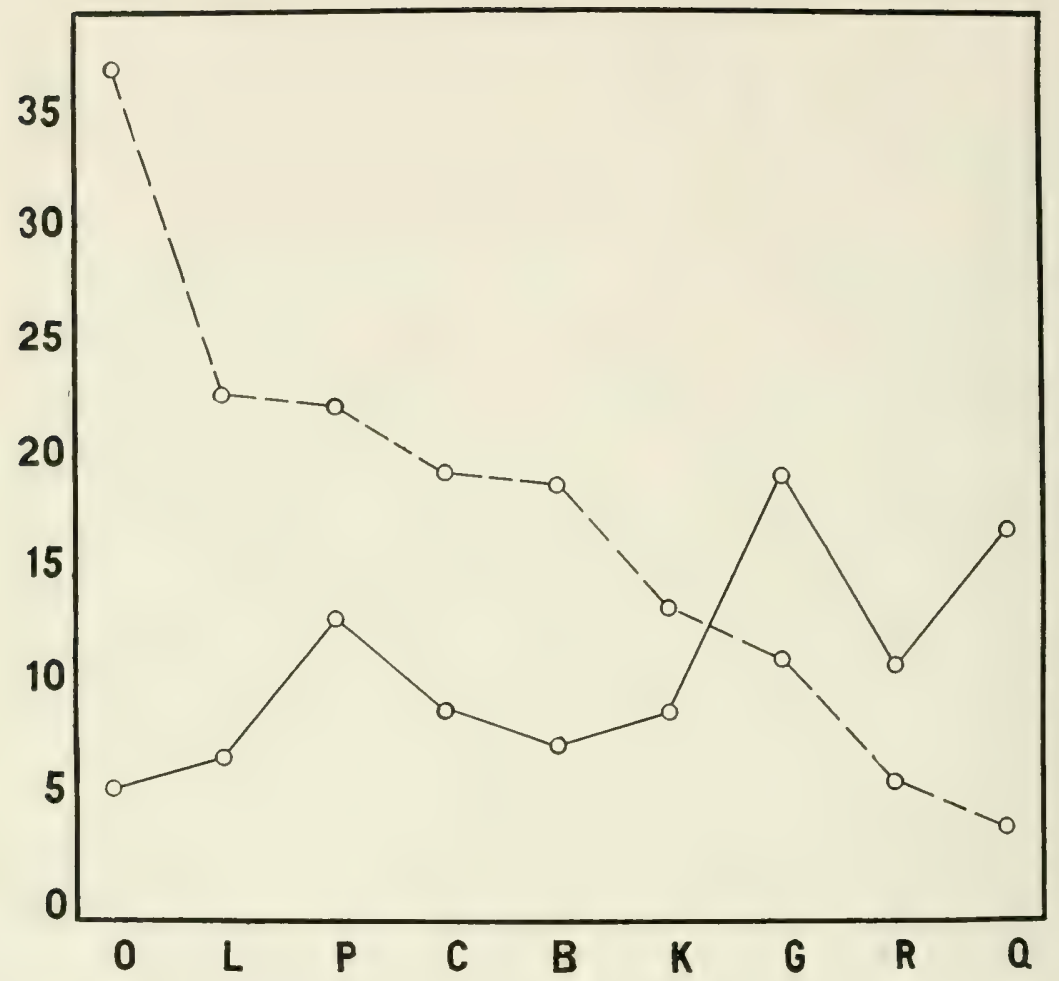

Fig. 20. Same as Fig. 19 except to show the relationships in the lower stems.

of place. The much greater leaf area developed by vegetative plants would seem to indicate the reverse of the first proposal, nor does the presence of increased amounts of carbohydrates in the non-vegetative plants of necessity indicate that they are therefore likewise synthesized in greater quantities. Evidence for or against the second point is not elear, but in keeping with the general findings of increased respiration accompanying more active growth there is a probability that more of the carbohydrates would be thus used in the vigorously vegetative plants. The third possibility has been previously suggested. The utilization of the carbohydrates in this manner as well as in the composition of portions of the walls of the new cells being formed and the thickening of others, probably affords the main reason why they are found as storage substances in relatively smaller quantities in the more actively growing stems.

In general, there is a close correlation between the amount of nitrate nitrogen, total nitrogen, and moisture. Among others, the several factors which follow might aid in accounting for this. (1) The nitrates may have a lyotropic effect in increasing the water-holding capacity of the plant. (2) Carbohydrates and dry matter, substances which have a relatively lower water- 


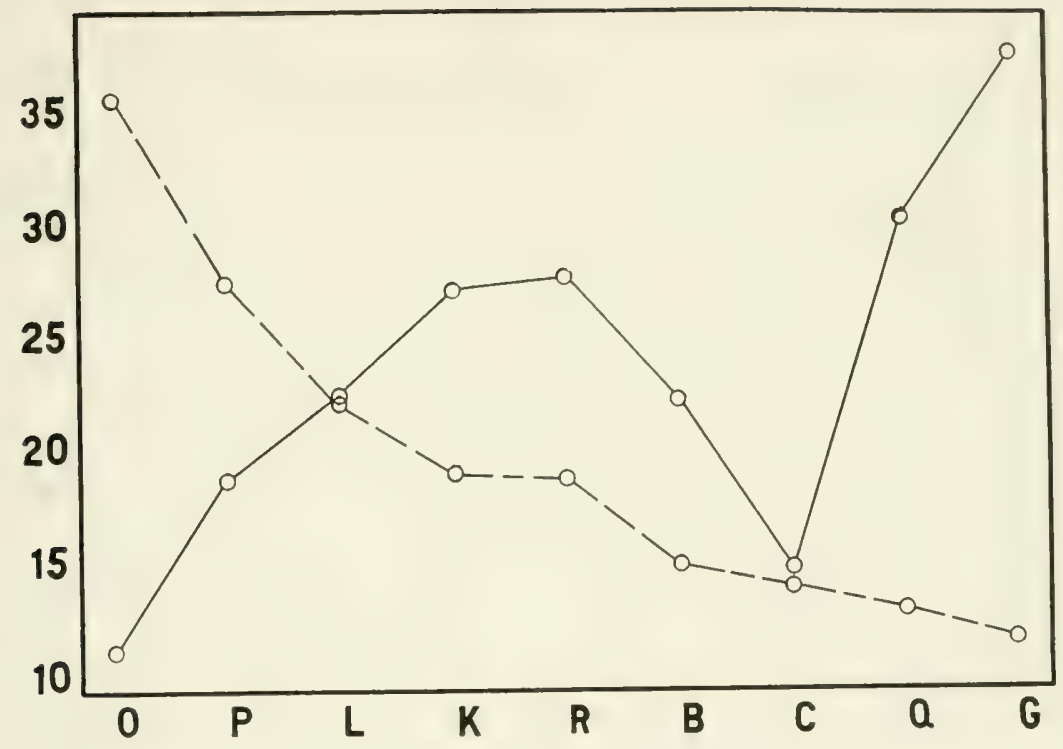

Fig. 21. Same as Fig. 19 except to show the relationships in the upper leaves.

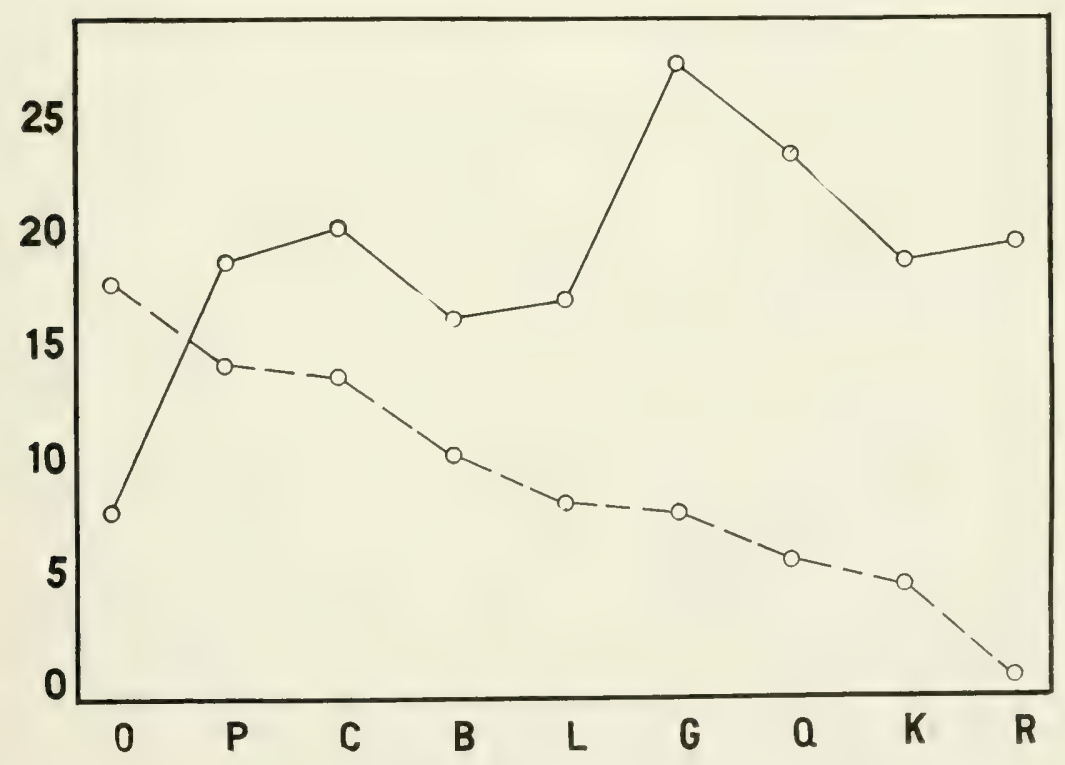

Fig. 22. Same as Fig. 19 except to show the relationships in the lower leaves. 
holding capacity, are greater where total nitrogen is less. (3) The nitrates may prevent the lignification and thickening of cell walls which have a relatively low water-holding capacity. (4) They may aid in rapid growth and the formation of new cells which have relatively thinner walls and a greater percentage of amphoteric substances whose water-holding capacity is relatively large. Then, too, the vacuoles are generally more numerous and larger in the decidedly vegetative tissues, and these may furnish more opportunity for the retention of water.

In the absence of conclusive evidence which might show that the lyotropic action of the nitrates is of significance, no definite conclusions can be drawn. The plants which constituted series $\mathrm{O}$ were grown in sand and the nitrates of the nutrient Kinop's solution were eliminated and partly substituted by calcium chloride. Even with the presence of the chloride ion, which has a lyotropic effect somewhat similar to the nitrate ion, the plants were very low in moisture. Of course since no quantitative chlorine determinations were made there is no way of comparing the quantities within the plant, and also the presence of the calcium ion may overshadow the effect of the chloride ion. Microchemical tests indicated an abundance of chloride in all types of plants. The second and third points are self explanatory. There were, however, no specific experiments on the influence of vacuoles on moisture -holding capacity, but the effect of protein-like substances in this regard is fairly well established. Microscopic examinations showed a lesser increase in cellular thickenings in the vegetative stems.

From the investigations of others as well as our own, it has certainly been shown that blooming, pollination, or even fertilization do not necessarily assure actual fertility even in plants actually considered self-fertile, and it would appear that at least some cases of self- or even inter-sterility are due, not so much to a stable hereditary character as to the condition of the nutrition of the plant under investigation. Both heredity and nutrition must be taken into consideration in a study of this problem, and while it is possible profoundly to modify the expression of any particular plant dependent upon the conditions imposed, it may well be argued that such modifications still remain within hereditary limits. Just where such limits can be drawn certainly cannot, as yet, be determined off-hand, and much more than the average or so-called normal conditions must be investigated.

In general, the observed results and the analyses made in connection with the foregoing experiments tend to support our proposed classification of vegetative and reproductive tendencies insofar as they may be based on a relationship of the carbohydrate and nitrogenous compounds. Throughout the investigation, many questions naturally have suggested themselves; a few of them have been indicated. We hope that further and more extended investigations may be instituted and conducted not only to establish or deny the general hypotheses proposed, but to furnish accurate and reliable data on which to base interpretations of the more intimate processes and compounds concerned. 


\section{SUMMARY}

1. Plants grown with an abundant supply of available nitrogen and the opportunity for carbohydrate synthesis, are vigorously vegetative and unfruitful. Such plants are high in moisture, total nitrogen, nitrate nitrogen, and low in total dry matter, free-reducing substances, sucrose, and polysaccharides.

2. Plants grown with an abundant supply of nitrogen and then transferred and grown with a moderate supply of available nitrogen are less vegetative but fruitful. As compared with the vegetative plants, they are lower in moisture, total nitrogen, and nitrate nitrogen, and higher in total dry matter, free-reducing substances, sucrose, and polysaccharides.

3. Plants grown with an abundant supply of nitrogen and then transferred and grown with a very low supply of available nitrogen are very weakly veget ative and unfruitful. As compared with the vegetative plants, they are very much lower in moisture and total nitrogen and are lacking in nitrate nitrogen; they are much higher in total dry matter, free-reducing substances, sucrose, and polysaccharides.

4. When plants which have been grown with a large supply of available nitrogen and moisture are subjected to a reduced moisture supply just about the wilting point there is a decrease in vegetative activity. These plants compared with those which are vigorously vegetative, are lower in total nitrogen and nitrate nitrogen and higher in free reducing substances, suerose, and polysaccharides.

5. Whatever the conditions under which a plant has been grown, considering the whole plant as a unit, increased total nitrogen and more particularly increased nitrate nitrogen are associated with increased moisture and decreased free-reducing substances, sucrose, polysaccharides, and total dry matter.

6. Fruitfulness is associated neither with highest nitrates nor highest carbohydrates but with a condition of balance between them.

7. There is a correlation between moisture content and nitrate nitrogen. This is probably due largely to the preponderance of non-carbohydrate materials to carbohydrates in the cases where nitrates are abundant.

8. In general, within the plant itself, in the stem from the top to bottom, there is a descending gradient of total notrogen and moisture, and an ascending gradient in total dry matter, polysaccharides and sucrose. The proportion of free-reducing substances to other carbohydrates, total nitrogen, and nitrate nitrogen is variable.

9. The great variations in the amount of carbohydrates in plants grown under different nutrient conditions and in different parts of the same plant indicate that in studying problems concerned with plant metabolism it is necessary to know the specific environment of the plant as a whole and of its several parts.

10. The conditions for the initiation of floral primordia and even blooming are probably different from those accompanying fruit setting. The greatest number of flowers are produced neither by conditions favoring highest vegetation nor by conditions markedly suppressing vegetation.

11. Lack of fruit development is not alone due to the lack of pollination or fertilization. The flowers may fall soon after pollination (markedly vegetative plants) or remain attached for many days without development of the fruit (markedly non-vegetative plants). 
12. The tomato stem in cross section is made up of an epidermis from which arise glandular hairs, several layers of cortical cells, endodermis, a more or less interrupted layer of bast cells, the phloem with small patches of sieve cells, primary and secondary xylem, small patches of internal phloem and internal xylem separated from each other and the protoxylem of the outer bundles by pith cells, and lastly the pith.

13. Vigorously vegetative stems are much greater in diameter than those which are feebly vegetative. This is due to the greater number and size of the pith cells in the former and is accompanied by a marked proportional reduction in xylem. The collenchyma of the cortex is much less and the walls of the bast and internal xylem much thicker in feebly vegetative stems than in those which are vigorously vegetative.

14. Starch is present in the starch sheath of all stems. Starch storage in the stems begins first in the pith cells near the primary vascular bundles, then extends throughout the pith, xylem, and the cortical cells.

15. In vegetative stems there is a much greater number of chloroplasts. These are present even in the central cells of the pith. In stems very feebly vegetativa there are no observable chloroplasts in the pith and their number and intensity of coloration is greatly reduced both in the cortex and in the leaves.

16. Stems without storage starch at the base when cut off close to the surface of the soil, fail to sprout but decay quickly; whereas those with large storage produce new shoots. Accompanying such growth there is a total or complete disappearance of the starch, depending upon the relative amount of growth made and the available nitrogen supply. If the latter is abundant vegetative extension is relatively great; if not, such extension soon ceases and starch is again stored in the new growth.

17. The available corbohydrates or the possibility for their manufacture or supply, constitute as much of a limiting factor in growth as the available nitrogen and moisture supply. When the opportunity for earbohydrate manufacture within the plant itself is greatly reduced or eliminated even though there is a relative abundance of moisture and available nitrogen, vegetation is decreased. But when there is a carbohydrate reserve within the tissues under the same conditions of nitrogen and moisture supply, growth is active. Very large proportional reserves of carbohydrates to moisture and nitrate supply, also accompany decreased vegetation.

18. Parts of the stems or cuttings of plants with a large amount of storage carbohydrates and particularly those parts where such storage is localized, when supplied with moisture or moist conditions, produce roots abundantly. This would be of particular interest in vegetative propagation.

19. Microchemical tests indicate very little difference in potassium content of individual cells whatever the condition of the plant.

20. Withholding moisture from plants grown under conditions of relative abundance of available nitrogen results in much the same condition of fruitfulness and carbohydrate storage as the limiting of the supply of available nitrogen itself.

21. Fertilizers containing available nitrogen or that which may be rade available, are mainly effective in producing vegetative response. They may either increase or decrease fruitfulness, according to the relative available carbohydrate supply.

22. Irrigation or moisture supply is effective in increasing growth or fruitfulness only when accompanied by an available nitrogen supply and vice versa, 
The effectiveness of the nitrogen value of leguminous cover crops is dependent upon the accompanying moisture supply.

23. Cultivation is largely effective in conserving moisture and in promoting the supply of available nitrogen. If in any given soil, moisture and available nitrogen are already present in quantities such that the plants growing upon it are largely vegetative, a decrease in cultivation will tend towards fruitfulness.

24. Non-leguminous companion crops or cover crops remove from the soil both available nitrogen and moisture. In regulating vegetation and fruitfulness by this means the relations of the available moisture, nitrogen, and carbohydrates largely determine the result.

25. Pruning is largely effective in promoting or retarding fruitfulness by its effects in balancing the carbohydrate supply within the plant, or the means for its manufacture, with the available moisture and nitrogen supply.

26. Girdling or ringing of the cortex or bark is effective through a modification of the carbohydrate-nitrate relationship. In practice the entire range of effects due to such a relationship may be expected from its application.

27. Fruit production is seemingly a specialized vegetative function usually more or less closely associated with the function of gametic reproduction. Parts eoncerned in reproduction range from but little-modified vegetative parts to those highly modified portions classified as fruits. The degree in which such modification is expressed, is dependent upon physiological changes within any specific plant, and may vary widely within the same variety or even the same individual.

28. At least some of the instances of sterility considered to be the result of physiological incompatibility may be due to the state or condition of nutrition of the plant itself.

29. Until more exact information is available, both environmental and hereditary factors must be considered in any attempted explanation of the reproductive or vegetative behavior of plants.

\section{ACKNOWLEDGMENTS}

The writers are indebted to the authorities of the Oregon Agricultural College Experiment Station for permission to carry on the foregoing studies away from the home Station. They desire especially to express their thanks and appreciation to Doctor William Crocker of the Department of Botany of the University of Chicago, for constant counsel and suggestions during the progress of their work, and to Doctor hophia $H$. Eckerson of the same Department for advice and direction, particularly on the microchemical studies.

\section{LITERATURE GITED}

1. Alderman, W. H.; Auchter, E. C.

1916. "The Apple as Affected by Varying Degrees of Dormant and Seasonal Pruning." In W. Va. Univ. Agr. Exp. Sta. Bul. 155 p. 1-56.

2. Batchelor, L. D.; Goodspeed, W. E.

1916. "The Summer Pruning of a Young Bearing Apple Orchard." In Utah Agr. Col. Exp. Sta. Bul, 140 p. 1-14. 
3. Bedford, Duke of; Pickering; S. U.

1911. In Thirteenth Report Woburn Exp. Fruit Farm.

4. Briggs, L. J.; Jensen, C. A.; McLane, J. W.

1916. "Mottle-leaf of Citrus Trees in Relation to Soil Conditions." In Journ. Agr. Res. v. 6. no. 19 p. 721-740.

5. Crocker, W.

1916. "Periodicity in Tropical trees." In Bot. Gaz. v. 62 p. 244-246.

6. Davis, B. M.

1915. "A Method of Obtaining Complete Germination of Seed in Oenothera and of Recording the Residue of Sterile Seed-like Structures. In Proc. Nat. Acad. Sci. v. 1 p. 360-363.

7. Drinkard, A. W.

1915. "Some Effects of Pruning, Root Pruning, and Stripping on the Formation of Fruit Buds on Dwarf Apple Trees." In Ann. Rept. Va. Polytech. Inst. Agr. Exp. Sta. Tech. Bul. 5, 19131914. p. $96-120$.

8. Fischer, A.

1891. "Beiträge zur Physiologie der Holzgewäschse." [In Jahrb. Wiss. Bot. v. 22 p. $73-160$.

9. Gardner, V. R.

1913. "A Preliminary Report on the Pollination of the Sweet Cherry." In Ore. Agr. Col. Exp. Sta. Bul. 116 p. 3-40.

10. Gardner, V. R.

1915. "Pruning the Bearing Apple and Pear Tree." In Ore. Agr. Col. Exp. Sta. Bul. 130. p. 48-60.

11. Gardner, V. R.

1916. "Pruning Investigations. The Early Summer Pruning of Young Apple Trees." In Ore. Agr. Col. Exp. Sta. Bul. 139 p. 3-45.

12. Goodspend, T. H.

1915. "Parthenogenesis, Parthenocarpy and Phenospermy in Nicotiana." In Univ. Calif. Pub. Bot. v. 5. p. 249-272.

13. Gourley, J. H.

1915. "Studies in Fruit Bud Formation." In N. H. Col. Agr. Exp. Sta. Tech. Bul. 9 p. 1-80.

14. Gourley, J. H.; Shunk, V. D.

1916. "Notes on the Presence of Nitrates in Orchard Soils." In $\mathrm{N}$. H. Col. Agr. Exp. Sta. Tech. Bul. 11. p. 1-31.

15. HaRTWELl, B. L

1916. "Starch Congestion Accompanying Certain Factors Which Retard Plant Growth." In R. I. State Col. Agr. Exp. Sta. Bul. 165 p. $1-23$.

16. Hedrick, U. P., TAYlor, O. M.; Wellington, R.

1907. "Ringing Herbaceous Plants." In N. Y. Agr. Exp. Sta. Bul. 288 p. 193-209.

17. Hedrick, U. P.

1909. "A Comparison of Tillage and Sod Mulch in an Apple Orchard." In N. Y. Agr. Exp. Sta. Bul. 314. p. 77-132.

18. HeINICKE, A. J.

1917. "Factors Influencing the Abscission of Flowers and Partially Developed Fruits of the Apple." In Proc. Am. Soc. Hort. Sci. 1916 p. $95-103$. 
19. HeINICKE, A. J.

1917. "Factors Influencing the Abscission of Flowers and Partially Developed Fruits of the Apple. (Pyrus malus L)." In Cornell Univ. Agr. Exp. Sta. Bul. 393. p. 43-114.

20. Hibino, Shin-Ichi.

1917. "Effekt der Ringelung auf die Stoffwanderung bei Cornus controversa Hemsl." In Journ. Col. Sci. Imp. Univ. Tokyo. v. 39 p. $1-40$.

21. Klebs, George.

1888. Uber die Organisation der Gallerte bei einigen Algen und Flagellaten." In Untersuch. Botan. Inst. Tub. v. 2 p. 333-417.

22. Klebs, George.

1890. "Ueber die Vermehrung von Hydrodictyon retriculatum." In Flora. v. 73 p. 351-410.

23. Klebs, George.

1903. "Willkürliche Entwickelungsänderungen bei Pflanzen." Jena.

24. Klebs, George.

1904. "Uber Probleme der Entwickelung." In Biol. Centrbl. v. 24 no. 8 p. $257-267$; no. 9 p. 289-305; no. 14 p. 449-465; no. 17 p. $545-559$; no. 18 p. $601-614$.

25. Klebs, George.

1910. "Alterations in the Development and Forms of Plants as a Result of Environment." In Proc. Roy. Soc. Lond. v. 82, p. 547558 .

26. Klebs, George.

1915. "Uber Wachstum und Ruhe tropischer Baumarten." In Jahrb Wiss. Bot. 56. p. 734-792.

27. Kraus, E.J.

1915. "The Study of Fruit Buds." In Ore. Agr. Col. Exp. Sta. Bul. 130 , p. $12-21$.

28. Kraus, E. J.

1915. "The Self-sterility Problem." In Jour. Hered. v. 6 no. 12 p. $549-557$.

29. Lewis, C. I.; Allen, R. W.

1916. "The Influence of Nitrogen Upon the Vigor and Production of Devitalized Apple Trees." In Rept. (1914-1915) Hood River Branch Exp. Sta. p. 5-19.

30. Lewis, C. I.; Brown, G. G.

1917. Influence of Commercial Fertilizer Upon the Bearing Apple Tree." In Rept. 1916 Hood River Branch Exp. Sta. p. 37-47.

31. Magness, J. R.

1916. "Pruning Investigations. The Influence of Summer Pruning on Bud Development in the Apple." In Ore. Agr. Col. Exp. Sta. Bul. 139. p. 46-77.

32. Magness, J. R.

1917. "Pruning Investigations. Second Report. Studies in Fruit-bud Formation." In Ore. Agr. Col. Exp. Sta. Bul. 146 p. 3-27.

33. МсBетн, I. G.

1917. "Relation of the Transformation and Distribution of Soil Nitrogen to the Nutrition of Citrus Plants." In Jour. Agr. Res. V. 9. no. 7.p. 183-252. 
34. Mitchell, H. H.; Shonle, H. A.; Grindley, H. S.

1916. "The Origin of the Nitrates in the Urine." In Jour. Biol. Chem. v. 24. p. 461-490.

35. PARKin, J.

1911. "The Carbohydrates of the Foliage Leaf of the Snowdrop (Galanthus nivalis L) and their Bearing on the First Sugar of Photosynthesis." In Biochem. Jour. v. 6. p. 1-47.

36. Petri, L.

1914. 'Studi sulla malattie dell' olivo-V. Richerche sulla biologia e patologia fiorale dell' olivo." In Mem. Della R. stazione Di Patologia Vegetale. Roma.

37. Petri, L.

1916. "Investigation on the Nitrogen Nutrition of the Olive." In Atti. R. Accad. Econ. Agr. Georg. Firenze, 5. Ser. 13 (1916) No. 3. p. 138-147. See also In Exp. Sta. Ree. v. 35, no. 9 p. 839.

38. ReMY, 'T'.

1913. "The Application of Nitrogen in Relation to Fruit-bud Formation." In Mitt. Deut. Landw. Gesell. v. 28. no. 29 p. 416-421. See also In Exp. Sta. Rec. v. 29 no. 6 p. 539.

39. Russel, E. J.

1915. "Soil Conditions and Plant Growth." p. 190. London.

40. SABLon, Leclercu.

1906. "Sur les Effets de la Decortication Annulaire." In Compt. Ren. Acad. Sci. v. 140, p. 1553-1555.

41. Stout, A, B.

1916. "Self and Cross Pollinations in Cichorium intybus with Reference to Sterility." In Mem. N. Y. Bot. Gard. v. 6 p. 333-454.

42. Walter, G.; Gartner, A.

1895. "Tiemann-Gärtner's Handbuch der Untersuchung und Beurtheilung der Wässer." 4 ed. p. 154-159. Braunschweig.

43.

1912. "Official and Provinsional Methods of Analysis." In U. S. Dept. Agr. Bur. Chem. Bul. 107. 







LIBRARY OF CONGRESS

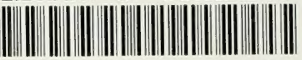

00215296131 